\title{
Water Recovery from Inorganic Solutions via Natural Freezing and Melting
}

by

Eric Shum

A thesis submitted in conformity with the requirements for the degree of Master of Applied Science

Department of Chemical Engineering and Applied Chemistry University of Toronto

(C) Copyright by Eric Shum MMXVII 


\title{
Water Recovery from Inorganic Solutions via Natural Freezing and Melting
}

\author{
Eric Shum \\ Master of Applied Science \\ Department of Chemical Engineering and Applied Chemistry \\ University of Toronto \\ MMXVII
}

\begin{abstract}
A combined natural freezing and melting water recovery process was evaluated for a 0.5 molal magnesium sulphate solution. $500 \mathrm{~mL}$ of solution was placed in a container open to the air, and the temperature was lowered to between -2 and $-26^{\circ} \mathrm{C}$. At equilibrium the solid produced, consisting of ice and entrapped solution or solute crystals, was removed and thawed at either $3{ }^{\circ} \mathrm{C}$ or $25^{\circ} \mathrm{C}$. The resulting liquid was analysed for magnesium. Microscopy of the solid was also performed. Although the purity of the liquid was not affected by the thawing temperature, solid frozen at $-26^{\circ} \mathrm{C}$ yielded the best purity when melted, as $40 \%$ of the original water could be recovered at a concentration of 0.075 molal magnesium sulphate. This is because during melting entrapped solution drains from the solid faster than the ice melts, increasing liquid concentration at earlier stages of melting.
\end{abstract}




\section{Acknowledgements}

I would like to thank my supervisor, Professor Vladimiros G. Papangelakis, for his patience and support over not just the two years of this MASc program, but the four years in which I have been a researcher in his laboratory. I would also like to thank Professor Donald W. Kirk and Professor Nikolai DeMartini for agreeing on such short notice to participate in my thesis committee at an extremely busy time of year. Their wisdom and sagacity are as much appreciated as they are necessary.

The support of the Aqueous Process Engineering and Chemistry (APEC) Group, headed by Professor Papangelakis, has been essential to my success, and I should especially like to thank Dr. Georgiana Moldoveanu, Dr. Srinath Garg Govindarajan, George Kolliopoulos, Igor Alfredo Guzman, Frank Cheuk, Douglass Duffy, and many others for their ready assistance and solid criticism over the past four years.

My time at the University of Toronto, happily now at an end, would not have been so enjoyable had it not been for the existence of the Robarts Library Book Room, located on the $2^{\text {nd }}$ floor next to the cafeteria and open on Tuesdays and Thursdays from 11:00 am to 3:00 pm (but closed for the winter holidays, and from June to August inclusive), where you will find used books sold at the lowest prices in Toronto. I enjoyed every moment working as a volunteer there for the past three years, and have learned a great deal. I will never forget the late Wiebke Smythe, and will always look forward to visiting every now and then to see Ross, Sylvia, Julia, Josie, Tessa, Theresa, Michael, Agata, Skye, and all the rest. 


\section{Table of Contents}

ACKNOWLEDGEMENTS _..................................................................................................II

TABLE OF CONTENTS …................................................................................................................. IV

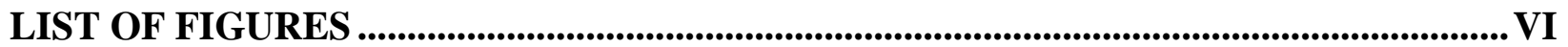

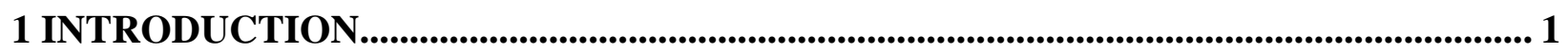

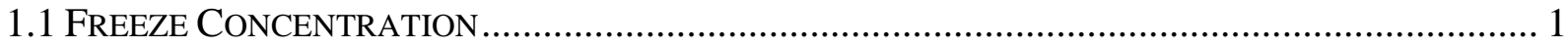

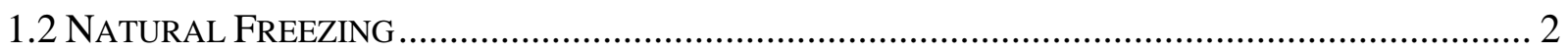

1.2.1 Dendritic Ice Growth due to Constitutional Undercooling.......................................... 3

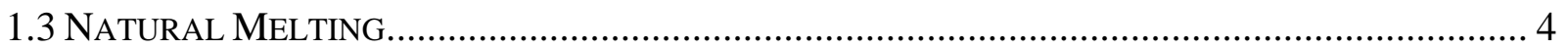

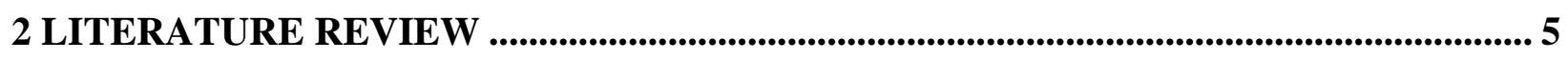

2.1 EARLY HISTORY OF FREEZE CONCENTRATION .............................................................. 5

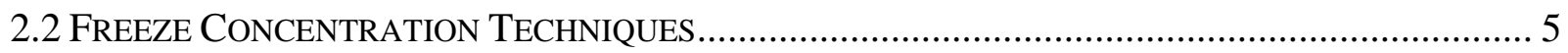

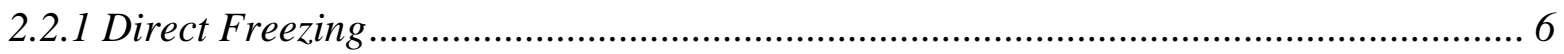

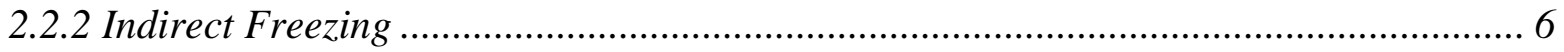

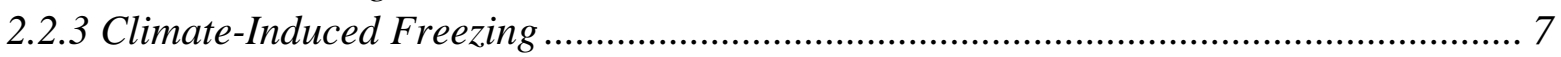

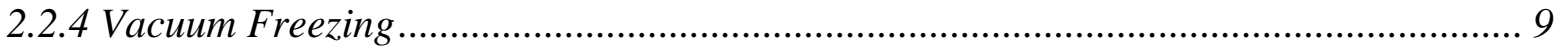

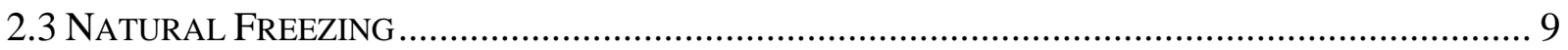

2.3.1 Recent Advances in Natural Freezing Research ..................................................... 9

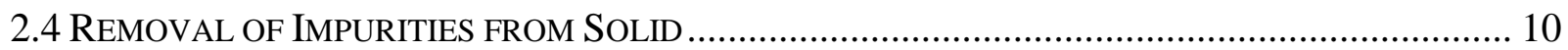

2.4.1 Recent Advances in Melting Research .................................................................... 10

3 OBJECTIVE .............................................................................................................................. 12

4 METHODOLOGY ............................................................................................................................ 13

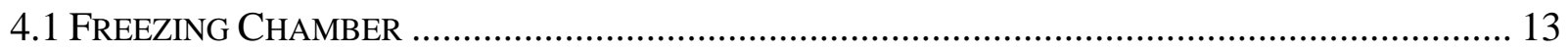

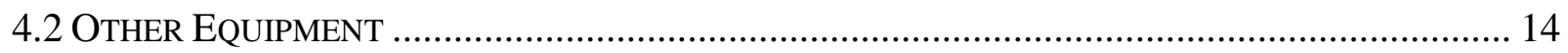

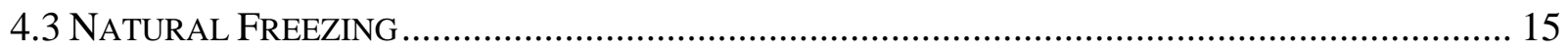

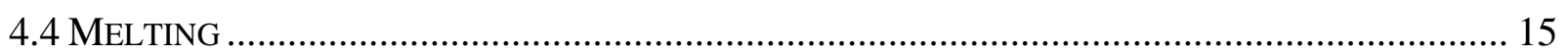

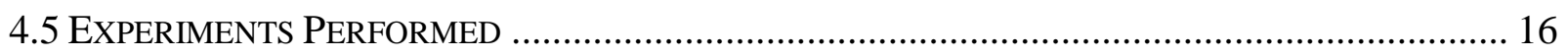

4.5.1 Natural Freezing Standalone Experiments............................................................ 16

4.5.2 Natural Freezing and Room Temperature Melting Experiments .............................. 16

4.5.3 Natural Freezing and $3{ }^{\circ} \mathrm{C}$ Melting Experiments................................................. 16

4.5.4 Natural Freezing and Other Melting Experiments................................................... 16

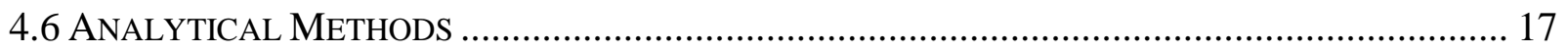

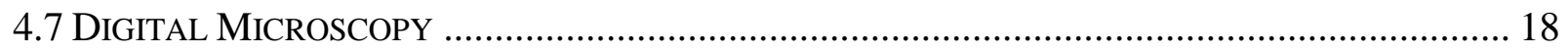

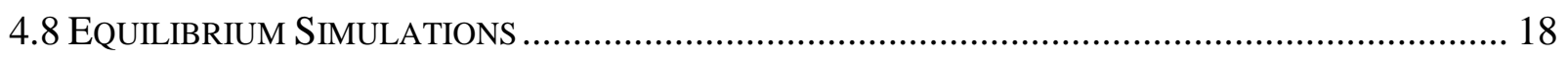

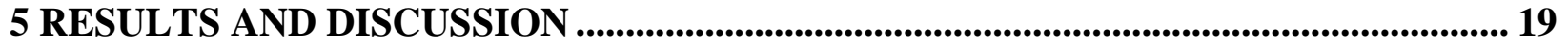

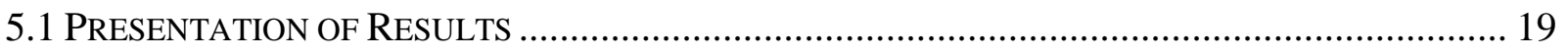

5.1.1 BiNARY PHASE DiagRAM AND EQUILIBRIUM........................................................... 19 
5.2 NATURAL FREEZING AND FAST MELTING .............................................................. 20

5.3 NATURAL FrEEZING AND RoOM TEMPERATURE MELTING ........................................... 22

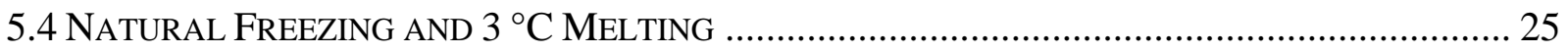

5.5 NATURAL FreEZING AND OTHER MELTING PROCESSES .................................................. 27

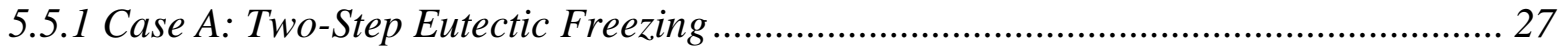

5.5.2 Case B: Ice Curing ...................................................................................................... 28

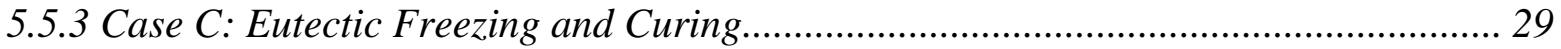

5.5.4 Case D: Multi-Stage Curing of Ice ............................................................................... 30

5.5.5 Case E: Multi-Stage Curing with Temperature Alterations ...................................... 31

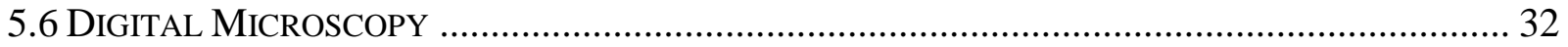

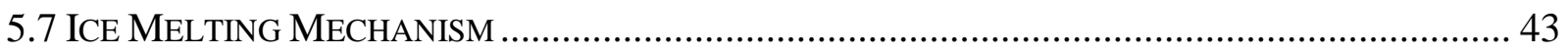

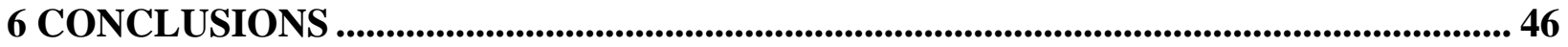

6.1 RECOMMENDATIONS AND FUTURE WORK .............................................................. 47

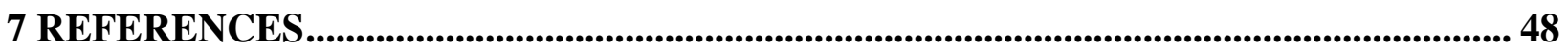

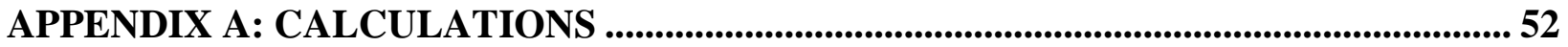

APPENDIX B: RAW DATA FOR NATURAL FREEZING AND FAST MELTING

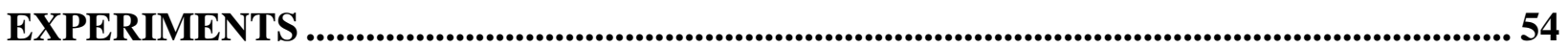

APPENDIX C: RAW DATA FOR NATURAL FREEZING AND ROOM

TEMPERATURE MELTING EXPERIMENTS................................................................... 57

APPENDIX D: RAW DATA FOR NATURAL FREEZING AND $3{ }^{\circ} \mathrm{C}$ MELTING

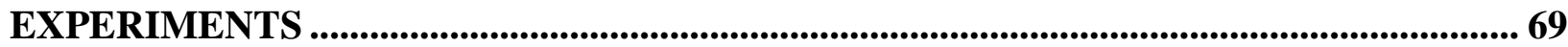

APPENDIX E: RAW DATA FOR NATURAL FREEZING AND OTHER MELTING

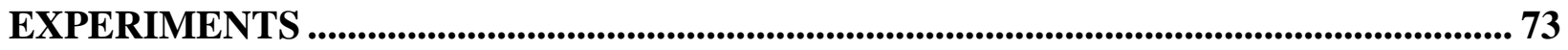




\section{List of Figures}

Figure 1: Magnesium Sulphate - Water Binary Phase Diagram............................................ 2

Figure 2: Dendritic Ice Growth on Bottom of Ice Layer ...................................................... 3

Figure 3: Freezing Chamber (top view) - A: Insulated silicone pans; B: USB fan; C: McMaster-

Carr Radiator-Style Heat Sinks; D: VWR External Pt100 Probe.

Figure 4: Magnesium Sulphate - Water Binary Phase Diagram with $-2{ }^{\circ} \mathrm{C}$ and $-3{ }^{\circ} \mathrm{C}$ Freezing

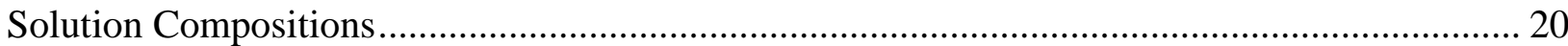

Figure 5: Natural Freezing and Fast Melting Experiments................................................... 21

Figure 6: Concentration of melt solution in Natural Freezing and Fast Melting experiments ..... 22

Figure 7: Natural Freezing and Room Temperature Melting ............................................. 23

Figure 8: Comparison of Natural Freezing with Fast Melting and Natural Freezing with Room

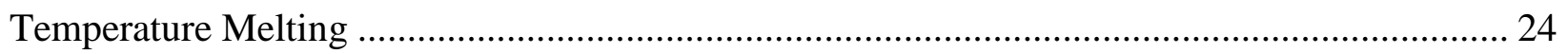

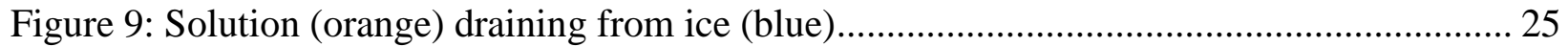

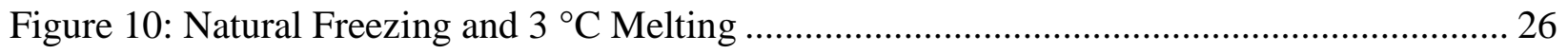

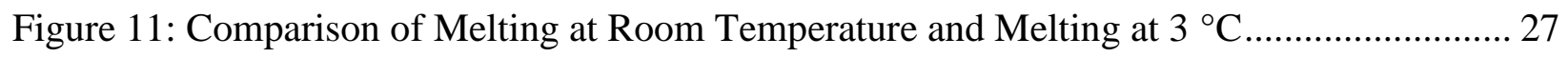

Figure 12: Natural Freezing at $-2{ }^{\circ} \mathrm{C}$ followed by placing the solid in a freezer at $-26{ }^{\circ} \mathrm{C}$ prior to

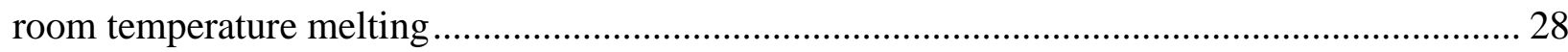

Figure 13: Natural Freezing at $-2{ }^{\circ} \mathrm{C}$ followed by leaving the solid only at $-2{ }^{\circ} \mathrm{C}$ prior to room

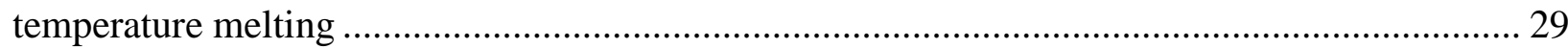

Figure 14: Natural Freezing at $-26^{\circ} \mathrm{C}$ followed by leaving the solid on a grille at $-0.2{ }^{\circ} \mathrm{C}$ before melting at room temperature.....

Figure 15: Natural Freezing at $-2{ }^{\circ} \mathrm{C}$ followed by ice curing at $-2{ }^{\circ} \mathrm{C}$ for 24 hours, $-1{ }^{\circ} \mathrm{C}$ for 24

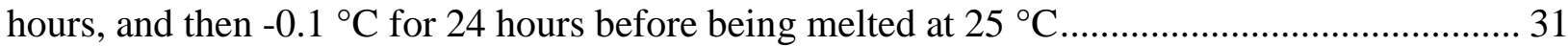
Figure 16: Natural Freezing at $-2{ }^{\circ} \mathrm{C}$, and then curing at $-2{ }^{\circ} \mathrm{C}$ for 72 hours, $-0.2{ }^{\circ} \mathrm{C}$ for 24 hours,

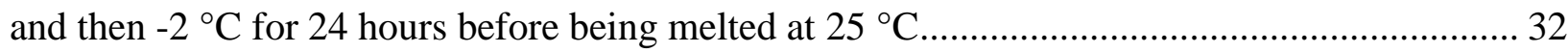
Figure 17: Freezing Temperature of $-2{ }^{\circ} \mathrm{C}, 50 \mathrm{x}$ Magnification .............................................. 33

Figure 18: Freezing Temperature of $-2{ }^{\circ} \mathrm{C}, 250 \mathrm{x}$ Magnification ............................................. 34

Figure 19: Freezing Temperature of $-10{ }^{\circ} \mathrm{C}, 50 \mathrm{x}$ Magnification .............................................. 35

Figure 20: Freezing Temperature of $-10{ }^{\circ} \mathrm{C}, 250 \mathrm{x}$ Magnification ............................................ 36

Figure 21: Underside of solid frozen at $-2{ }^{\circ} \mathrm{C} .250 \mathrm{x}$ magnification. ........................................ 37 
Figure 22: Ice dendrites on underside of solid frozen at $-2{ }^{\circ} \mathrm{C}$ during melting. $250 \mathrm{x}$ magnification 38

Figure 23: Solid frozen at $-2{ }^{\circ} \mathrm{C}$ and then placed in a freezer at $-26^{\circ} \mathrm{C} .250 \mathrm{x}$ magnification..... 39 Figure 24: Solid frozen at $-26^{\circ} \mathrm{C}$. No features can be distinguished from this mix of magnesium

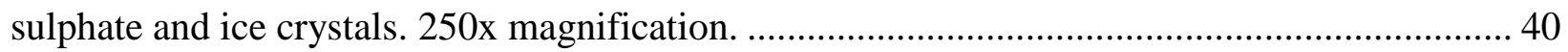

Figure 25: The surface of the solid begins to melt. 250x magnification. ................................. 41

Figure 26: The surface of the solid continues to melt. 250x magnification. ............................. 42

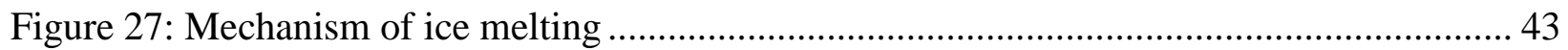

Figure 28: (I) Solute particles in red dissolve surrounding ice to form pockets of solution (II) in orange. These pockets increase in size (III) to form connected channels (IV), which drain from the solid. 


\section{Introduction}

Water requirements for process industries are restricted by the need to reduce fresh water intake. For this reason many industries are looking to a wide variety of water recovery techniques in order to reuse water, decreasing intake and effluent alike. Advances in refrigeration technology have made low-temperature separation processes increasingly appealing to an energy-conscious society. A wide variety of processes have been developed that fall under the general term "Freeze Concentration", which describes techniques in which an aqueous solution is concentrated at low temperatures by the creation and subsequent removal of ice [1].

Further efforts to decrease energy costs have focused on investigating the use of low atmospheric temperatures in cold climates to induce Freeze Concentration in a process known as "Natural Freezing”. Similar to the winter freezing of surface bodies of water, natural freezing is a process in which the surface of an inorganic solution is exposed to freezing temperatures, causing a layer of ice to form and grow downwards, which is subsequently recovered [3].

During natural freezing, pockets of liquid solution are entrapped within the growing ice layer due to dendritic ice growth, decreasing the purity of the solid recovered. A process in which the solid produced is passively melted in order to selectively remove entrapped solute, described using the term "melting" in this work, is investigated as a low-energy means of purifying the solid recovered - a suitable complement to natural freezing. The purpose of this work is to investigate the efficacy of a combined Natural Freezing and Melting process in the recovery of water from an inorganic solution.

\subsection{Freeze Concentration}

The general term used to describe processes in which water is recovered from an inorganic solution in the form of ice is "Freeze Concentration". These processes exploit the freezing behaviour of aqueous solutions as dictated by their respective water-salt phase diagram. When, for example, a solution of magnesium sulphate is cooled to a temperature below its freezing point but above its eutectic temperature of $-4.1^{\circ} \mathrm{C}$ (Figure 1), if the concentration of magnesium sulphate is less than the eutectic concentration (approximately 1.7 molal), ice will form until the 
solution concentration reaches the equilibrium value at the given temperature on its phase diagram, as indicated by the blue liquidus line. The situation can be viewed as the precipitation of ice in order to concentrate the magnesium sulphate solution. It is for this reason that ice can be selectively produced in Freeze Concentration processes [2]. If the concentration is greater than the eutectic concentration, magnesium sulphate dodecahydrate solid will precipitate until the concentration reaches equilibrium (this process is not freeze concentration). Below the eutectic temperature of the solution, both ice and solute crystals will form in a process known as Eutectic Freeze Crystallization [19].

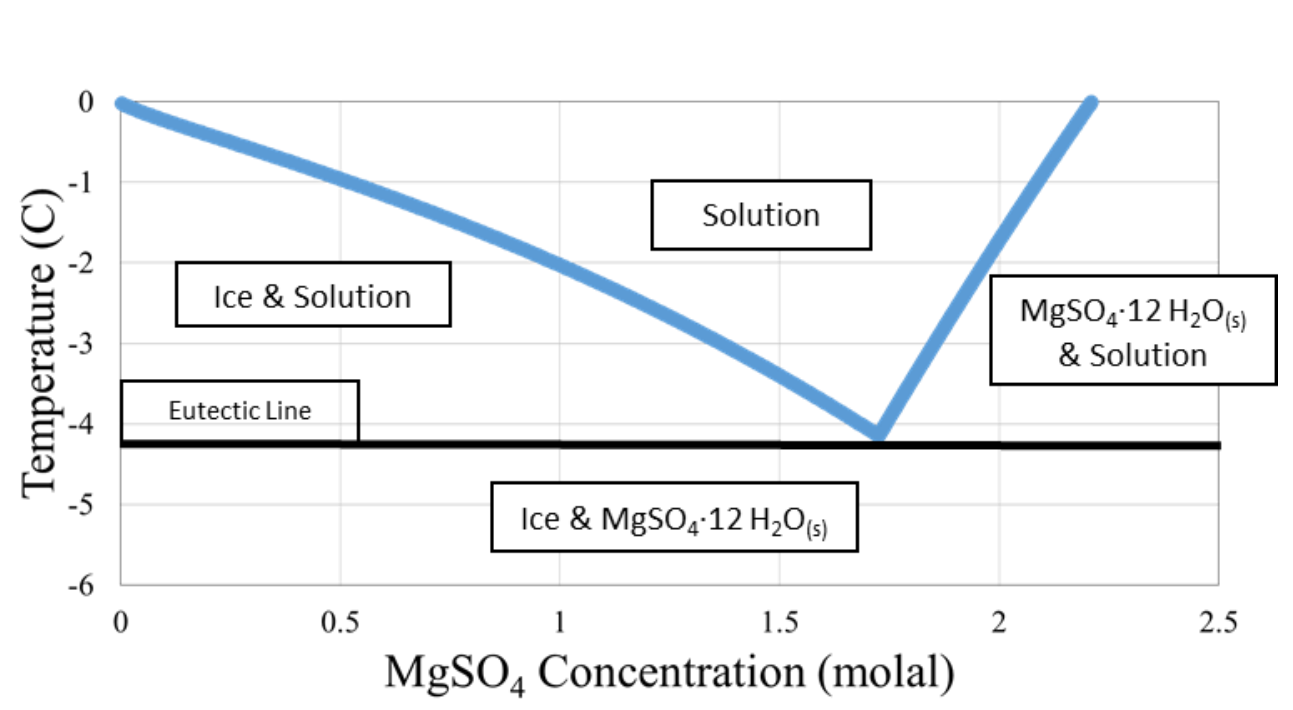

Figure 1: Magnesium Sulphate - Water Binary Phase Diagram

\subsection{Natural Freezing}

Despite decreasing energy costs as a result of improvements to refrigeration methods, attempts to reduce energy requirements even further have resulted in the development of climate-driven techniques to freeze and purify aqueous solutions. Consequently, Natural Freezing, which makes use of low atmospheric temperatures to induce ice growth, has become a recent area of interest as a method of recovering water as ice in cold climates [3]. The theoretical products of the natural freezing process, and all freeze concentration processes in general, are pure ice crystals and a more concentrated solution [1]. This is generally true when planar ice growth occurs. However, in practice, the "constitutional undercooling" of the liquid results in the dendritic growth of ice - analogous to phenomena also observed in alloy solidification $[4,5]$. 


\subsubsection{Dendritic Ice Growth due to Constitutional Undercooling}

Dendritic ice growth typically occurs at rates of surface growth of tens of microns per second or higher, and in practice is extremely difficult to avoid in solidification processes [38]. As the ice growth front advances, the exclusion of solute from the ice layer [3] creates a concentration gradient, with a higher concentration of solute in front of the growing ice. This results in "constitutional undercooling", where a difference between the equilibrium liquidus temperature (dictated by the concentration) and the actual solution temperature at a given distance away from the growth front exists. The existence of constitutional undercooling creates conditions suitable for dendritic growth [38].

A random protuberance of ice on the growth front will be exposed to a solution with a slightly lower concentration than the rest of front because it physically extends through the gradient. Furthermore, it will be extending into an undercooled region of solution. Due to the higher freezing temperature of the less concentrated solution, the growth of ice at the tip of the protuberance is favoured, causing the dendrite to grow. Continued growth further exposes the dendrite to areas of lower concentration. Secondary and tertiary dendrites form from protuberances on the primary dendrite [38] (Figure 2).

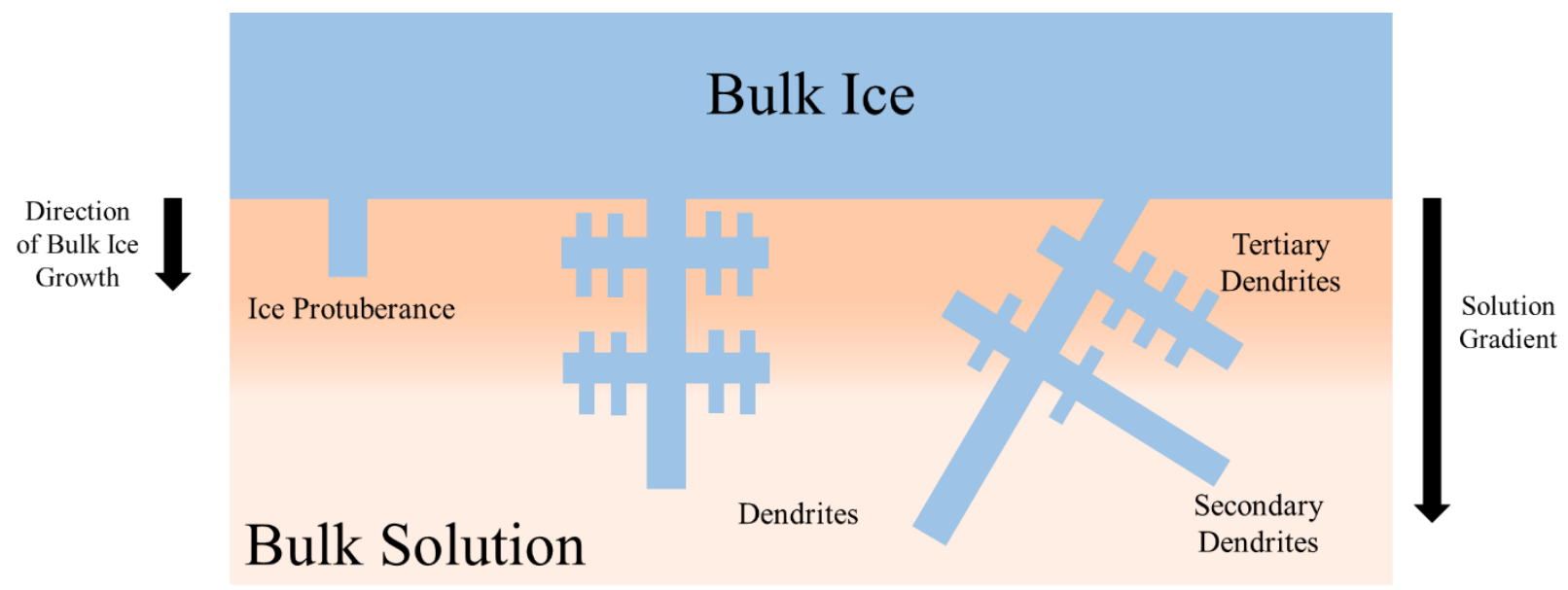

Figure 2: Dendritic Ice Growth on Bottom of Ice Layer 
The growth of these dendrites trap liquid pockets, within which solute is incapable of diffusing away and remains locked between the grain boundaries of ice crystals, decreasing the purity of the solid recovered [6].

\subsection{Natural Melting}

The presence of impurities trapped within the ice necessitates further processing to obtain pure water. Research that has focused on water recovery from oil sands tailings waste water has examined the viability of initially freezing the tailings via spray-freezing, before thawing the frozen heap produced to remove concentrated melt water [7]. The food industry has also conducted research into the thawing of frozen juices, and while their focus is on the recovery of concentrated solution as opposed to pure ice, their techniques are still applicable to water recovery [8]. Furthermore, the production of large sheets or blocks of ice in the food industry is more comparable to the ice produced via natural freezing than to irregular spray-frozen particles. It is believed that the thawing of ice crystals causes the release of solution trapped between their grain boundaries $[9,10]$. There is further speculation that dendritic crystals beyond a given fineness - the result of high solute concentrations during ice growth requiring greater heat transfer - are too small to form channels, and instead melt away along with the trapped solution [11]. 


\section{Literature Review}

\subsection{Early History of Freeze Concentration}

Prior to the invention of modern refrigeration the distinction between Freeze Concentration and Natural Freezing simply did not exist. The best work describing this period exists in the form of a rather terse paper published by Nebbia and Menozzi in 1968 [12]. The paper delineates the history of freeze concentration beginning with observations on the relative purity of sea ice by Thomas Bartholin (Thomas Bartholinus) in 1661, and progresses chronologically with Robert Boyle, a Jesuit by the name of Athanasios Kircher (Athanasii Kircheri), Samuel Reyher (Samuelis Reyheri), Tobias Smollett - who will forever be remembered for his literary achievements rather than his scientific observations - Captain James Cook, Edward Nairne, Anton Maria Lorgna, and Thomas Jefferson. This peculiar constellation of names is sufficient to gratify the vanity of any historically-inclined researcher.

Nebbia and Menozzi, being Italians, focus on the research of Anton Maria Lorgna, who in the late $18^{\text {th }}$ century performed freeze concentration experiments on sea water, urine, and what is politely termed "impure liquids collected from stables." A summary in English of Lorgna's work provided in the paper, available nowhere else, show that by successive freezing of the ice recovered each time, a drinkable liquid could be obtained from sea water.

Due to the absence of modern refrigeration technology (Lorgna conducted his experiments by placing metal pots filled with liquid outside during cold Venetian winters), interest in freeze concentration waned until the advent of the modern era.

\subsection{Freeze Concentration Techniques}

There is great diversity in the classification of Freeze Concentration (FC) methods. Some reviewers [1,2] prefer to categorise FC processes by the manner in which heat is removed from the system: "Direct Freezing" refers to freezing that occurs when coolant is mixed directly with the solution, while "Indirect Freezing" refers to processes in which coolant is used to lower the temperature of some form of heat exchanger which, when placed in contact with the solution, 
induces the formation of ice. Research into FC has resulted in the development of processes that do not readily fit either category. In other review papers [13], attention is paid to the difference between the inducement of crystallisation in the form of numerous ice crystals, and in the form of a single large piece of ice. "Suspension Crystallization" (SC) describes the growth of multiple ice crystals within a solution, and "Layer Crystallization" (LC) describes the growth of a single large layer of ice. $[2,13]$ In practice most processes currently available make use of Indirect Freezing, and most Indirect Freezing Processes result in Layer Crystallisation [1].

\subsubsection{Direct Freezing}

In direct freezing a pressurised refrigerant, such as butane, is directly injected into the solution. The refrigerant then evaporates due to depressurization, cooling the solution and inducing the crystallisation of ice as a suspension which is subsequently removed. [14] The capacity of this technology is limited by the ability of the refrigerant compressor, and although this has been overcome by the proposed use of a hydraulic refrigerant compressor [2], in practice there is little research on direct freezing techniques past the mid-1990s.

\subsubsection{Indirect Freezing}

Indirect freezing covers a variety of processes which can produce either a suspension of ice crystals or a single sheet of ice, depending on the heat transfer equipment used and the mechanism for ice recovery. The common theme of Indirect Freezing is the use of a heat exchanger to provide cooling when contacted with the solution. Ice formation occurs on the surface of these heat exchangers. During batch operation ice is removed at the end of the process, while the development of "Scraped Surface Heat Exchangers" (SSHE), which have impellers fitted with blades sized so that they "scrape" the surface of the heat exchanger to remove nucleated ice crystals $[15,16]$, has allowed for continuous operation.

(1) Layer freeze concentration has been a topic of frequent research by the fruit juice industry. In this process the solution is run over a cooled metal plate positioned vertically. Over time a layer of ice forms, and is removed when the process is stopped. [13] This technique, although it must be optimised to decrease entrainment of impurities, is extremely simple, with no moving parts and relatively simple separation 
required. However, as it is normally run as a batch process longer times are required. [2]

(2) Progressive Freeze Concentration (PFC) is a process in which a column filled with a salt solution is slowly lowered into a bath of refrigerant. A layer of ice forms at the bottom of the column, and as the column continues to be lowered the layer of ice increases in thickness. An impeller positioned just above the ice level ensures that there is no concentration gradient. [17, 18]

(3) Eutectic Freeze Crystallisation (EFC) is a process unique in FC because the objective is to simultaneously crystallize ice as well as a dissolved salt by lowering the temperature of the solution below its eutectic temperature [19]. Unlike FC, the EFC aims to recover not only water as ice but also the dissolved salts as solids. When both ice and salt crystals form, density differences cause the ice to float to the top of the solution and the salt crystals to sink to the bottom, resulting in a theoretical recovery of $100 \%$. Research into EFC techniques currently revolves around the "Scraped Cooled Wall Crystallizer" (SCWC) design developed in 2008. [20, 30, 35] One interesting advantage of EFC is its ability to selectively remove salts from a solution at their respective eutectic temperatures. [2] At the present time, experimental results are promising, and simulations suggest that the use of Scraped-Cooled Wall Crystallizers are suitable for process implementation. [21, 22, 23]

\subsubsection{Climate-Induced Freezing}

A variety of processes have been developed which take advantage of low temperatures during the winter months in order to supply the cooling required for FC. While all of them can be considered "natural" freezing processes, the term "natural freezing" refers only to a very specific process intended for stagnant bodies of liquid. Climate-induced freezing can be considered a form of indirect freezing in some instances if passive contact with air is viewed as contact with a "surface". However, such a definition is too specific to be useful. 
(1) Natural freezing (See Sections $1.2 \& 2.3$ )

(2) Freeze-thaw describes a wide variety of processes in which an aqueous solution is frozen either partially to form ice and concentrated solution, or completely in order to form a single frozen mass that is subsequently melted. The process most commonly used is to completely freeze a solution by spraying it through nozzles into the cold air, and leaving the ice and salt crystals to remain in a frozen heap. Melting occurs when winter ends, and as the more concentrated parts of the heap melt first, the resulting run-off is initially of a much higher concentration than the original solution. [26, 27, 28]

(3) Trickle freeze separation involves running an aqueous solution along a channel exposed to the atmosphere under laminar flow conditions. At sub-zero conditions ice will freeze in layers along the channel, while a more concentrated aqueous solution will percolate through and emerge as run-off. Once enough ice as formed, solution flow is stopped and the mass of ice is slowly melted. As in freeze-thaw processes, the solution produced at the beginning of the melting process is more concentrated. [26] This technique is analogous to layer freeze concentration.

(4) Spray freezing uses both sub-zero atmospheric conditions as well as a pressure drop in order to produce either ice crystals and concentrated solution, or both ice and salt crystals. The solution is cooled by passing it through a nozzle from a pipe into the cold air. The small liquid particles produced, already cooled by their passage through the nozzle, contact the cold air and are readily frozen. When both solid ice and concentrated solution are formed, the solution percolates through the ice and is collected as a run-off. Depending on the atmospheric conditions, the ice droplets formed may contain aqueous solution within them, and when the droplets fall to the ground they shatter, releasing the solution. [27] When both ice and salt crystals are formed the resulting mass is melted, and the initial concentrated run-off from the melting process is collected. [28] 


\subsubsection{Vacuum Freezing}

Vacuum freezing has been investigated for use as a desalination process, and in the place of ordinary refrigeration instead makes use of a strong vacuum, which vaporises some of the water in order to cool the solution [14]. In order to compensate for the large energy required to vaporise water, several variations on the basic principle of vacuum freezing have been proposed, but none tested [1]. This use of water vaporisation to induce freezing was once investigated in combination with natural freezing in the Chilean Andes [24].

\subsection{Natural Freezing}

Natural freezing is a type of climate-induced indirect freezing that uses cold temperatures from the natural environment in order to crystallise pure ice as a layer on top of an aqueous solution. The general procedure is to expose quiescent basins of salt solution to a sub-zero environment, resulting in the formation of a layer of ice on the cooled surface. The sides of the basin are typically insulated in order to maintain growth in only one direction. Evaporation of water can also contribute to cooling the solution [24]. The ice formed has a lower concentration of salt than the resulting brine due to the diffusion of solutes away from the advancing ice front [25, 34], and can either be further melted and refrozen or selectively melted in order to remove some of the entrapped solute [24].

\subsubsection{Recent Advances in Natural Freezing Research}

As natural freezing can only function in areas that frequently experience sub-zero temperatures, development has been limited. For instance, in 1974 a study [24] was performed, applying natural freezing for drinking water recovery in the Chilean Andes in which lower pressures at higher elevations were exploited to produce ice at air temperatures above $0{ }^{\circ} \mathrm{C}$. A 2009 study [36] briefly examined the use of natural freezing to treat petroleum refinery and pulp mill effluent, although the term "UniDirectional Freezing (UDF)" was used instead. In general, however, prior to 2015 virtually no research has been conducted on the use of natural freezing for water recovery.

Recent research by a group at Lappeenranta University of Technology in Finland focused on developing a mathematical model for natural freezing processes, culminating in several papers 
published from 2015 onwards [3, 25] which have been collected into a thesis [6]. In these papers a theoretical mathematical model of solid growth rates due to natural freezing was derived and validated experimentally using a sodium sulphate. It was found that lower growth rates induced by higher freezing temperatures, as well as shorter growth times, produce purer solid. Microscopy of the solid revealed that solute is trapped between grain boundaries of ice, preventing perfect separation. Furthermore, microscopy and visual observation of the solid resulted in the conclusion that this entrapment was the result of dendritic ice growth. The principal focus on the practical applications of the research was on quantifying rates of solute recovery, which varied according to the initial concentration of the solution.

Natural freezing at eutectic temperatures is explored in another paper by the same authors [31]. Because the system was not allowed to equilibrate fully in that work, solute crystals were produced separately from the ice due to Eutectic Freeze Crystallization. These solute crystals were separated from the solution and analysed.

\subsection{Removal of Impurities from Solid}

Although the objective of FC is to produce concentrated solution and pure ice, the presence of impurities trapped within the solid, between the grain boundaries of ice [6], necessitates further processing in order to decrease solution concentration. As mentioned in Section 1.3, research has been performed to examine the viability of initially freezing the tailings via spray-freezing, before thawing the frozen heap produced to remove concentrated melt water. [8] Furthermore, the food industry has conducted research into the thawing of freeze-concentrated juices [8]. In general, it is believed that the thawing of ice crystals releases solutes trapped between their grain boundaries, leaving behind a solid with fewer impurities. $[9,10]$

\subsubsection{Recent Advances in Melting Research}

Due to the dominance of food engineers in freeze concentration research, research into further purifying solid is principally pioneered by food engineering researchers. Centrifugation and crushing are two common methods of extracting entrapped solute from solid produced by freeze concentration. However, several studies [8, 9, 11, 32, 33] have focused on the removal of 
entrapped solute via a passive melting or "sweating" technique, in which a block of solid produced via layer crystallisation is allowed to melt at controlled air temperatures. This technique has led to improvements in solid purity, at the cost of recovery rates as solid mass is lost due to melting. Another study, performed on frozen blocks of coffee brews [37], incorporates microwaves and vacuums in the thawing stage.

A precise explanation of the mechanics of this melting was attempted by Nakagawa et al. in 2009 [32] and 2010 [33]. It was suggested that solute particles elute from within solid ice to a melting ice drop in a process called "solute elution". The conclusion reached by the authors is that solid solute particles migrate through solid ice in order to reach a drop of pure water produced by melting ice in order to concentrate it. However, this proposed process of "solute elution" - a term normally used in chromatography but entirely novel to freeze concentration does not take into account the possibility that solute particles might dissolve surrounding ice to form pockets of concentrated solution which might drip from the solid once they reach an exposed surface.

Mandri et al. [10] concluded from microscopy of a frozen sodium chloride solution that solute frozen above its eutectic temperature resulted in either pockets or channels of solute between grains of ice, depending on the rate of freezing as controlled by freezing temperature, and suggested that the selective draining of these solutes from those pockets or channels resulted in improved ice purity.

In general, studies that make of use of a melting / sweating / thawing technique to improve water recoveriy from blocks of solid with entrapped solute do not provide any explanation as to why their results are obtained, with the exception of the singular conclusions of Nakagawa et al. [32, 33], which do not appear to have met with widespread recognition. The phenomenon is merely empirically accepted and, with the exception of Mandri et al. [10], no research has been conducted on the structure of the solid once it begins to melt. 


\section{Objective}

The objective of this study was to identify conditions of natural freezing, followed by melting, suitable for the recovery of as pure solid ice as possible from an inorganic solution. A 0.48 molal magnesium sulphate solution was selected as the test solution. To this end, the following investigations were pursued:

1. The effects of a standalone natural freezing process were evaluated and

2. compared against the results of a combined natural freezing and melting process.

3. The effects of variations in freezing and melting temperatures were examined.

4. The solid produced was viewed under a digital microscope in order to obtain a greater understanding of the physical processes associated with water recovery from the solid produced. 


\section{Methodology}

A freezing chamber designed to simulate natural freezing conditions was constructed (Figure 3), and an apparatus for melting was assembled. The experiments performed simulated the natural freezing and melting of $500 \mathrm{~mL}$ of an approximately 0.48 molal magnesium sulphate solution at freezing temperatures ranging from $-2{ }^{\circ} \mathrm{C}$ to $-26{ }^{\circ} \mathrm{C}$, with the solution reaching its equilibrium, and melting temperatures ranging from $-2{ }^{\circ} \mathrm{C}$ to room temperature $\left(25^{\circ} \mathrm{C}\right)$. The magnesium sulphate solution was selected as an analogue to effluent from an existing hydrometallurgical process, while the temperature range extends over the regions of non-eutectic and eutectic freezing.

\subsection{Freezing Chamber}

The body and lid of the freezing chamber was constructed using sheets of Styrofoam insulation 2 inches in thickness. The dimensions of the chamber are 60 x 45 x $45 \mathrm{~cm}(\mathrm{LxWxH})$. The chamber was cooled using a VWR Refrigerated Circulating Bath with Advanced Digital Controller, which circulated a 30/70 ethylene glycol/water mixture through two McMaster-Carr Radiator-Style Heat Sinks. The air temperature of the freezing chamber was controlled using a VWR External Pt100 Probe connected to the Advanced Digital Controller. The tip of the probe was placed immediately above the surface of the solution. Air circulation within the freezing chamber was maintained by a small USB fan.

The solution used for freezing experiments was placed in a silicone pan (dimensions $21 \times 12 \mathrm{~cm}$ ), which was placed in the Styrofoam box. Gaps between the silicone pan and the box were sealed using spray-on insulating foam. This container was placed inside the freezing chamber when natural freezing experiments occurred (Figure 3). 


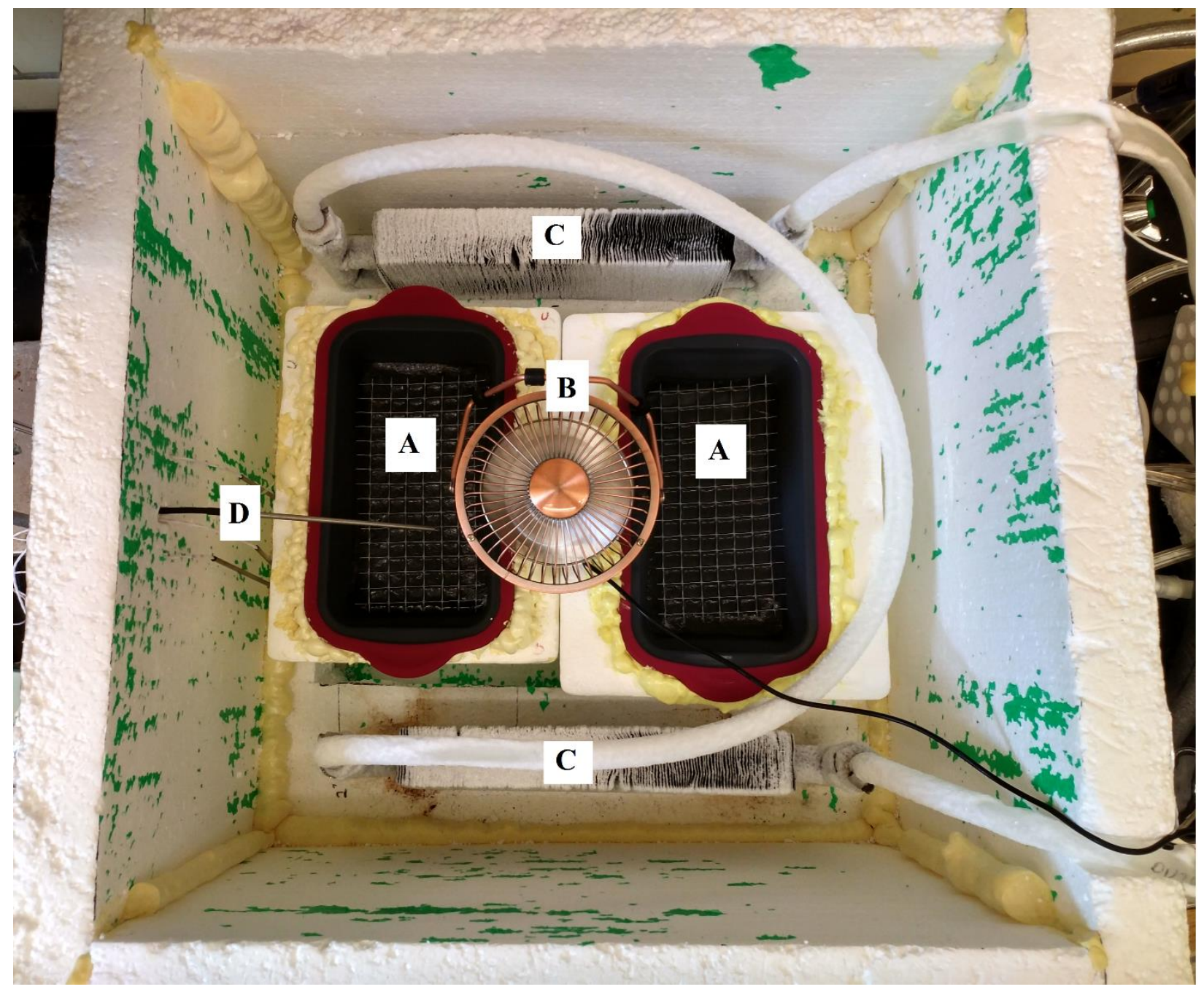

Figure 3: Freezing Chamber (top view) - A: Insulated silicone pans; B: USB fan; C: McMasterCarr Radiator-Style Heat Sinks; D: VWR External Pt100 Probe

In practice, the minimum air temperature achievable in the freezing chamber was approximately $-20{ }^{\circ} \mathrm{C}$. For experiments at $-26{ }^{\circ} \mathrm{C}$ the insulated silicone pans were placed inside a Danby Premiere Chest Freezer.

\subsection{Other Equipment}

During freezing experiments a piece of plastic wire netting approximately the length and width of the silicone pan was placed on the surface of the 0.5 molal magnesium sulphate solution in order to induce nucleation of ice. 
During the melting experiments ice was placed on top of a plastic drying rack with a pan underneath to capture the melting solution. A hole drilled into one corner of the pan allowed the solution to drain into a $50 \mathrm{~mL}$ Falcon tube positioned underneath. A Thermo Scientific Forma Lab Refrigerator was used for melting experiments occurring at $3{ }^{\circ} \mathrm{C}$.

Microscopy of the ice was performed using a Firefly RW180 Digital Microscope connected via USB cable to a laptop. A magnification of up to $250 \mathrm{x}$ could be achieved using the microscope.

\subsection{Natural Freezing}

Natural freezing experiments occurred at air temperatures of $-2,-3,-10$, and $-26{ }^{\circ} \mathrm{C}$. For the -2 , 3 , and $-10{ }^{\circ} \mathrm{C}$ experiments, $500 \mathrm{~mL}$ of 0.5 molal magnesium sulphate solution was placed in an insulated silicone pan, which was then placed in the freezing chamber. The USB fan was turned on and the refrigerating circulator, set to the desired air temperature, was started. The lid was placed over the freezing chamber, and the solution was left for 48 hours to ensure that the system had reached equilibrium.

In the case of experiments at $-26^{\circ} \mathrm{C}$, the insulated silicone pan was placed in the Danby Chest Freezer, where the solution was left for 24 hours to reach equilibrium.

\subsection{Melting}

After the allotted freezing time the solid was removed from the insulated silicone pan and placed on a plastic rack. Melting occurred at room temperature $\left(25{ }^{\circ} \mathrm{C}\right), 3{ }^{\circ} \mathrm{C},-0.2{ }^{\circ} \mathrm{C},-1{ }^{\circ} \mathrm{C}$, and $-2{ }^{\circ} \mathrm{C}$ respectively. At room temperature this rack was placed in the open, while for melting at $3{ }^{\circ} \mathrm{C}$, the rack was placed inside a Thermo Scientific Forma Lab Refrigerator. "Melting" below $0{ }^{\circ} \mathrm{C}$ took place inside the freezing chamber.

For experiments in which the solute distribution in solid was examined, the solid was melted on a pan heated to around $75^{\circ} \mathrm{C}$ on top of a hot plate in order to rapidly obtain horizontal "slices" of the solid representative of its actual magnesium sulphate distribution. 


\subsection{Experiments Performed}

\subsubsection{Natural Freezing Standalone Experiments}

The solution was frozen at air temperatures of $-2{ }^{\circ} \mathrm{C}$ and $-10{ }^{\circ} \mathrm{C}$ for 48 hours. The solid produced was then melted on a heated pan (surface temperature in excess of $70{ }^{\circ} \mathrm{C}$ ), with melted solution being periodically collected and analysed.

\subsubsection{Natural Freezing and Room Temperature Melting Experiments}

The solution was frozen at air temperatures of $-2,-3$, and $-10{ }^{\circ} \mathrm{C}$ for 48 hours, or at $-26{ }^{\circ} \mathrm{C}$ for 24 hours. The solid produced was then placed on a plastic grille above a pan and left to melt at room temperature (approximately $25{ }^{\circ} \mathrm{C}$ ), with melted solution being periodically collected and analysed.

\subsubsection{Natural Freezing and $3{ }^{\circ} \mathrm{C}$ Melting Experiments}

The solution was frozen at air temperatures of -2 and $-10{ }^{\circ} \mathrm{C}$ for 48 hours. The solid produced was then placed on a plastic grille above a pan inside a refrigerator set to $3{ }^{\circ} \mathrm{C}$ and left to melt, with melted solution being periodically collected and analysed.

\subsubsection{Natural Freezing and Other Melting Experiments}

A variety of freezing and melting experiments were performed at conditions different from those experiments listed above in order to examine the effects of exposing the solid to different subzero temperatures and for different lengths of time prior to melting. The experiments performed were as follows:

\section{Case A: $\quad$ Two-Step Eutectic Freezing}

Freeze at air temperature of $-2{ }^{\circ} \mathrm{C}$, remove solid and freeze at $-26^{\circ} \mathrm{C}$ for 24 hours before melting at room temperature.

\section{Case B: $\quad$ Ice Curing}


Freeze at air temperature of $-2{ }^{\circ} \mathrm{C}$, remove solid and leave on grille at $-2{ }^{\circ} \mathrm{C}$ for 48 hours before melting at room temperature.

\section{Case C: $\quad$ Eutectic Freezing and Curing}

Freeze at air temperature of $-26^{\circ} \mathrm{C}$, remove solid and leave on grille at $-0.2{ }^{\circ} \mathrm{C}$ for 48 hours before melting at room temperature.

\section{Case D: $\quad$ Multi-Stage Curing of Ice}

Freeze at air temperature of $-2{ }^{\circ} \mathrm{C}$, remove solid and leave on grille at $-2{ }^{\circ} \mathrm{C}$ for 24 hours, then $-1{ }^{\circ} \mathrm{C}$ for 24 hours, and then $-0.1^{\circ} \mathrm{C}$ for 24 hours before melting at room temperature.

\section{Case E: $\quad$ Multi-Stage Curing with Temperature Alterations}

Freeze at air temperature of $-2{ }^{\circ} \mathrm{C}$, remove solid and leave on grille at $-2{ }^{\circ} \mathrm{C}$ for 24 hours, then $-0.2{ }^{\circ} \mathrm{C}$ for 24 hours, and then $-2{ }^{\circ} \mathrm{C}$ again for 24 hours before melting at room temperature.

\subsection{Analytical Methods}

Once a sample was collected it was weighed and then diluted with deionised (DI) water to a known volume of either $100 \mathrm{~mL}$ or $250 \mathrm{~mL}$ in a volumetric flask. These diluted samples were further diluted using $5 \%$ nitric acid in a ratio of $1 / 100$ or $1 / 1000$, depending on the concentration of the initial sample.

The nitric acid-diluted samples were analysed for magnesium content using ICP-OES. The results of ICP-OES analysis report a mass-based concentration in parts per million. The sample was assumed to have a density of $1 \mathrm{~g} / \mathrm{mL}$, which permitted a conversion to a mass of magnesium. Through subsequent calculation the molality of the initial sample was obtained. 


\subsection{Digital Microscopy}

At the end of a freezing experiment the solid produced was removed from the silicone tray and placed on rack. A Firefly RW180 Digital Microscope was positioned to image the side of the solid produced. The magnifications employed ranged from 50x to 250x. Microscopy occurred within 5-10 minutes of removal of solid, before the exposed surfaces began to melt. However, microscopy of solid frozen at -10 and $-26{ }^{\circ} \mathrm{C}$ also occurred immediately after the surface began to melt in order to demonstrate the melting of ice around trapped solute crystals.

\subsection{Equilibrium Simulations}

Simulations of the magnesium sulphate - water system were performed using OLI Studio: Stream Analyser version 9.2. This software was used to determine the equilibrium composition of a solution at a given temperature, and therefore to produce a binary phase diagram of the system. 


\section{Results and Discussion}

\subsection{Presentation of Results}

Each sample of melted solution analysed represents a portion of the original solid ice obtained by freezing. As the solid is melted, it loses mass as the solution drains away. Magnesium concentration in the remaining solid ice is plotted against the fraction of the ice remaining which in turn corresponds to the fraction of the cleaner water that can be recovered once the remaining ice s melted completely. Thus water "recovered" is still in solid form, as the melted solution is considered waste material that is sacrificed to increase solid purity (while decreasing solid ice yield). Furthermore, the curves shown here are trendlines drawn through the points representing samples from multiple experiments. The trendlines are second-order polynomial functions, with the exception of the $-10{ }^{\circ} \mathrm{C}$ natural freezing standalone line found in Section 1.2 , which is a third-order polynomial function. R-squared values of the trendlines are included in the figures. A comprehensive explanation of the calculations used to obtain the data points is provided in Appendix A.

\subsubsection{Binary Phase Diagram and Equilibrium}

All freezing experiments performed in this study reached equilibrium prior to their removal from the freezing chamber. This was easily confirmed in cases where the freezing temperature was below the eutectic temperature of $-4.1{ }^{\circ} \mathrm{C}$, as the complete absence of liquid remaining was sufficient proof. In the case of $-2{ }^{\circ} \mathrm{C}$ and $-3{ }^{\circ} \mathrm{C}$ freezing experiments, the magnesium concentrations of the remaining liquid were placed on the binary phase diagram produced by OLI Studio: Stream Analyser 9.2 of the magnesium sulphate - water system in order to confirm that the systems had reached equilibrium (and therefore lie on the liquidus line).

The equilibrium magnesium composition of the solution as determined by OLI at $-2{ }^{\circ} \mathrm{C}$ and $3{ }^{\circ} \mathrm{C}$ is 1.01 molal and 1.38 molal, respectively. The mean composition of solution from all $-2{ }^{\circ} \mathrm{C}$ freezing experiments was 1.02 molal with a standard deviation of 0.14 , while the mean composition from all $-3{ }^{\circ} \mathrm{C}$ freezing experiments was 1.34 molal with a standard deviation of 0.09 (Figure 4). 


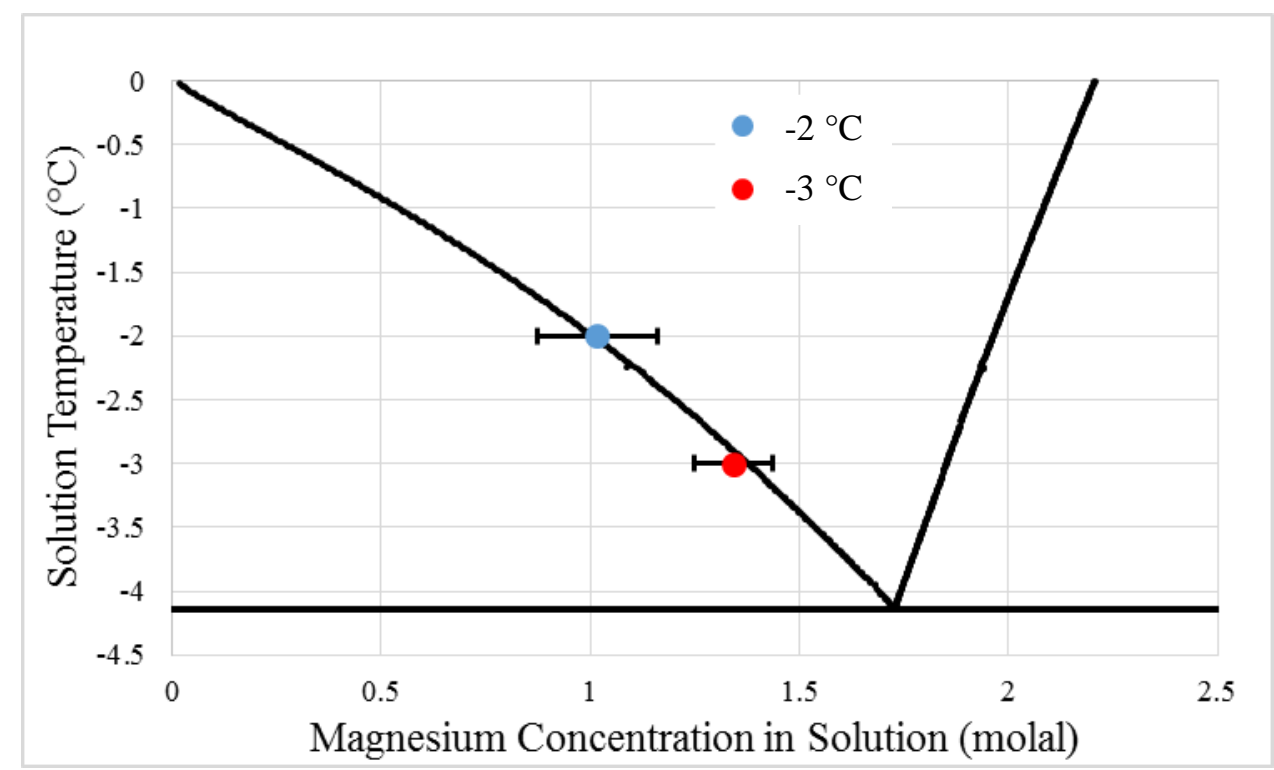

Figure 4: Magnesium Sulphate - Water Binary Phase Diagram with $-2{ }^{\circ} \mathrm{C}$ and $-3{ }^{\circ} \mathrm{C}$ Freezing Solution Compositions

\subsection{Natural Freezing and Fast Melting}

In Figure 5, the magnesium concentration in molal units was plotted against the water recovery $(\%)$ of the solid when produced by freezing at -2 and $-10{ }^{\circ} \mathrm{C}$ and fast-melted on a pan heated to around $75{ }^{\circ} \mathrm{C}$ in order to examine the effects of natural freezing only on water recovery (see Appendix B for raw data). The use of the heated pan results in the uniform removal of an entire horizontal section of the solid, at a rate high enough to prevent the melting of any solid above the contact surface. This means that the results obtained approximate the distribution of magnesium sulphate within the solid after natural freezing, without the influence of any other processes. 


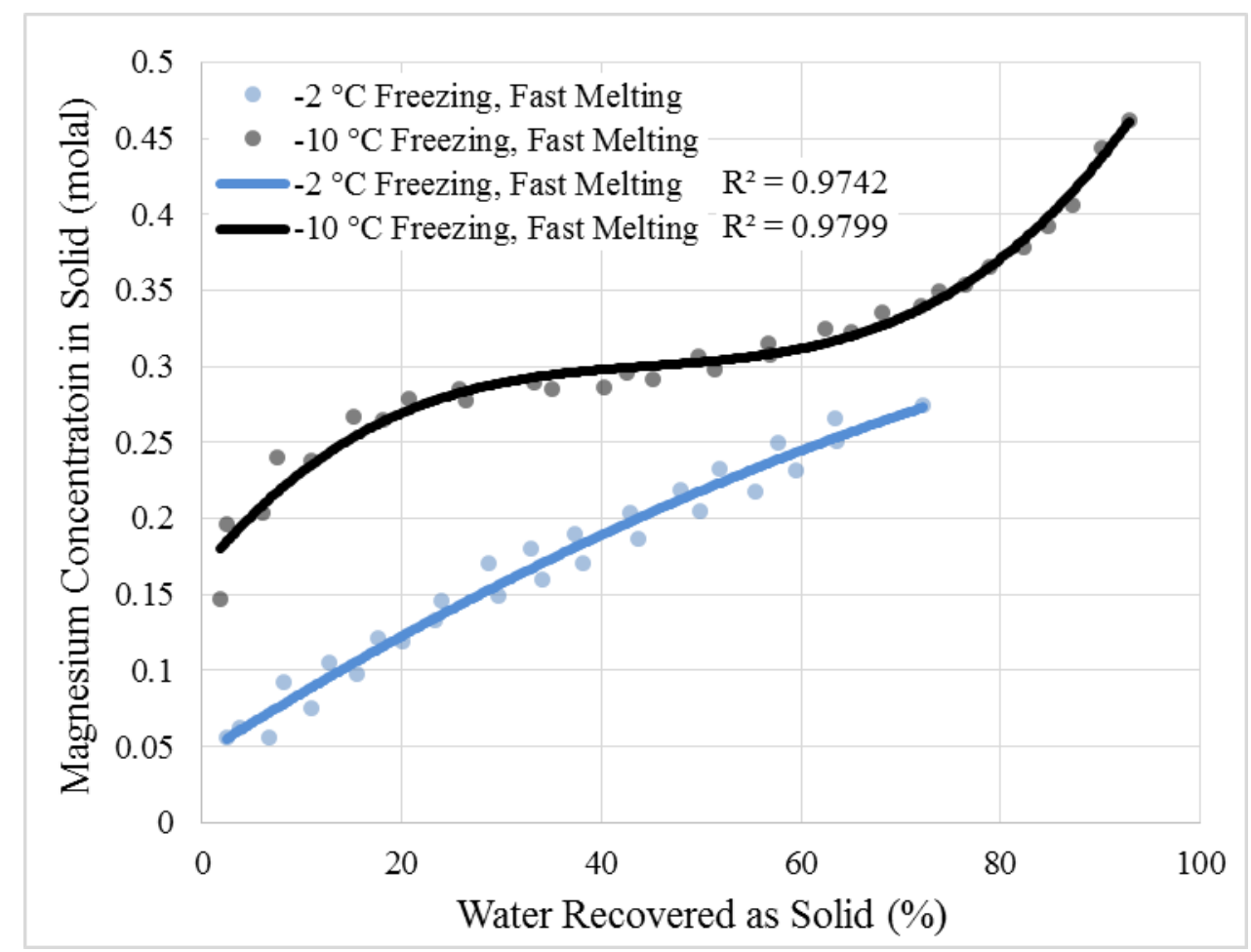

Figure 5: Natural Freezing and Fast Melting Experiments

As expected, there is far greater inclusion of impurities in the solid at all water recovery percentages when the solution is frozen at $-10{ }^{\circ} \mathrm{C}$ compared to $-2{ }^{\circ} \mathrm{C}$. This is due to the fact that the faster freezing at $-10{ }^{\circ} \mathrm{C}$ results in greater entrapment of solute by the advancing ice layer. The water recovery of the solid frozen at $-2{ }^{\circ} \mathrm{C}$ stops at approximately $70 \%$ due to the system having reached equilibrium.

Figure 6 shows the actual concentrations of discrete quantities of melt solution. At up to around $30 \%$ water recovery, more solute remains in the $-10{ }^{\circ} \mathrm{C}$ freezing case than the $-2{ }^{\circ} \mathrm{C}$ case. This indicates that more solute was entrapped in the $-10{ }^{\circ} \mathrm{C}$ case - the result of a lower freezing temperature. However, between 30 and $70 \%$ water recovery the amount of solute released is virtually the same, which suggests that similar amounts of solute were entrapped in that region in both cases. Above $70 \%$ water recovery the solution concentration rapidly increases in the $-10{ }^{\circ} \mathrm{C}$ case, as large quantities of solute trapped in the solid are released in the initial phases of fast melting. 


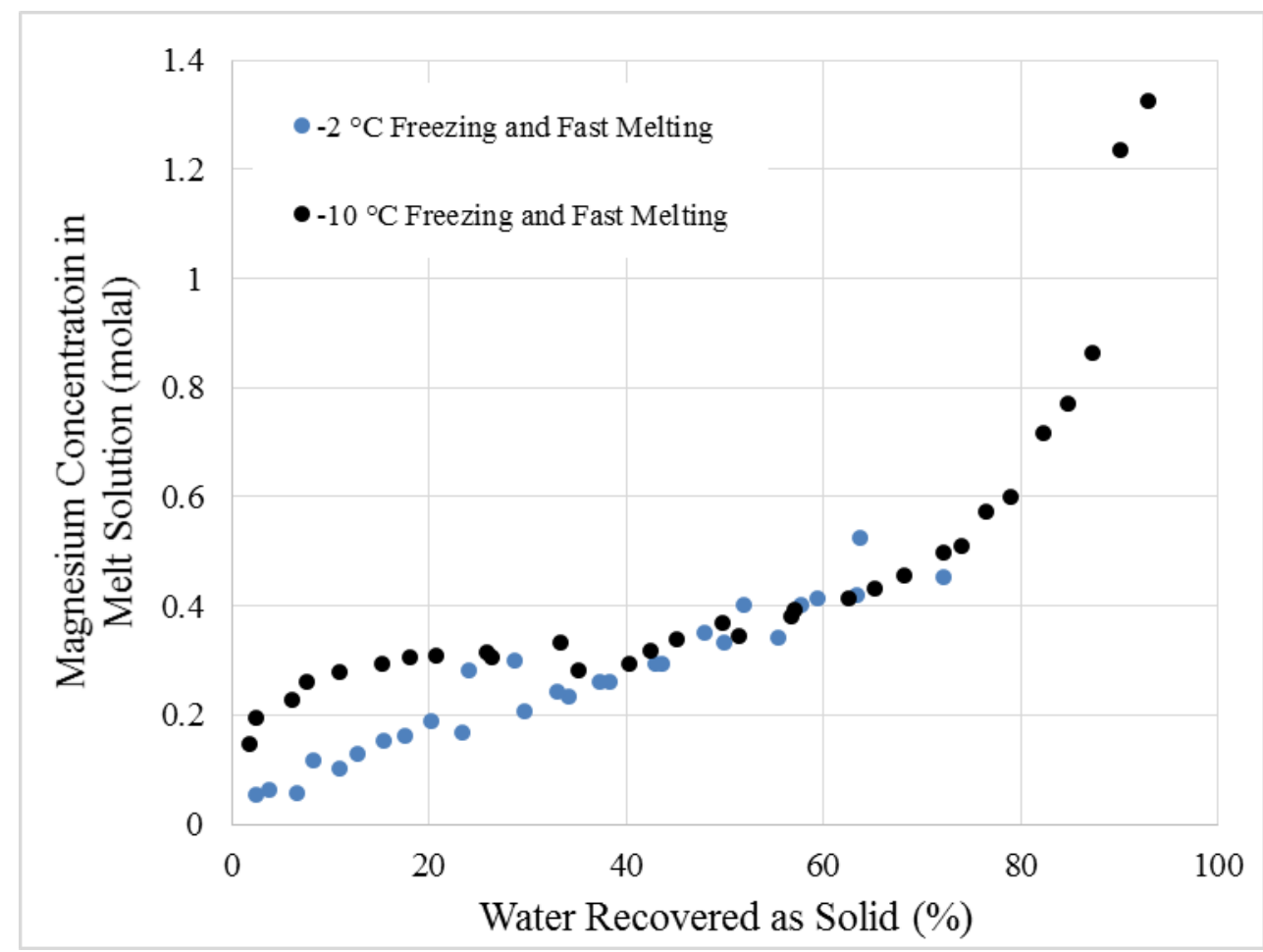

Figure 6: Concentration of melt solution in Natural Freezing and Fast Melting experiments

\subsection{Natural Freezing and Room Temperature Melting}

The magnesium concentration (molal) was plotted against the water recovery (\%) of the solid when produced by freezing at $-2,-3,-10$ and $-26{ }^{\circ} \mathrm{C}$ and melted at room temperature $\left(25{ }^{\circ} \mathrm{C}\right)$ (Figure 7). See Appendix C for raw data. 


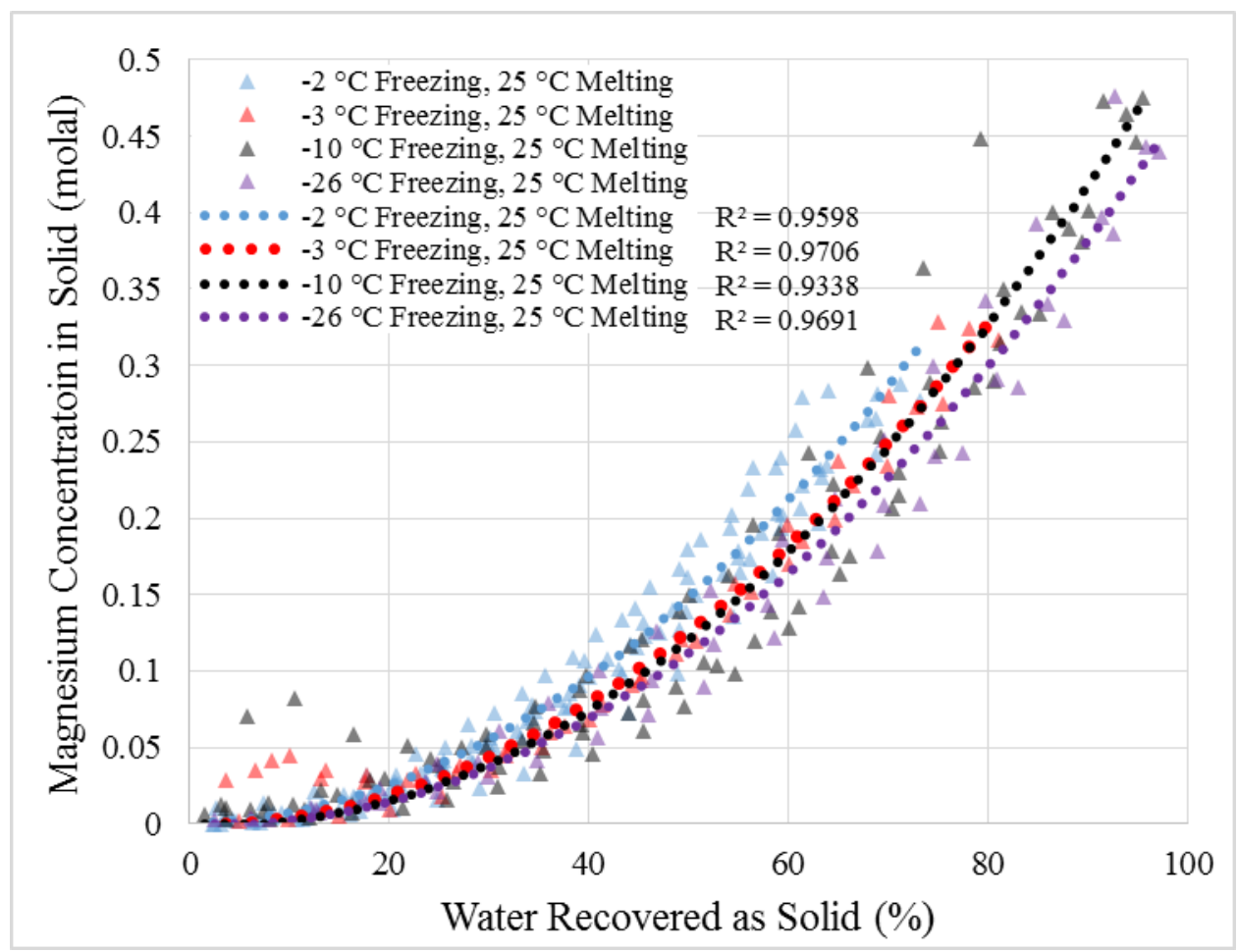

Figure 7: Natural Freezing and Room Temperature Melting

The results for solid frozen at $-2{ }^{\circ} \mathrm{C}$ are inferior to those for solid frozen at lower temperatures; the best water recovery vs. magnesium concentration plots are derived from solution frozen at $26{ }^{\circ} \mathrm{C}$ in spite of the fact that it is frozen below the eutectic temperature of magnesium sulphate. In this case solute inclusion is in the form of magnesium sulphate dodecahydrate crystals, as opposed to solution, was trapped between grain boundaries. It is also important to note that not only do the early stages (above 50\% water recovery) of melting yield better results, the water recovery and magnesium concentration is superior across the board at lower freezing temperatures.

This observation appears contradictory to nature, as it might be presumed that higher freezing temperatures causing slower ice growth would produce a solid with fewer entrapped impurities. While this is certainly the case with natural freezing, the mechanism responsible for improved recovery at $25^{\circ} \mathrm{C}$ is melting, not freezing. That is the reason why it is possible to obtain satisfactory water recovery even when the solution is frozen below its eutectic temperature, and all of the solution has been converted into solid ice and magnesium sulphate crystals. 
Temperature conditions that would result in the production of a highly impure solid if only natural freezing were applied are in fact quite beneficial in a process that includes the treatment of the solid produced via melting.

A comparison of the room temperature melting experiments at $-2{ }^{\circ} \mathrm{C}$ and $-10{ }^{\circ} \mathrm{C}$ against the results of the natural freezing and fast melting experiments (Figure 8) dramatically demonstrates the efficacy of passive melting as a means of decreasing the magnesium concentration in the ice produced without hindering water recovery.

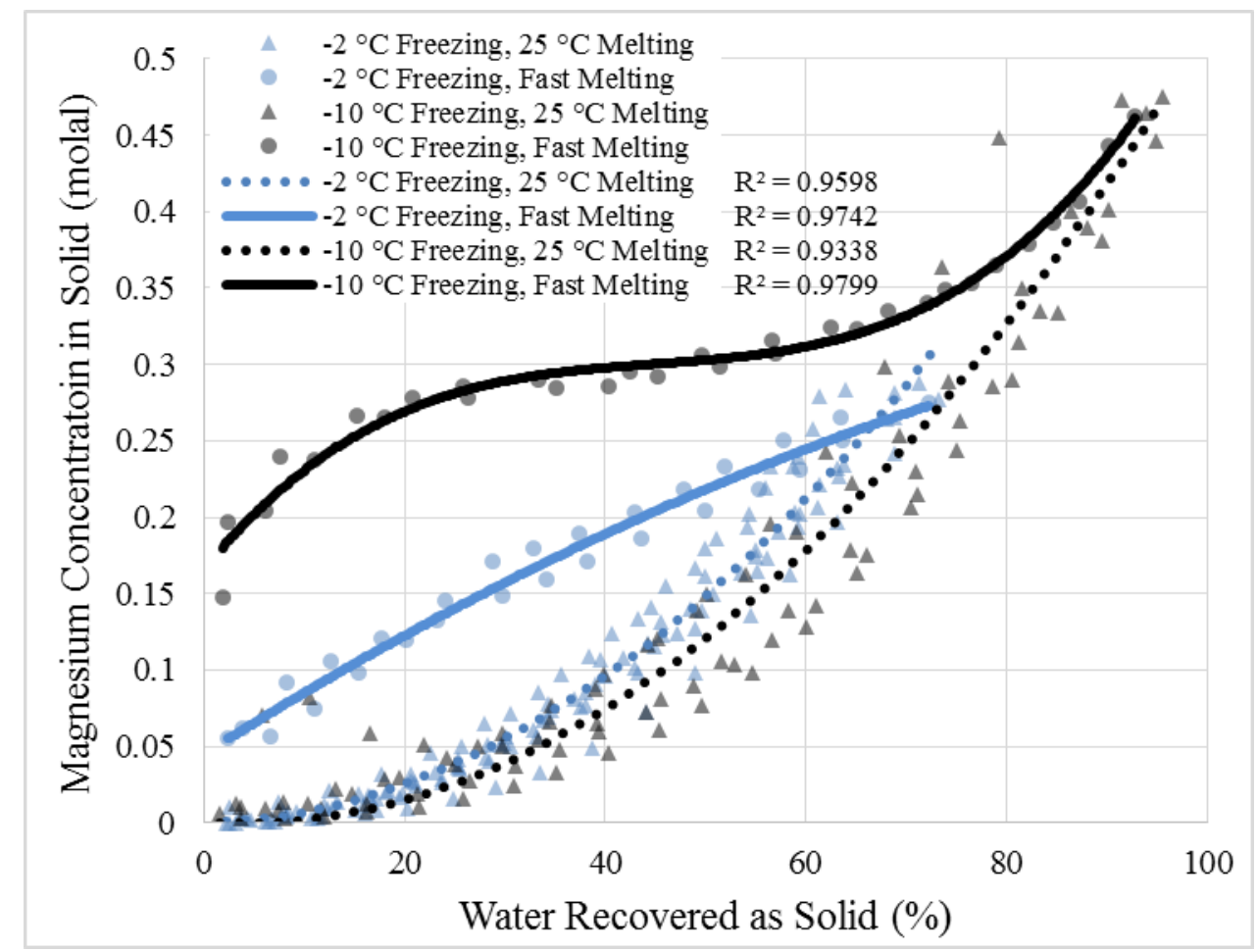

Figure 8: Comparison of Natural Freezing with Fast Melting and Natural Freezing with Room Temperature Melting

This validates the use of natural melting as a method of purifying ice produced by natural freezing. This improvement occurs because solution is removed from the solid faster than the pure ice melts, to the extent that solution entrapped in ice will flow past un-melted ice and leave the solid. Three possible cases are available for entrapped solution (Figure 9): in case (A), solute drains from channels linking the top of the solid to the bottom. As the solute drains away, channels at the top empty out, resulting in purer solid at the end of melting. Case (B) is similar, 
except the channels do not reach to the top of the solid. In case (C) the channels do not connect to the bottom of the solid, preventing them from draining. Therefore, the only way for the solute to be removed is for the bottom of the solid to melt away until the channels are exposed, or for the solute to dissolve surrounding ice until it can "tunnel" its way to the bottom of the solid.

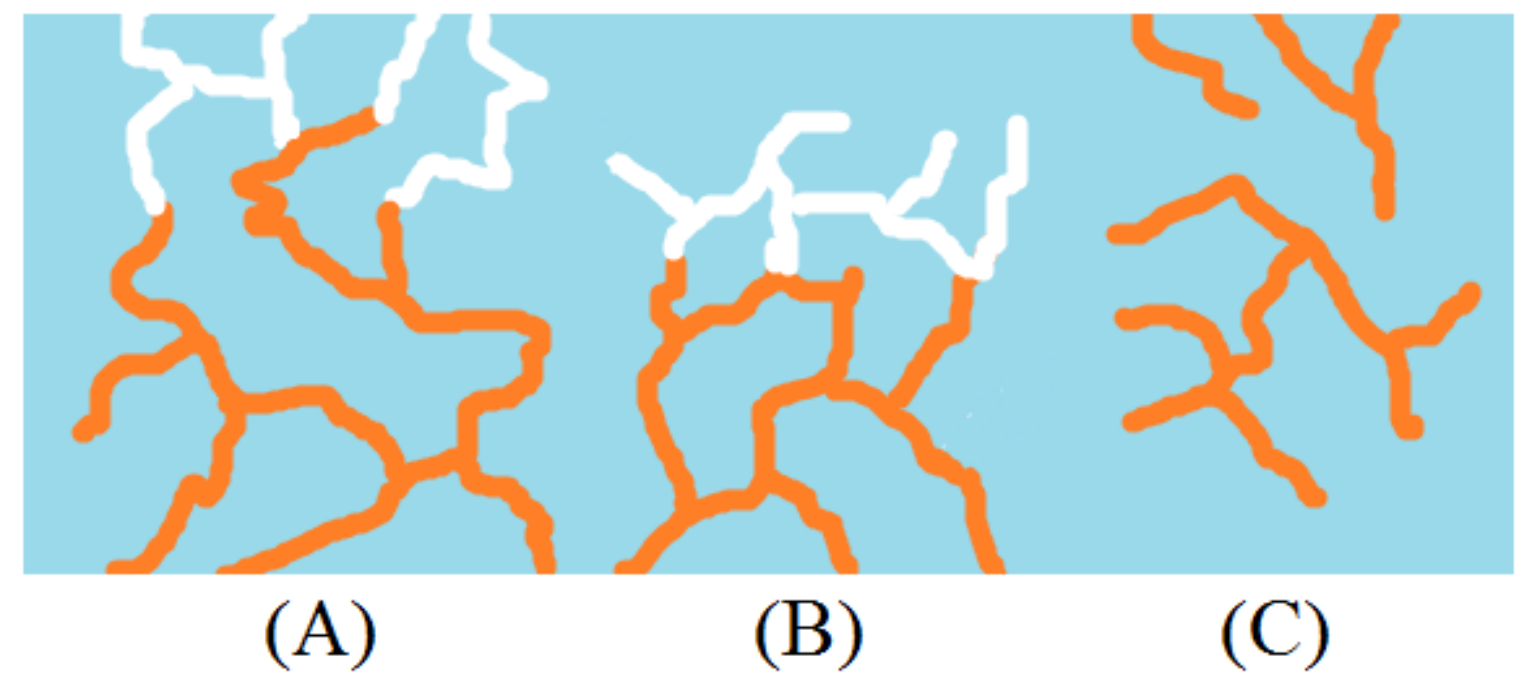

Figure 9: Solution (orange) draining from ice (blue)

Although the solute leaves the solid faster than the rate of ice melting, the fact that there is always some amount of magnesium present in the solid up to virtually the end of the melting phase, as well as the fact that the concentration of the melted solution is always below the initial concentration ( 0.48 molal magnesium sulphate) and, in the $-2{ }^{\circ} \mathrm{C}$ case, far below the equilibrium concentration of approximately 1 molal, proves that the melted solution is being diluted by the melting of pure ice. This melting is necessary for some of the solution to be removed, as it would otherwise be trapped by the ice.

\subsection{Natural Freezing and $3{ }^{\circ} \mathrm{C}$ Melting}

The magnesium concentration (molal) was plotted against the water recovery $(\%)$ of the solid when produced by freezing at -2 , and $-10{ }^{\circ} \mathrm{C}$ and melted in a fridge at $3{ }^{\circ} \mathrm{C}$ (Figure 10). Refer to Appendix D for raw data. 


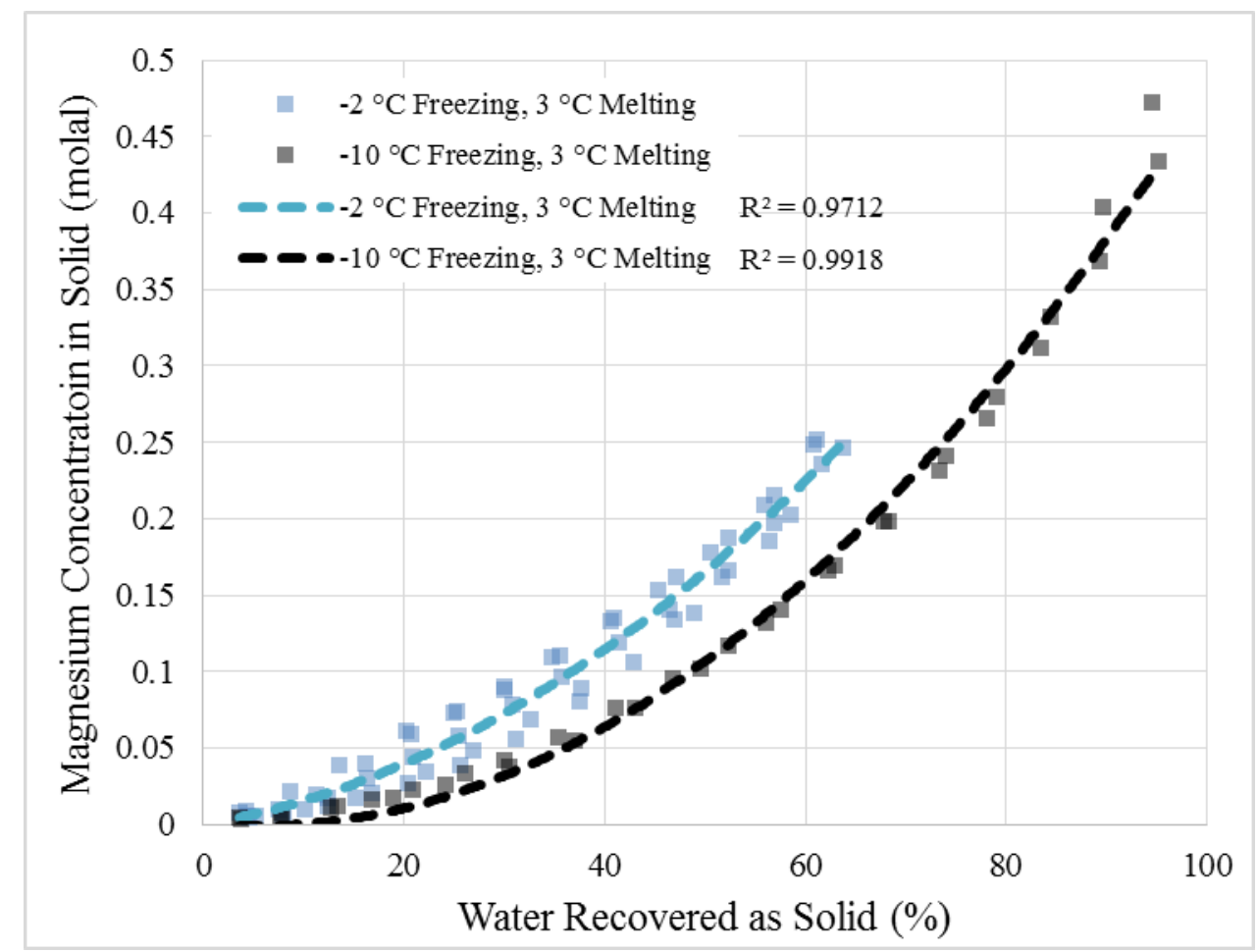

Figure 10: Natural Freezing and $3{ }^{\circ} \mathrm{C}$ Melting

Similar to room temperature experiments, the thawing of solid frozen at $-2{ }^{\circ} \mathrm{C}$ produces worse results than the solid frozen at a lower temperature $\left(-10^{\circ} \mathrm{C}\right)$. However, a comparison of melting at room temperature and in a fridge at $3^{\circ} \mathrm{C}$ (Figure 11) shows that there is very little difference between melting at room temperature and melting at $3{ }^{\circ} \mathrm{C}$. 


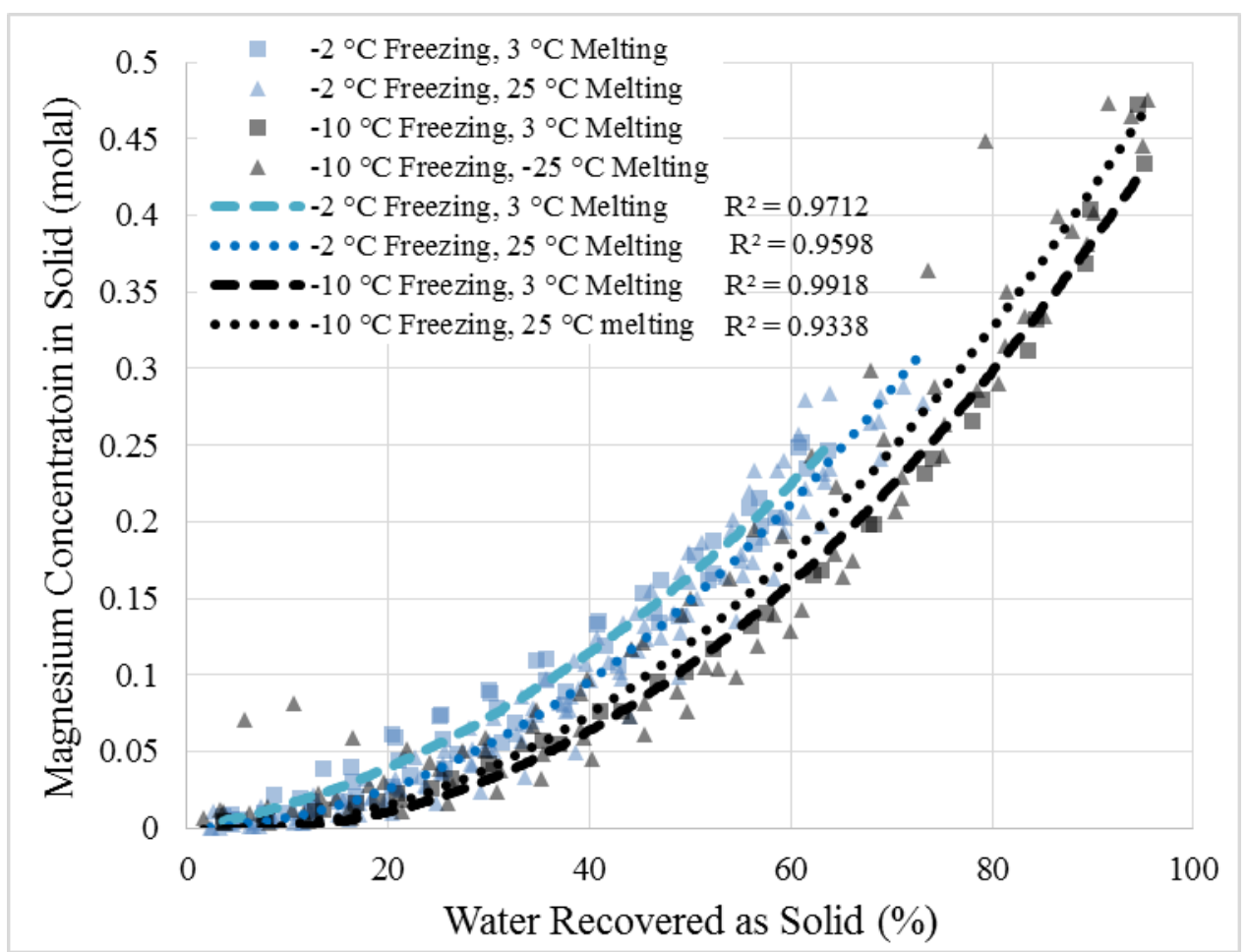

Figure 11: Comparison of Melting at Room Temperature and Melting at $3{ }^{\circ} \mathrm{C}$

It appears that differences in melting temperature, which affect the speed of melting, do not materially affect the manner in which it occurs, although it does alter the time frame in which the melting takes place.

\subsection{Natural Freezing and Other Melting Processes}

Refer to Appendix E for raw data.

\subsubsection{Case A: Two-Step Eutectic Freezing}

Solid frozen at $-2{ }^{\circ} \mathrm{C}$ and then $-26{ }^{\circ} \mathrm{C}$ before being melted at room temperature exhibited slightly improved behaviour over solid frozen at $-2{ }^{\circ} \mathrm{C}$, although still inferior to solid frozen at $-26{ }^{\circ} \mathrm{C}$ (all solid melted at room temperature) (Figure 12). 


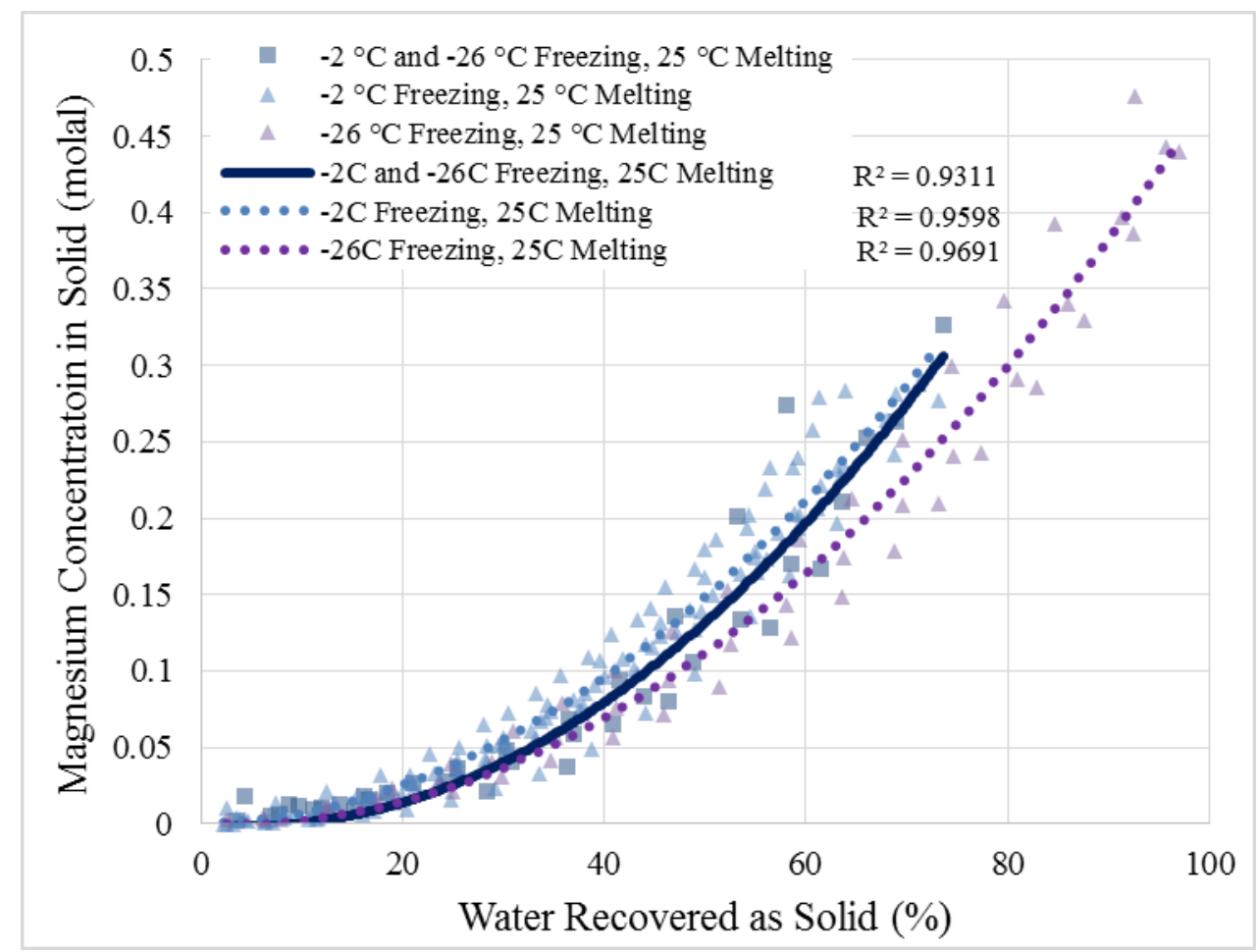

Figure 12: Natural Freezing at $-2{ }^{\circ} \mathrm{C}$ followed by placing the solid in a freezer at $-26{ }^{\circ} \mathrm{C}$ prior to room temperature melting

The effect of freezing the solid at $-26{ }^{\circ} \mathrm{C}$ prior to room temperature melting is to convert the solution trapped between the ice within the solid into a single homogeneous mass consisting of ice and solute crystals. The favourable characteristics of the melting of solid frozen below the eutectic temperature is transmitted to the solid in this case by the additional freezing of the solid at $-26{ }^{\circ} \mathrm{C}$.

\subsubsection{Case B: Ice Curing}

Solid frozen at $-2{ }^{\circ} \mathrm{C}$, removed and then left on a grille inside the freezing chamber at an air temperature of $-2{ }^{\circ} \mathrm{C}$ before being melted at room temperature exhibits mixed results compared to ordinary room temperature melting of solid frozen at $-2{ }^{\circ} \mathrm{C}$ (Figure 13). Initially, melting removes impurities at a higher rate than the normal case. 


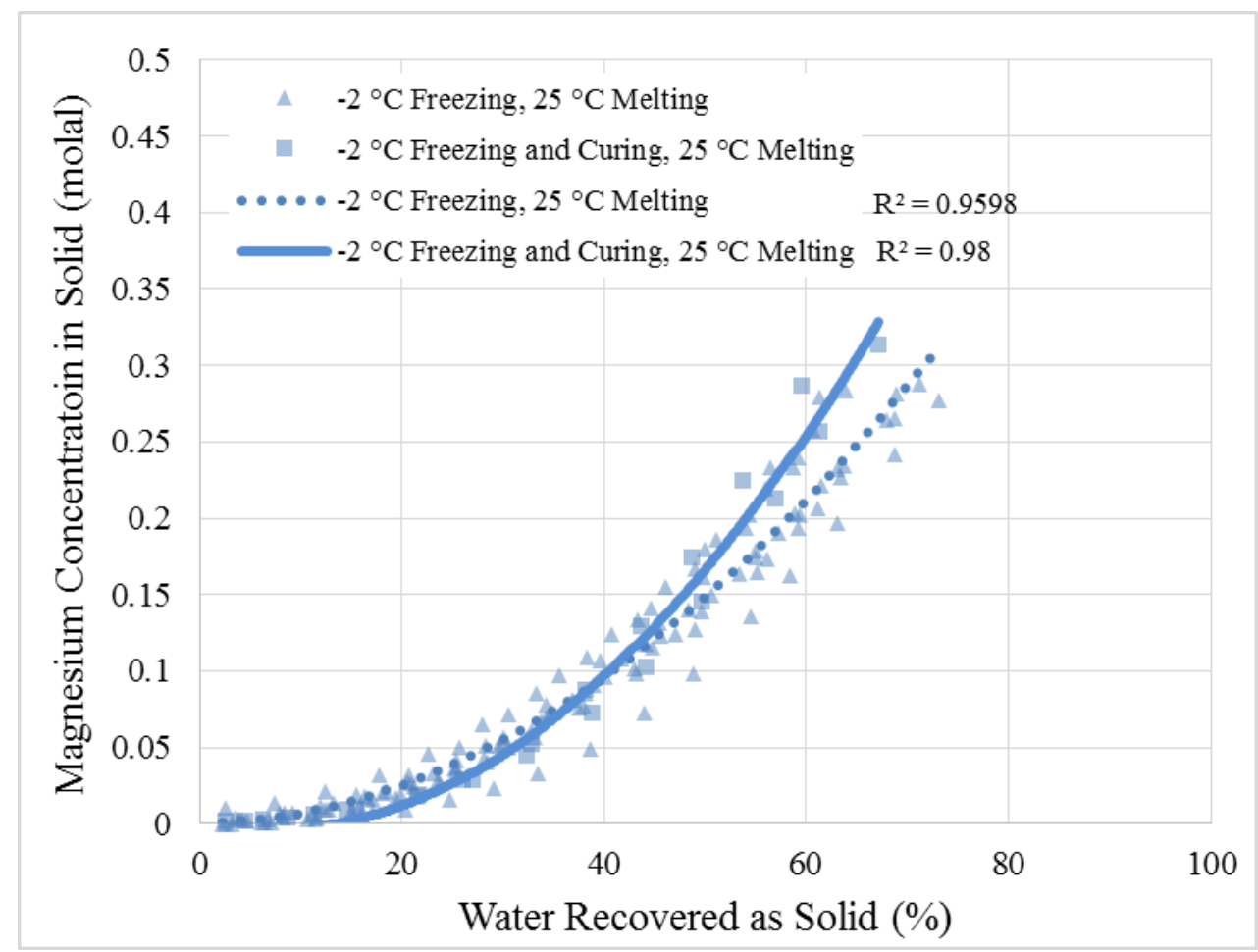

Figure 13: Natural Freezing at $-2{ }^{\circ} \mathrm{C}$ followed by leaving the solid only at $-2{ }^{\circ} \mathrm{C}$ prior to room temperature melting

Between $40 \%$ and $70 \%$ water recovery, impurities are removed at a faster rate in the solid cured at $-2{ }^{\circ} \mathrm{C}$ compared to the uncured solid. This is because the curing stage results in the draining of entrapped solution without the melting of ice, as the entrapped solution is at equilibrium with the ice at $-2{ }^{\circ} \mathrm{C}$. Therefore the rate of ice melting is lower for the cured solid, which shows that the dissolution of ice by entrapped solution is a factor in the diluting of the solution.

The low magnesium concentration when the water recovery is below $40 \%$ is attributable to the "settling" of solution from the top part of the solid to the bottom while the solid is left on the grille at $-2{ }^{\circ} \mathrm{C}$.

\subsubsection{Case C: Eutectic Freezing and Curing}

Solid frozen at $-26{ }^{\circ} \mathrm{C}$ and then left on a grille in the freezing chamber at $-0.2{ }^{\circ} \mathrm{C}$ for 48 hours before being melted at room temperature also exhibited worse behaviour compared to the case in which solid frozen at $-26^{\circ} \mathrm{C}$ was removed and melted at room temperature (Figure 14). 


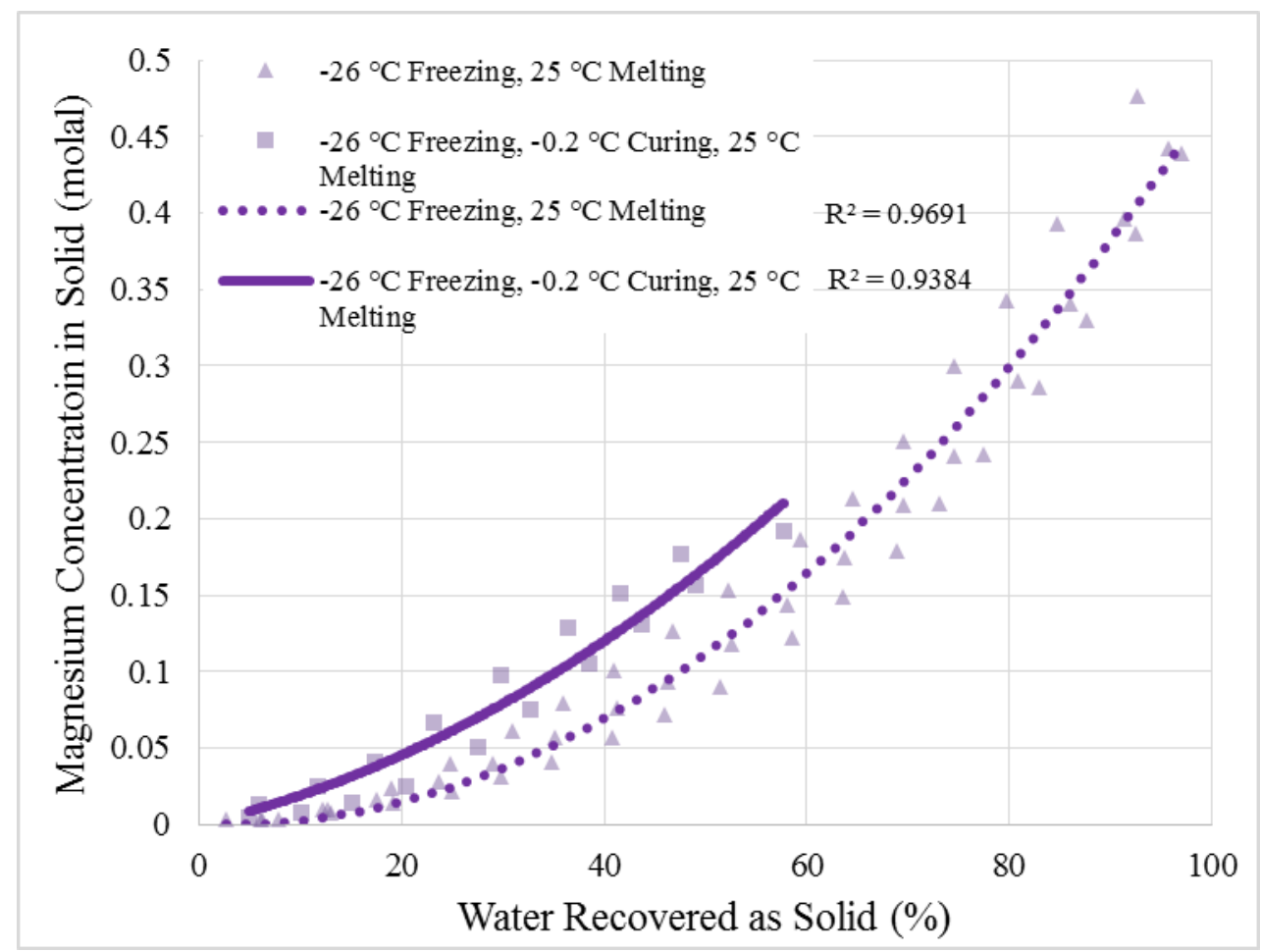

Figure 14: Natural Freezing at $-26{ }^{\circ} \mathrm{C}$ followed by leaving the solid on a grille at $-0.2{ }^{\circ} \mathrm{C}$ before melting at room temperature

Although it might be expected that by leaving the solid at just below the freezing temperature of water all of the solution would leave (along with a large amount of melted ice), sufficient solution was still entrapped to result in worse recovery than the base case of natural freezing at $26{ }^{\circ} \mathrm{C}$ followed by melting at room temperature. This is attributable to the fact that the remaining ice does not melt at $-0.2{ }^{\circ} \mathrm{C}$, thus maintaining an impermeable barrier preventing the entrapped solution from leaving the solid.

\subsubsection{Case D: Multi-Stage Curing of Ice}

Solid frozen at $-2{ }^{\circ} \mathrm{C}$ and then left on a grille at $-2{ }^{\circ} \mathrm{C}$ for 24 hours, $-1{ }^{\circ} \mathrm{C}$ for 24 hours, and then $0.1{ }^{\circ} \mathrm{C}$ for 24 hours before being melted at room temperature exhibited far worse results compared to the normal case of room temperature melting of solid froze at $-2{ }^{\circ} \mathrm{C}$ (Figure 15 ). 


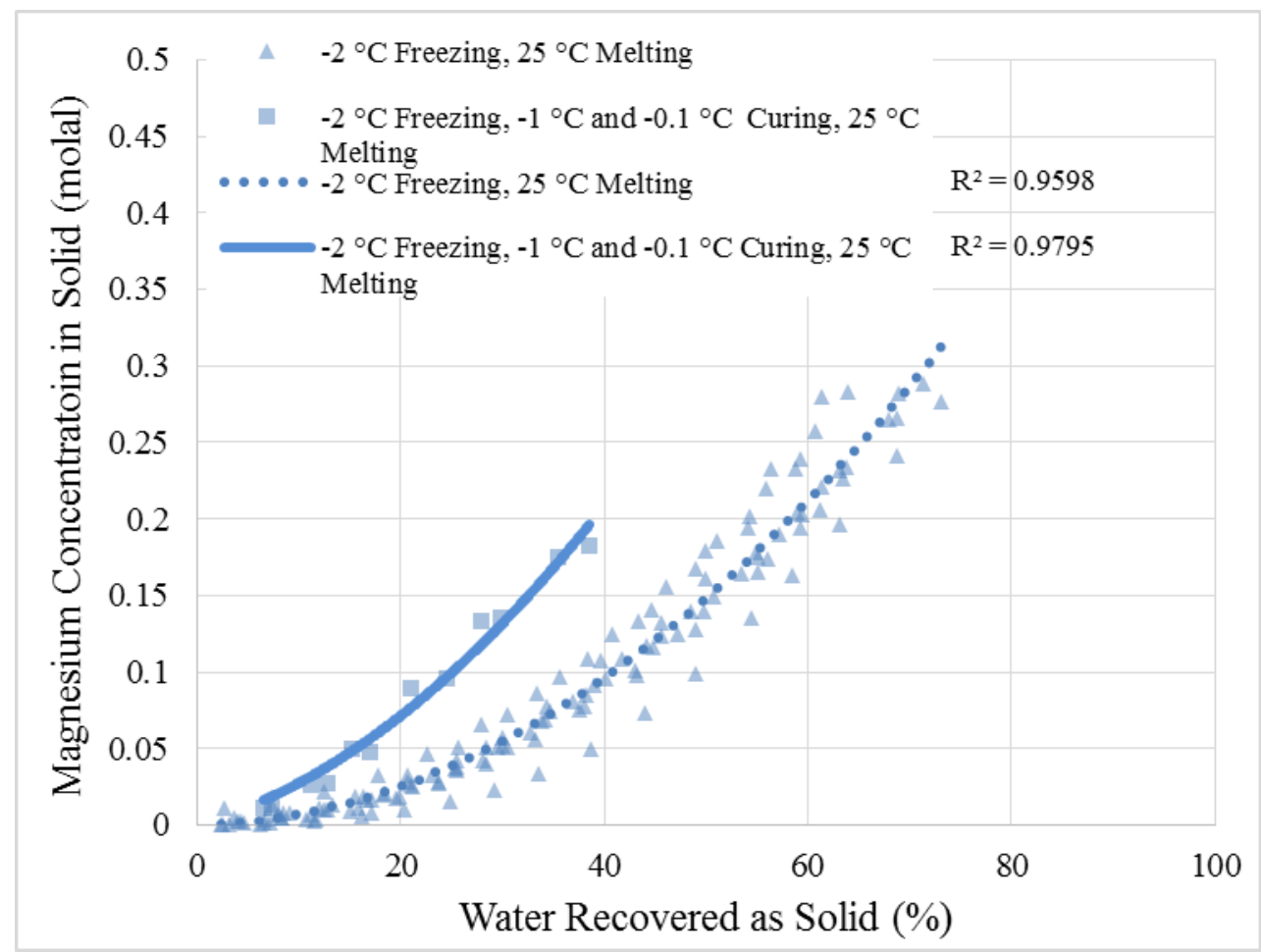

Figure 15: Natural Freezing at $-2{ }^{\circ} \mathrm{C}$ followed by ice curing at $-2{ }^{\circ} \mathrm{C}$ for 24 hours, $-1{ }^{\circ} \mathrm{C}$ for 24 hours, and then $-0.1{ }^{\circ} \mathrm{C}$ for 24 hours before being melted at $25^{\circ} \mathrm{C}$

Similar to Case $\mathrm{C}$, the decreased water recovery against magnesium concentration is the result of the ice at $-0.1{ }^{\circ} \mathrm{C}$ which prevents solution from leaving the solid.

\subsubsection{Case E: Multi-Stage Curing with Temperature Alterations}

When solid was frozen at $-2{ }^{\circ} \mathrm{C}$, left on a grille at $-2{ }^{\circ} \mathrm{C}$ for 72 hours, then $-0.2{ }^{\circ} \mathrm{C}$ for 24 hours, and then back to $-2{ }^{\circ} \mathrm{C}$ for 24 hours before being melted at room temperature, the results (Figure 16) were inferior to the base case in which solid frozen at $-2{ }^{\circ} \mathrm{C}$ was melted at room temperature. 


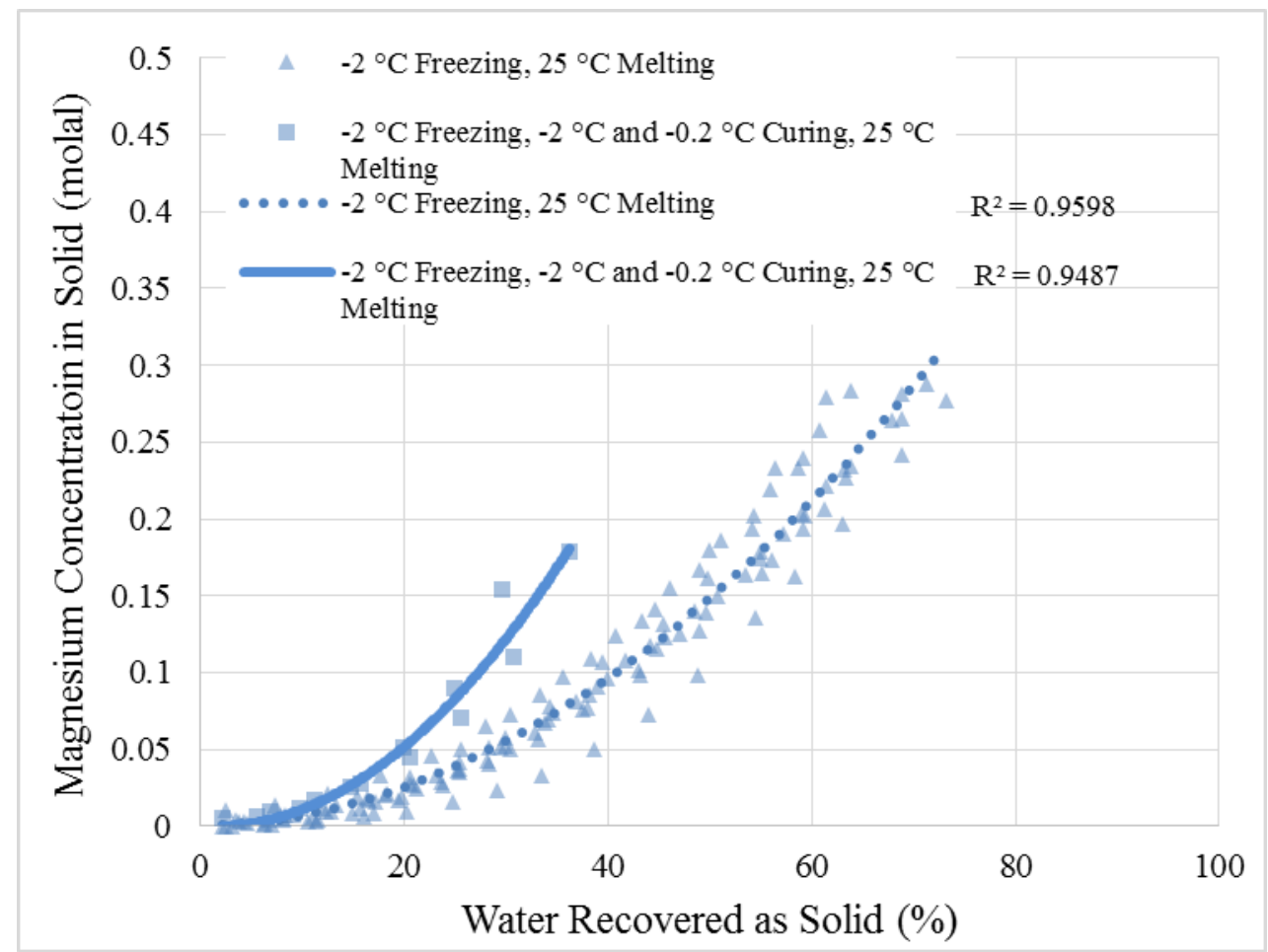

Figure 16: Natural Freezing at $-2{ }^{\circ} \mathrm{C}$, and then curing at $-2{ }^{\circ} \mathrm{C}$ for 72 hours, $-0.2{ }^{\circ} \mathrm{C}$ for 24 hours, and then $-2{ }^{\circ} \mathrm{C}$ for 24 hours before being melted at $25^{\circ} \mathrm{C}$

Similar to Case C and Case D, the lower water recovery against magnesium concentration is the result of the ice at $-0.2{ }^{\circ} \mathrm{C}$ which prevents solution from leaving the solid. This curve is slightly more favourable than the curve in Case D, probably owing to the fact that the solid, when removed for melting at room temperature, is at $-2{ }^{\circ} \mathrm{C}$ (as opposed to $-0.1{ }^{\circ} \mathrm{C}$ in Case D). This decreases the overall rate of ice melting, which therefore decreases the dilution of the solution.

\subsection{Digital Microscopy}

Because ice does not adhere to silicon, it was possible to examine a "cross-section" of the solid by viewing a side of the solid that had been in contact with the silicon. There was a window of several minutes between the removal of the solid and the commencement of melting, which allowed for unimpaired views of the ice. In all photographs the direction of ice growth is from the top of the image to the bottom. 
Figure 17 shows solid frozen at $-2{ }^{\circ} \mathrm{C}$ at $50 \mathrm{x}$ magnification. The (grey-white) grains of ice seen in the picture are randomly oriented in different directions. Entrapped solution is found between the grains of ice.

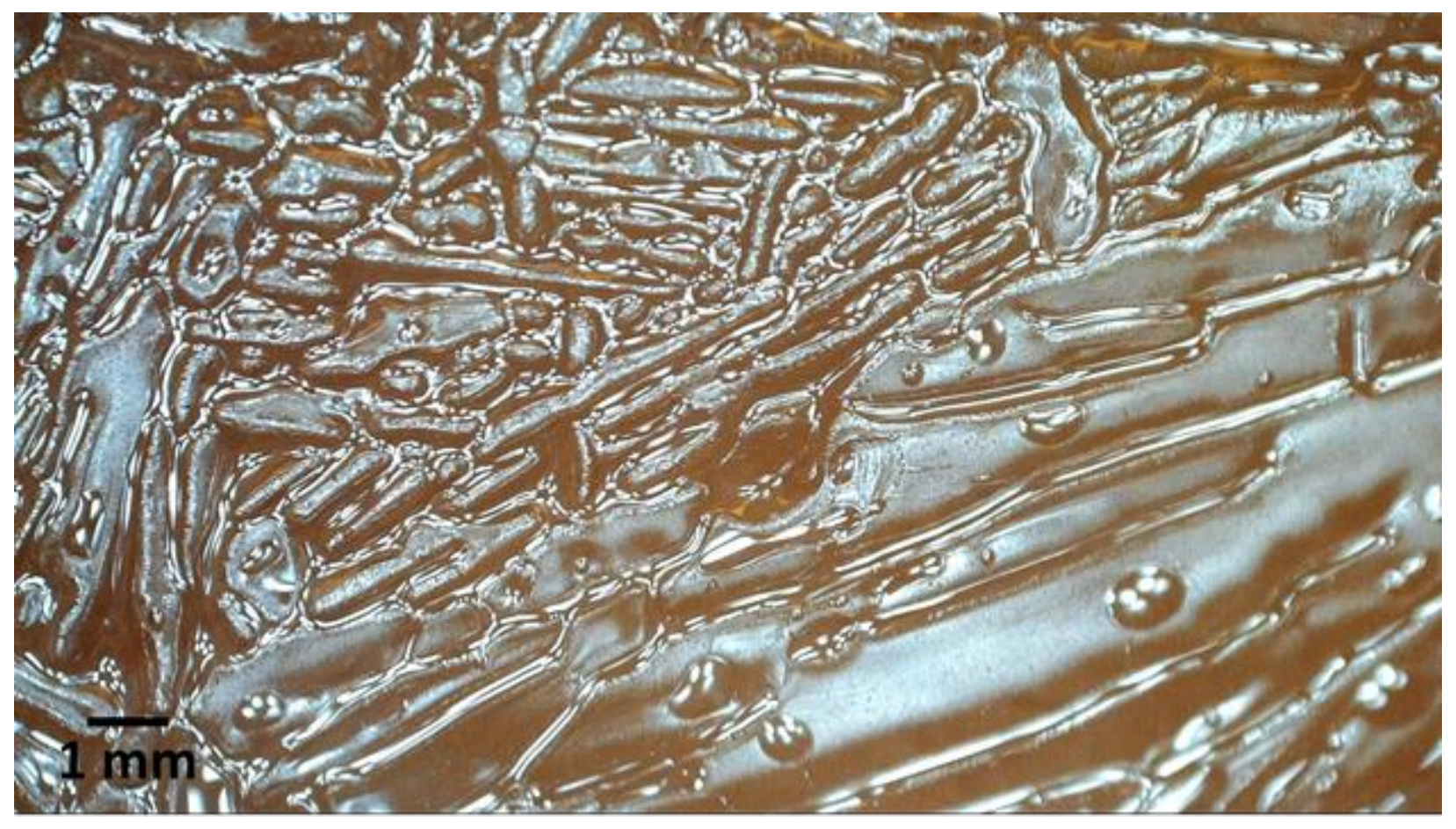

Figure 17: Freezing Temperature of $-2{ }^{\circ} \mathrm{C}, 50 \mathrm{x}$ Magnification 
Figure 18 is a view of solid frozen at $-2{ }^{\circ} \mathrm{C}$ viewed at a greater magnification than in Figure 17. The ice and solution entrapped between the grains can be clearly distinguished here. The white shapes are the result of the light from the microscope being reflected by the surface of the entrapped solution.

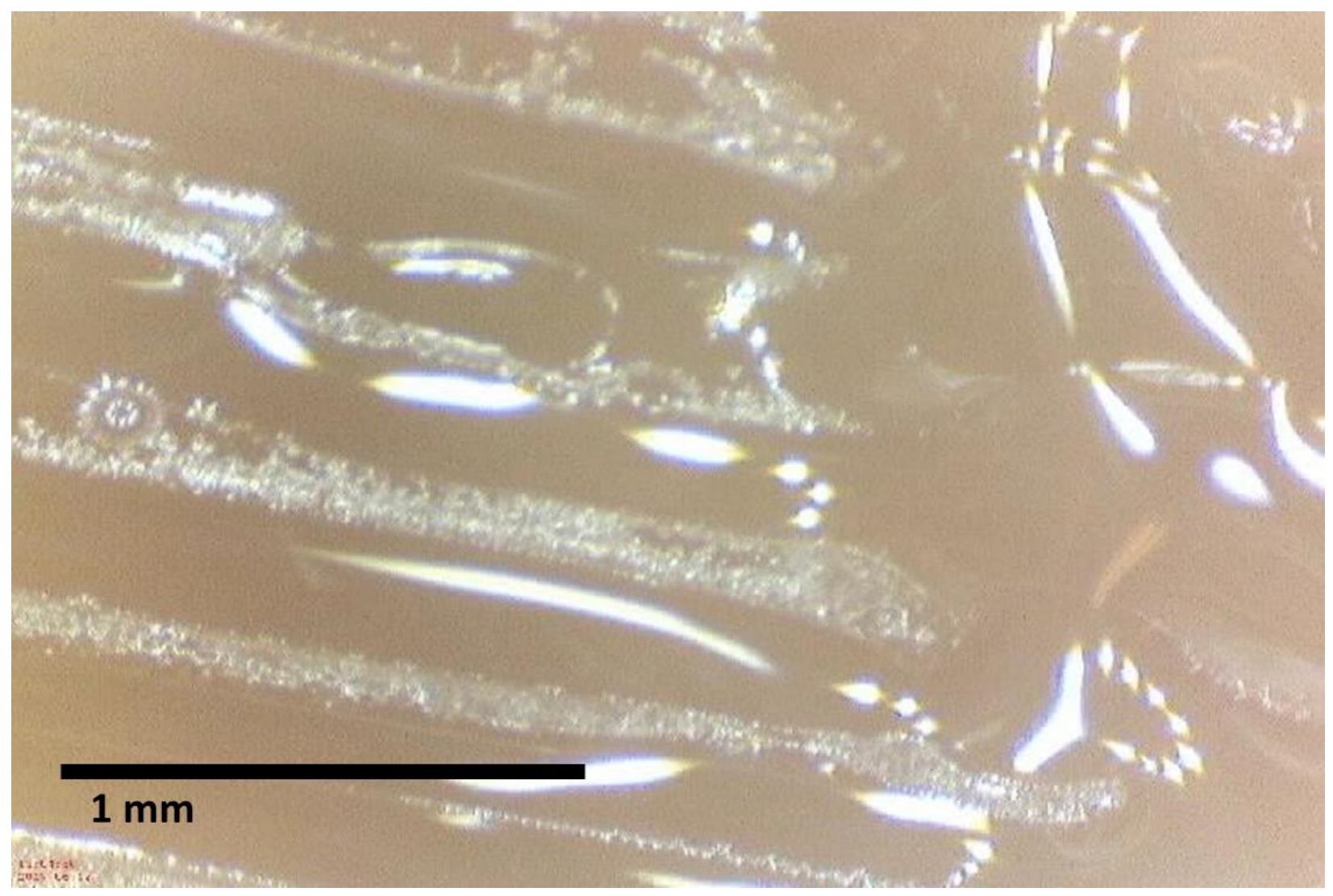

Figure 18: Freezing Temperature of $-2{ }^{\circ} \mathrm{C}, 250 \mathrm{x}$ Magnification 
Figure 19 shows solid frozen below the eutectic temperature of the solution at $-10{ }^{\circ} \mathrm{C}$ taken, like Figure 17, at 50x magnification. However, unlike Figure 17, some melting was permitted to occur, as otherwise the view would be of a homogenous surface with both ice and solute crystals. Furthermore, in contrast to Figure 17 it is more difficult to make out individual grains of ice, as the solute crystals distributed throughout the solid each melt surrounding ice, creating more networks of a smaller size in comparison to solid frozen at $-2{ }^{\circ} \mathrm{C}$.

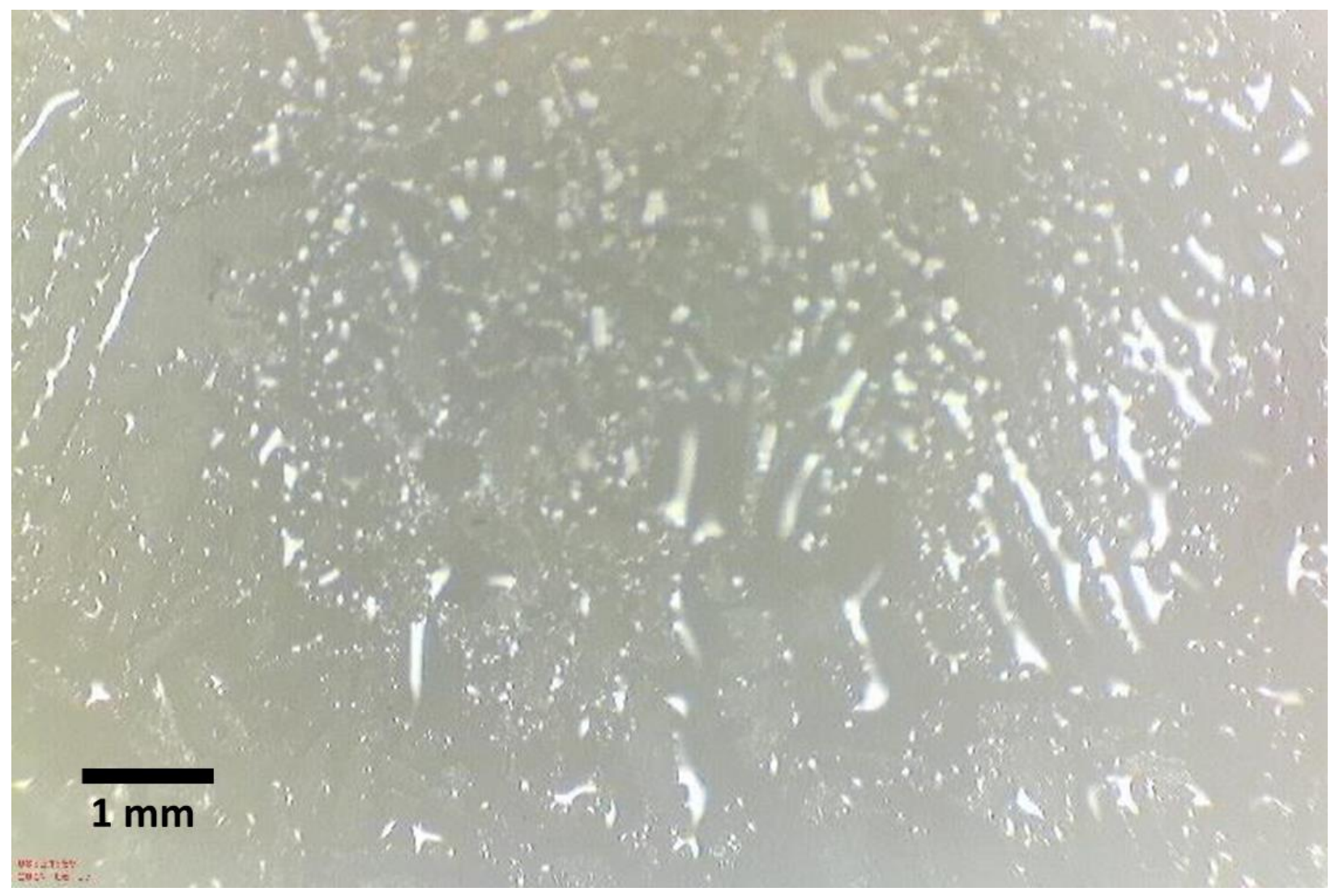

Figure 19: Freezing Temperature of $-10{ }^{\circ} \mathrm{C}, 50 \mathrm{x}$ Magnification 
Figure 20 shows solid frozen at $-10{ }^{\circ} \mathrm{C}$ at $250 \mathrm{x}$ magnification. The appearance of the solid is not improved by this magnification, as it can be seen that the structure is far more "porous" and consists of more interconnected channels than the solid frozen at $-2{ }^{\circ} \mathrm{C}$ seen in Figure 18.

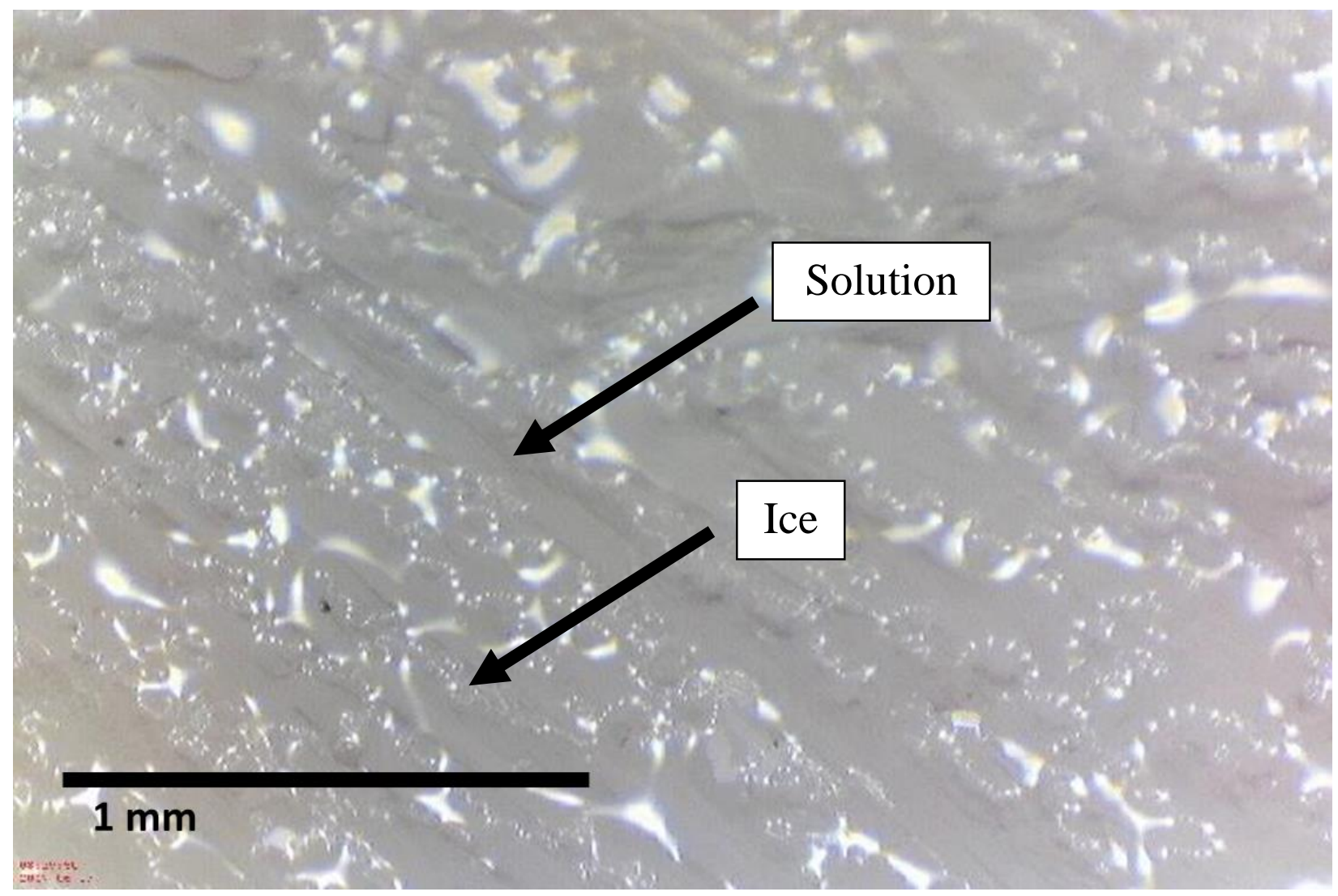

Figure 20: Freezing Temperature of $-10^{\circ} \mathrm{C}, 250 \mathrm{x}$ Magnification 
Figure 21 shows the underside of solid frozen at $-2{ }^{\circ} \mathrm{C}$ with solution accumulating on the underside (the cloudy-white area; the whiteness is caused by reflection of the grille) before it drips away. Very little deterioration of ice occurs during this time.

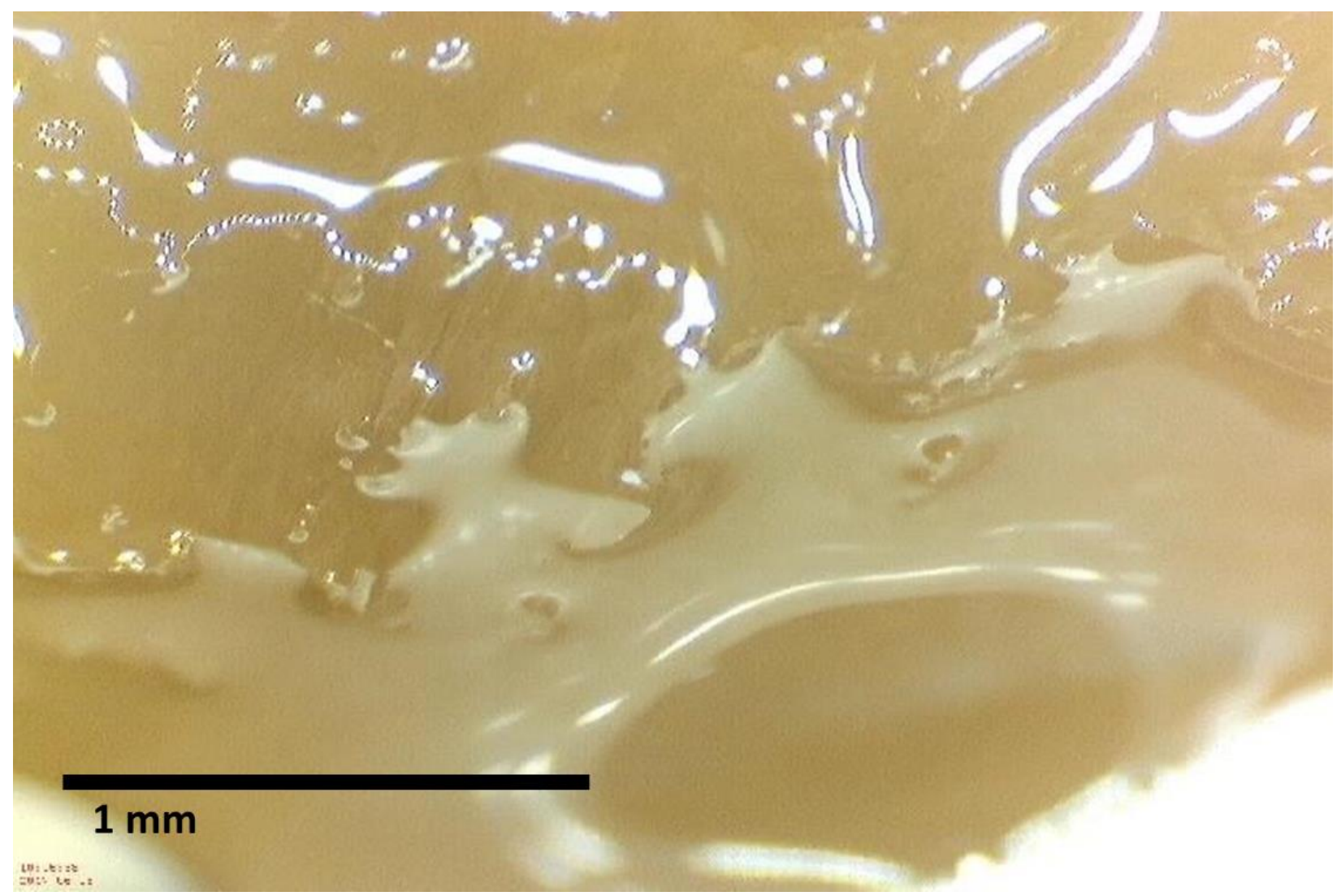

Figure 21: Underside of solid frozen at $-2{ }^{\circ} \mathrm{C}$. 250x magnification. 
Figure 22 shows small dendrites of ice that appear as the solid melts, with melted solution receding upwards to later collect in other areas to drip away (as in Figure 21). These dendrites do not survive for more than a few seconds, as they rapidly melt into the receding solution.

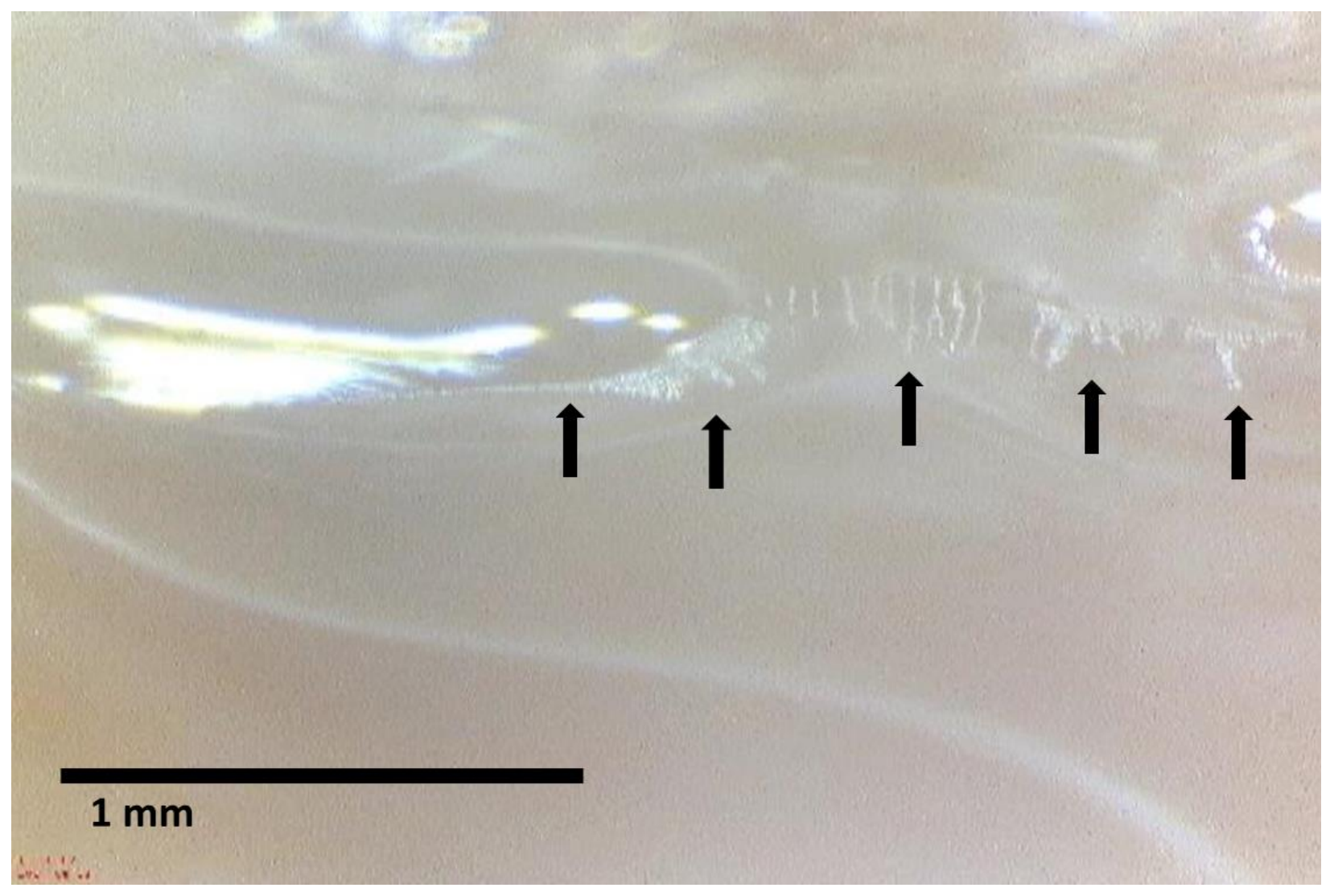

Figure 22: Ice dendrites on underside of solid frozen at $-2{ }^{\circ} \mathrm{C}$ during melting. 250x magnification 
Figure 23 shows solid frozen at $-2{ }^{\circ} \mathrm{C}$ and then placed in a freezer at $-26{ }^{\circ} \mathrm{C}$. The dark areas are grains of ice, while the light areas are a mixture of the resulting eutectically-frozen ice and magnesium sulphate dodecahydrate crystals.

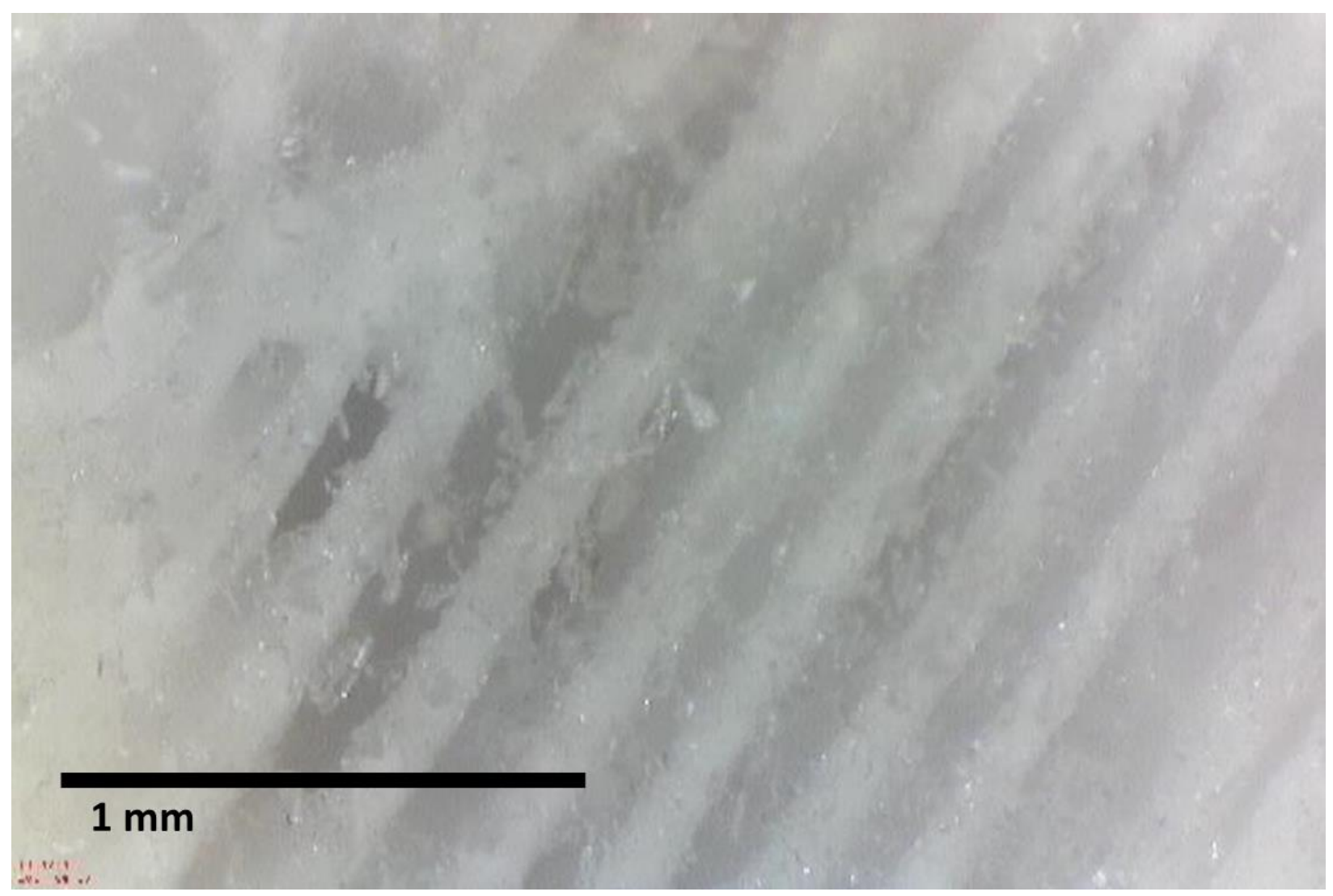

Figure 23: Solid frozen at $-2{ }^{\circ} \mathrm{C}$ and then placed in a freezer at $-26^{\circ} \mathrm{C}$. $250 \mathrm{x}$ magnification. 
Figure 24, Figure 25, and Figure 26 show solid frozen at $-26^{\circ} \mathrm{C}$ and removed from the freezer. Over time, an initially largely featureless surface (Figure 24) becomes increasingly pock-marked (Figure 25 and Figure 26) as magnesium sulphate crystals melt surrounding ice to form pockets that quickly connect to each other.

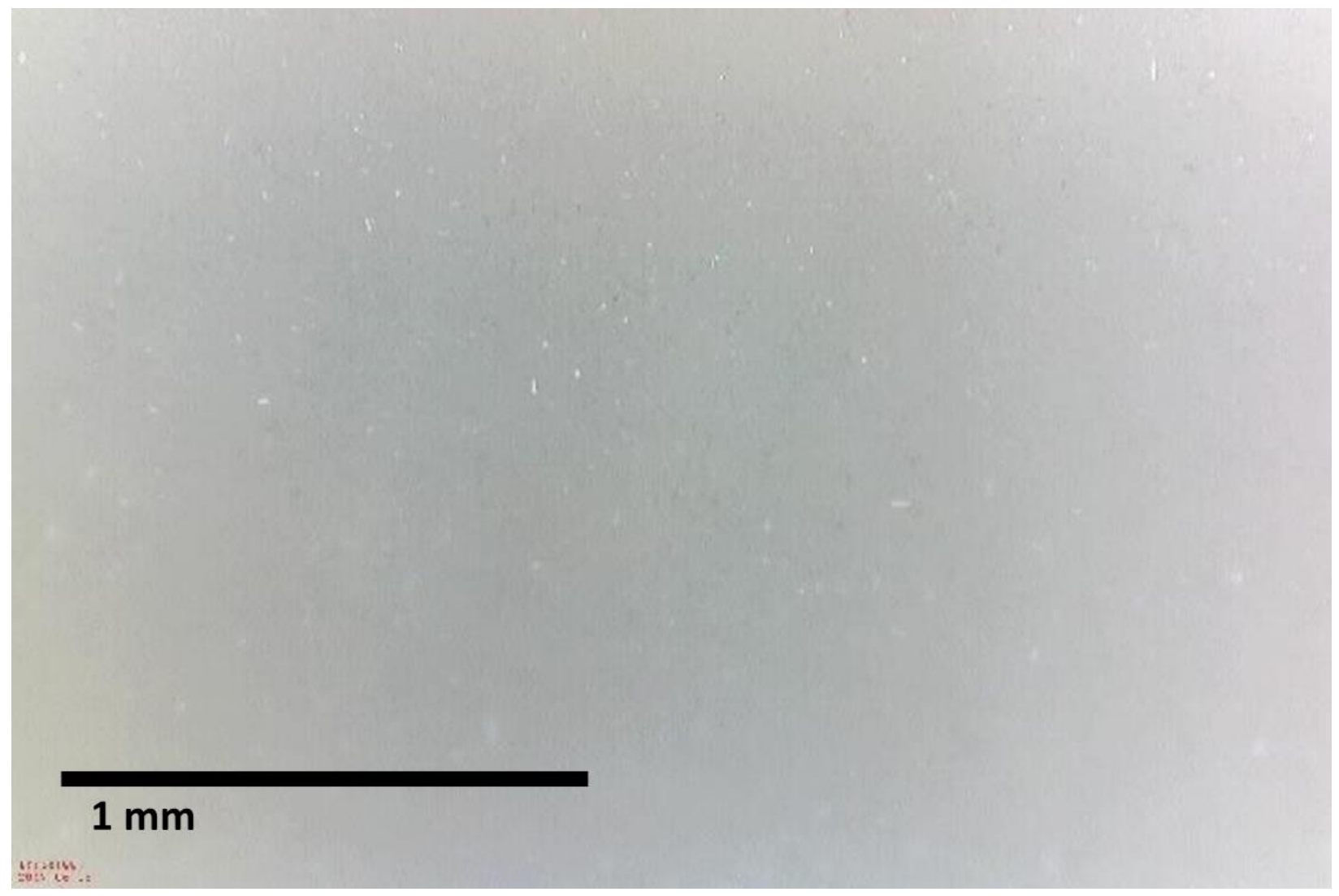

Figure 24: Solid frozen at $-26^{\circ} \mathrm{C}$. No features can be distinguished from this mix of magnesium sulphate and ice crystals. 250x magnification. 


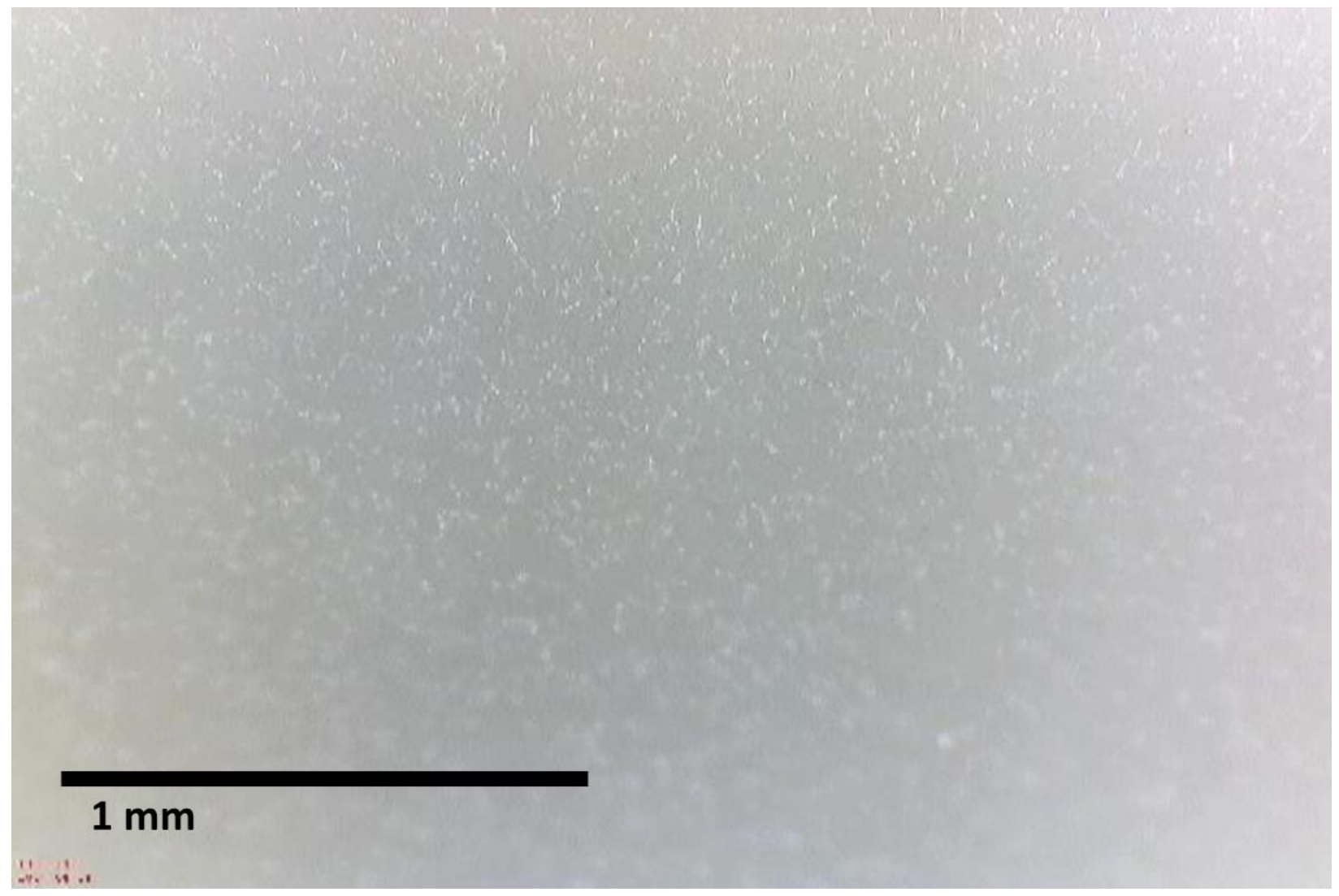

Figure 25: The surface of the solid begins to melt. 250x magnification. 


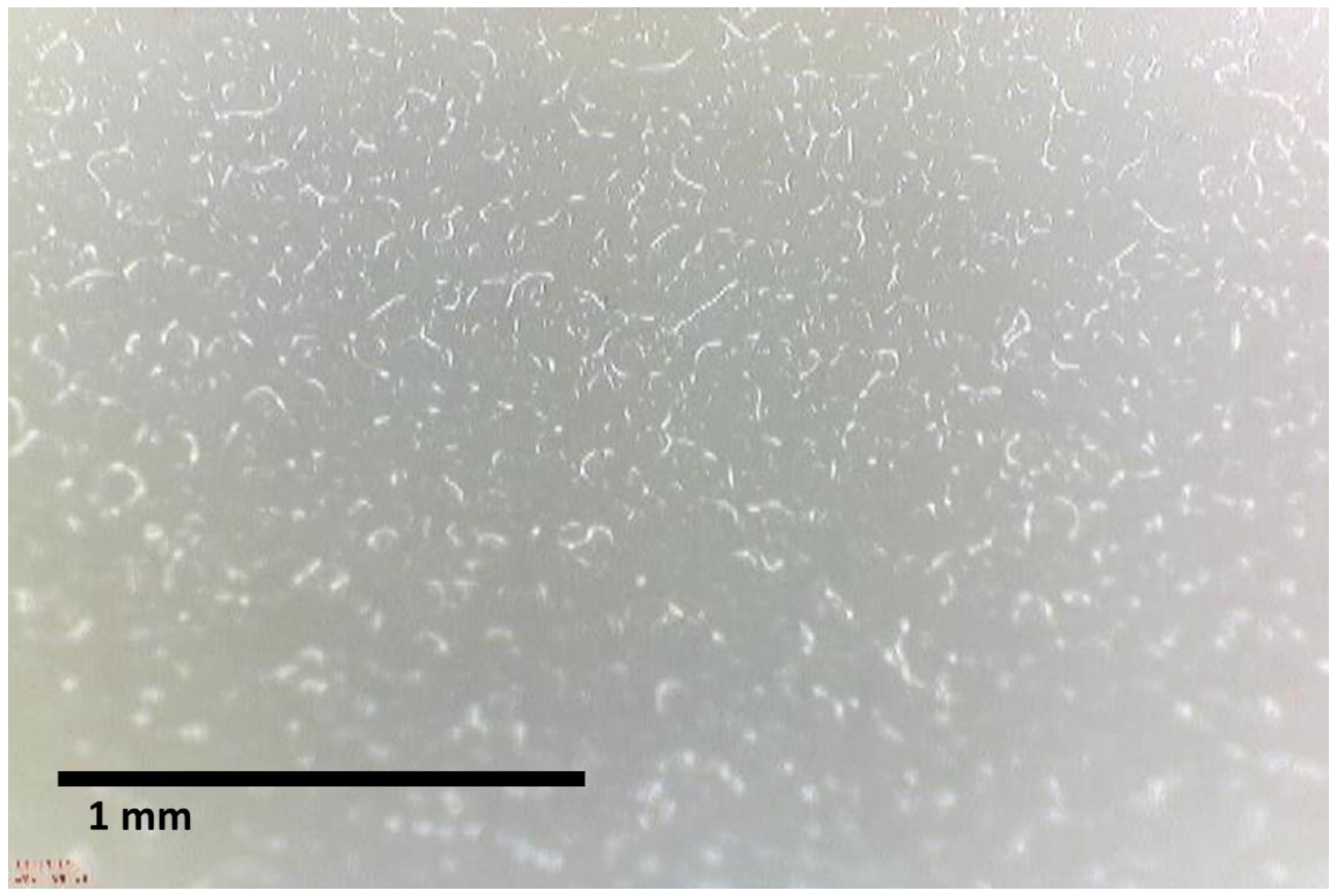

Figure 26: The surface of the solid continues to melt. 250x magnification. 


\subsection{Ice Melting Mechanism}

Based on the above results and observations, a mechanism is proposed that explains how the melting of ice results in progressively more pure remaining ice. When the solution is frozen to a temperature above its eutectic temperature, the solid produced consists of grains of ice which trap solution between them. The solution is trapped between and adheres to these grains.

The proposed mechanistic steps of the removal of magnesium sulphate solution from the solid are shown in Figure 27. The solution drains from the solid, collecting at (A) in drops. As it leaves the solid the space which the solution previously occupied empty out (B). However, the ice along the bottom melts (C), mixing with and diluting the collected solution at the bottom prior to it dripping away. Solution which cannot escape from the solid because it is completely trapped by the ice (D), and solution still adhering to the sides of ice grains (E) decrease the effectiveness of melting, as the solution cannot be removed until the surrounding ice has been melted. Another factor, not labelled on the chart as it occurs at every point where solution is in contact with ice, is the dissolution of ice by solution as the temperature increases within the solution channels. This dilutes the solution while decreasing water recovery.

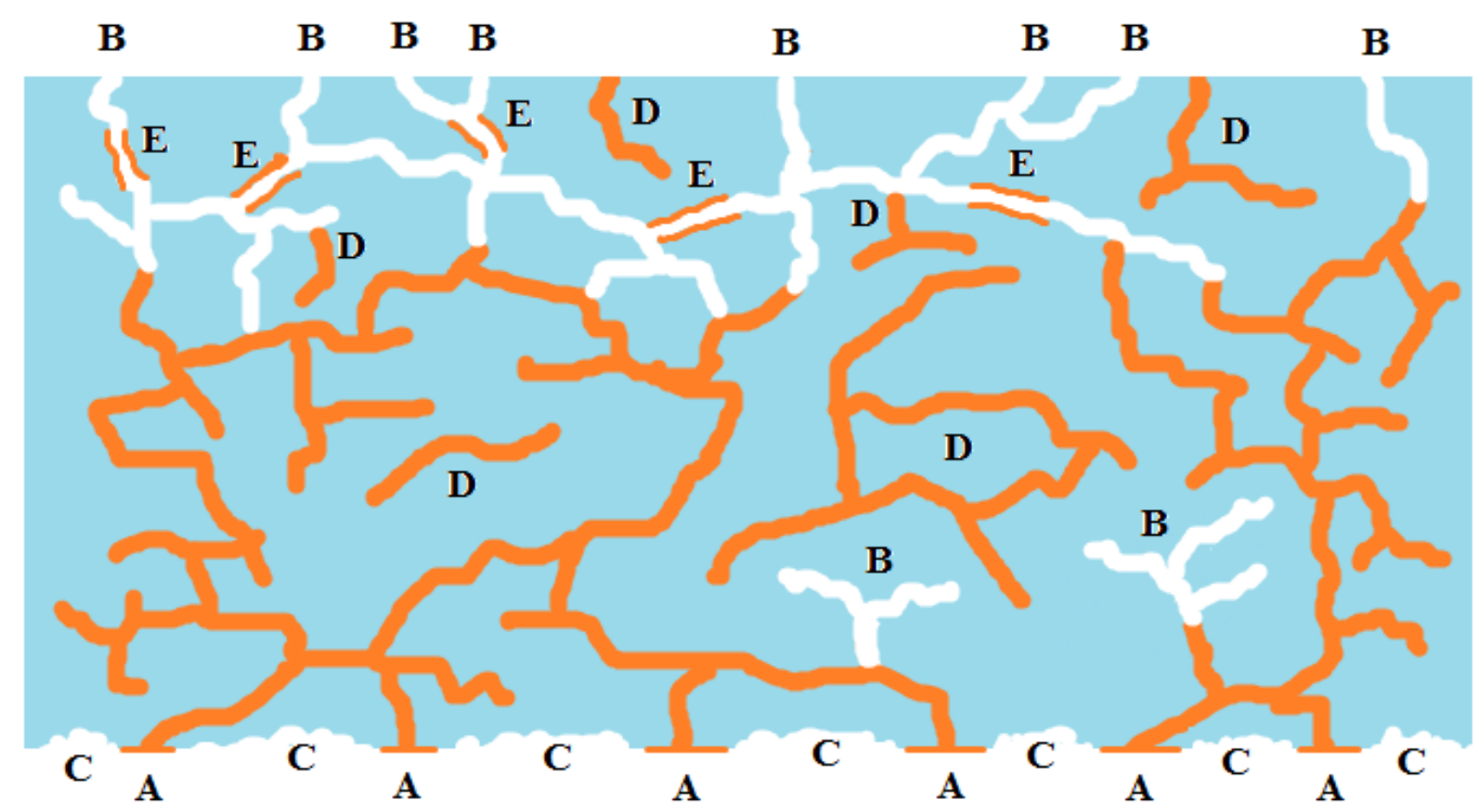

Figure 27: Mechanism of ice melting 
When the solution is frozen to a temperature below its eutectic temperature, the solid produced consists of a solid block of ice made up of multiple ice grains, and with magnesium sulphate dodecahydrate crystals interspersed throughout. As the ice begins to melt these crystals are dissolved, forming pockets of concentrated solution throughout the solid which link up (Figure 28) to form a connected network much like the mechanism shown in Figure 27. The draining of solution therefore follows the path outlined above.
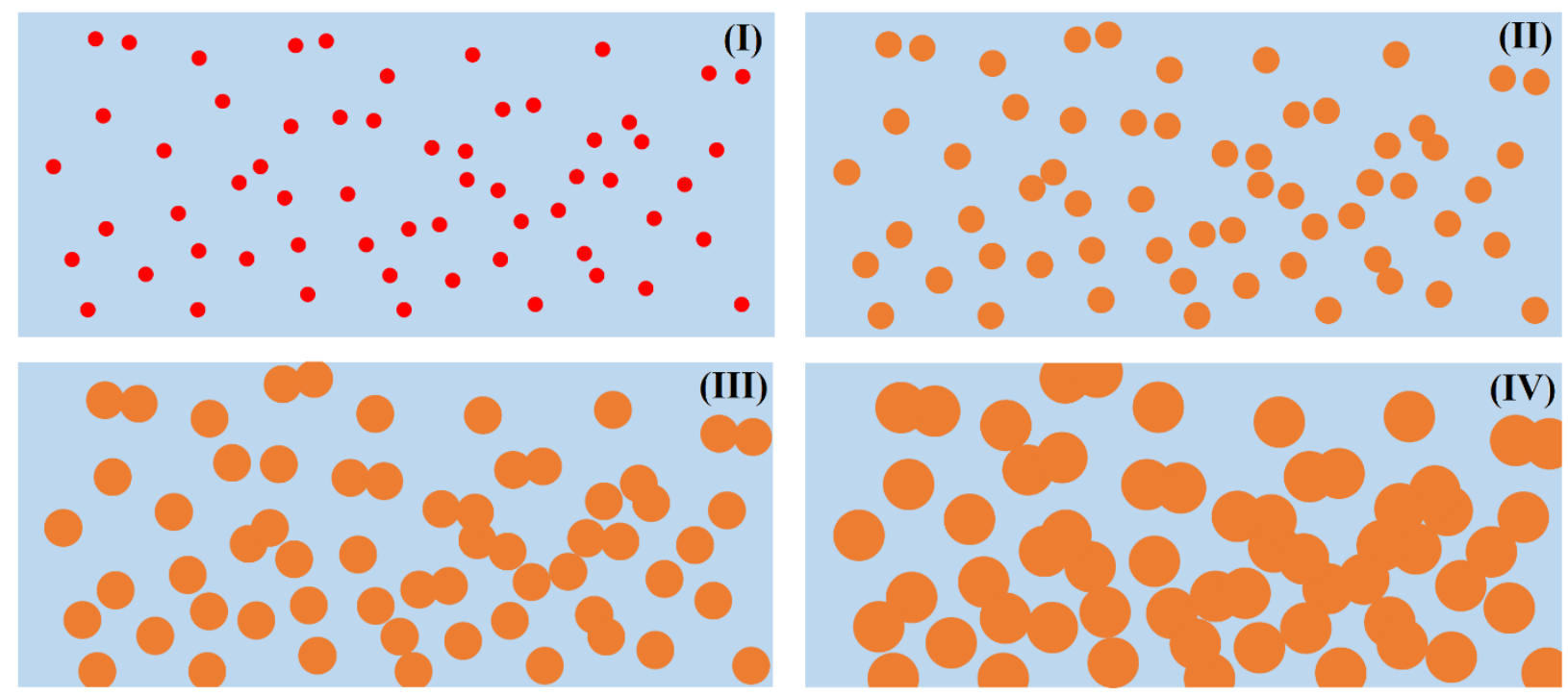

Figure 28: (I) Solute particles in red dissolve surrounding ice to form pockets of solution (II) in orange. These pockets increase in size (III) to form connected channels (IV), which drain from the solid.

The enhanced water recovery from solid frozen at temperatures below the eutectic temperature of the solution, as shown in section 5.2, indicates that the draining of solution from pockets of concentrated solution is a more effective practice than draining solution from between grain boundaries of ice. This is due to the higher solution concentration that can be achieved in the pockets. Above the eutectic temperature the concentration of entrapped solution is directly linked to the freezing temperature. Accordingly the "starting" concentration of solution entrapped by freezing above the eutectic temperature has a specific upper limit, and immediately begins to be diluted when melting commences. In contrast, the concentration of solution created by melting a solid frozen below the eutectic temperature is limited only by the solubility of magnesium sulphate at the particular temperature of the solid, meaning in practice that the solution concentration can be higher. 
In addition, the greater number of solute channels produced when melting solid frozen below the eutectic temperature (Figure 20) compared to the solute channels between grains of ice when freezing above the eutectic temperature (Figure 18) appear to contribute to improved ice drainage in the latter case. Solution cannot flow through the solid grains of ice in Figure 18, and must instead go around the ice until it has melted. However, in Figure 20 there are numerous pathways throughout the ice for solution to leave. 


\section{Conclusions}

The natural freezing and melting of a 0.48 molal magnesium sulphate solution was examined at a variety of freezing temperatures ranging from $-2{ }^{\circ} \mathrm{C}$ (above the eutectic temperature of $-4.1{ }^{\circ} \mathrm{C}$ ) to $-26{ }^{\circ} \mathrm{C}$ (below the eutectic temperature), and at melting temperatures of $3{ }^{\circ} \mathrm{C}$ and $25{ }^{\circ} \mathrm{C}$ (room temperature). Furthermore, as a benchmark, solution frozen at $-2{ }^{\circ} \mathrm{C}$ and $-10{ }^{\circ} \mathrm{C}$ was melted on a plate heated to above $70{ }^{\circ} \mathrm{C}$ in order to establish the magnesium sulphate distribution throughout the solid in a standalone natural freezing process.

It was found that the combined natural freezing and melting process is superior to a standalone natural freezing process (Figure 8). For example, forty percent of the water from a 0.5 molal magnesium sulphate solution can be recovered as an approximately 0.075 molal magnesium sulphate solution when frozen at $-26{ }^{\circ} \mathrm{C}$ (Figure 7). Depending on the desired magnesium sulphate concentration, a higher or lower water recovery can be obtained. Optimum conditions leading to maximum water recovery and minimum impurity contamination were determined. The effect of varying melting temperature was negligible (Figure 11), as ice melting is necessary for solution removal. Freezing below the eutectic point creates solid that more readily improves in purity after partial melting (Figure 7). This is due to the behaviour of the solid as it melts with

respect to both solution concentration and solid structure. Solute crystals dissolve surrounding ice to form a more porous network of channels of more concentrated solution from which to drain (Figure 20) than when freezing above eutectic temperatures (Figure 18).

The principal factors affecting the purity of solid produced were identified, as tools to further optimize the process (Figure 27). These factors are:

- The draining of solution from the solid

- The melting of ice, diluting the solution

- The dissolution of ice by the solution resulting in further dilution

- The entrapment of solution in isolated pockets that can only be released when the surrounding ice melts

- The adhesion of solution to ice grains, preventing them from leaving the solid 


\subsection{Recommendations and Future Work}

The relatively high eutectic temperature of magnesium sulphate $\left(-4.1^{\circ} \mathrm{C}\right)$ limits the extent to which differences in above-eutectic freezing temperatures can be studied. Chloride salts have lower eutectic temperatures, for which reason a similar study to this using a chloride salt instead of magnesium sulphate might yield more precise comparisons of above-eutectic freezing temperatures.

Gradual freezing in small steps along the liquidus line of the binary phase diagram should decrease constitutional undercooling, thus reducing dendritic growth in favour of planar growth. This may result in purer ice, thus creating a better "starting point" for melting operations.

In this study the solution was brought to equilibrium with the air temperature before the solid was removed. While this is not a problem with above-eutectic freezing as the increased solute entrapment over time due to a more concentrated liquid is well-established, in the case of beloweutectic freezing the natural tendency of solute crystals to sink and ice to float might produce different results if the solute crystals are not forced to incorporate themselves into the solid.

The solution is trapped between grains of ice within the solid, which hinder their elution. Pretreatment of the solid prior to melting via centrifugation, pressing, or the application of a vacuum - all at temperatures below freezing - are other avenues that might be pursued. In this case the use of melting might be unnecessary for above-eutectic freezing temperatures.

Improved imaging of the ice via microscopy of a sample obtained from a microtome placed in a cold room could allow for a composite view of "real-time" melting, which would give additional credence to the conclusions reached via digital microscopy of the sides of the solid produced.

Natural freezing and melting of a multicomponent system consisting of more than one inorganic salt might be examined, especially with respect to eutectic freezing behaviour. It is possible to remove a specific salt via eutectic freezing, but this has hitherto not been examined in the context of natural freezing. 


\section{References}

[1] Williams, P. M., M. Ahmad, B. S. Connolly and D. L. Oatley-Radcliffe (2015). "Technology for freeze concentration in the desalination industry." Desalination 356(January): 314327.

[2] Randall, D. G. and J. Nathoo (2015). "A succinct review of the treatment of Reverse Osmosis brines using Freeze Crystallization." Journal of Water Process Engineering 8: 186-194.

[3] Hasan, M. and M. Louhi-Kultanen (2016). "Water purification of aqueous nickel sulfate solutions by air cooled natural freezing." Chemical Engineering Journal 294: 176-184.

[4] Terwilliger, J. P. and S. F. Dizio (1970). "Salt rejection phenomena in the freezing of saline solutions." Chemical Engineering Science 25: 1331-1349.

[5] Flesland, O. (1995). "Freeze Concentration by Lay Crystallization." Drying Technology 13(8 \& 9): 1713-1739.

[6] Hasan, M. (2016). Purification of Aqueous Electrolyte Solutions by Air-Cooled Natural Freezing, Lappeenranta University of Technology. PhD Thesis. Retrieved September 4, 2017, from http://www.doria.fi/handle/10024/125550

[7] Gao, W., D. W. Smith and D. C. Sego (2003). "Spray freezing treatment of water from oil sands tailing ponds." Journal of Environmental Engineering Science 2: 325-334.

[8] Miyawaki, O., S. Kato and K. Watabe (2012). "Yield improvement in progressive freezeconcentration by partial melting of ice." Journal of Food Engineering 108: 377-382.

[9] Yee, P. L., M. Wakisaka, Y. Shirai and M. A. Hassan (2004). "Effect of Sodium Chloride on Freeze Concentration of Food Components by Freezing and Thawing Technique." 日 本 食品工学会誌 5(2): 97-102.

[10] Mandri, Y., A. Rich, D. Mangin, S. Abderafi, C. Bebon, N. Semlali, J.-P. Klein, T. Bounahmidi and A. Bouhaouss (2011). "Parametric study of the sweating step in the seawater desalination process by indirect freezing." Desalination 269: 142-147.

[11] Yee, P. L., M. Wakisaka, Y. Shirai and M. A. Hassan (2003). "Effects of Single Food Components on Freeze Concentration by Freezing and Thawing Technique." 日本食品 工学会誌 4(3): 77-82.

[12] Nebbia, G. and G. N. Menozzi (1968). "Early Experiments on Water Desalination by Freezing." Desalination 5: 49-54. 
[13] Sanchez, J.E., J. M. Auleda, E. Hernandez-Perez and M. Raventos (2009). "Review. Freeze Concentration in the Fruit Juices Industry." Food Science and Technology International 8: 303-315.

[14] Rahman, M. S., M. Ahmed and X. D. Cen (2006). "Freezing-Melting Process and Desalination: I. Review of the State-of-the-Art." Separation \& Purification Reviews 35: 59-96.

[15] Heldman, D. R. and R. W. Hartel (1998). Principles of Food Processing. Gaithersburg, Maryland, Aspen Publishers, Inc. 138-176.

[16] Tahti, T. (2004). Suspension Melt Crystallization in Tubular and Scraped Surface Heat Exchangers, Martin Luther University of Halle-Wittenberg. PhD Thesis. Retrieved September 4, 2017, from https://sundoc.bibliothek.uni-halle.de/diss-online/04/04H181/prom.pdf

[17] Miyawaki, O., L. Liu and K. Nakamura (1998). "Effective partition constant of solute between solid and liquid phases in progressive freeze-concentration." Journal of Food Science 63(5): 756-758.

[18] Jusoh, M., R. Mohd and M. Ariffin Abu Hassan (2009). Development of a New Crystallisation Chamber for a Progressive Freeze Concentration System. Recent Advances in Technologies. M. A. Strangio. 587-596.

[19] van der Ham, F. (1999). Eutectic Freeze Crystallization, Delft Technical University. PhD Thesis. Retrieved September 4, 2017 from https://repository.tudelft.nl/islandora/object/uuid:5a127123-3d40-41e7-a71bc91a8fcb1702?collection=research

[20] Pascual, M. R. (2008). Physical Aspects of Scraped Heat Exchanger Crystallizers, Delft Technical University. PhD Thesis. Retrieved September 4, 2017 from https://repository.tudelft.nl/islandora/object/uuid\%3A1828157b-e27d-4bfc-b57db45d77b7545e

[21] Reddy, S. T., A. E. Lewis, G. J. Witkamp, H. J. M. Kramer and J. van Spronsen (2010). "Recovery of $\mathrm{Na} 2 \mathrm{SO} 410 \mathrm{H} 2 \mathrm{O}$ from a reverse osmosis retentate by eutectic freeze crystallisation technology." Chemical Engineering Research and Design 88: 1153-1157.

[22] Lewis, A. E., J. Nathoo, K. Thomsen, H. J. M. Kramer, G. J. Witkamp, S. T. Reddy and D. G. Randall (2010). "Design of a Eutectic Freeze Crystallization process for multicomponent waste water stream." Chemical Engineering Research and Design 88: 1290-1296. 
[23] Randall, D. G., J. Nathoo and A. E. Lewis (2011). "A case study for treating a reverse osmosis brine using Eutectic Freeze Crystallization - Approaching a zero waste process." Desalination 266: 256-262.

[24] Fournier, J., J. L. Grange and S. Vergara (1974). "Water desalination by natural freezing." Desalination 15(2): 167-175.

[25] Hasan, M. and M. Louhi-Kultanen (2015). "Ice growth kinetics modeling of air-cooled layer crystallization from sodium sulfate solutions." Chemical Engineering Science 133: 44-53.

[26] Beier, N., D. Sego, R. Donahue and K. Biggar (2007). "Trickle-freeze separation of contaminants from saline waste water." International Jounral of Mining, Reclamation and Environment 21(2): 144-155.

[27] Tatarniuk, C., R. Donahue and D. Sego (2009). "Freeze separation of salt contaminated melt water and sand wash water at snow storage and sand recycling facilities." Cold Regions Science and Technology 57(2-3): 61-66.

[28] Biggar, K. W., R. Donahue, D. Sego, M. Johnson and S. Birch (2005). "Spray freezing decontamination of tailings water at the Colomac Mine." Cold Regions Science and Technology 42: 106-119.

[29] Halde, R. (1980). "Concentration of Impurities by Progressive Freezing." Water Research 14: $575-580$.

[30] Pascual, M. R., F. Ravelet, R. Delfos, J. J. Derksen and G. J. Witkamp (2009). "Large eddy simulations and stereoscopic particle image velocimetry measurements in a scraped heat exchanger crystallizer geometry." Chemical Engineering Science 64: 2127-2135.

[31] Hasan, M., N. Rotich, M. John and M. Louhi-Kultanen (2017). "Salt recovery from wastewater by air-cooled eutectic freeze crystallization." Chemical Engineering Journal 326: $192-200$.

[32] Nakagawa, K., S. Maebashi and K. Maeda (2009). "Concentration of Aqueous Dye Solution by Freezing and Thawing." The Canadian Journal of Chemical Engineering 87(October): 779-797.

[33] Nakagawa, K., S. Maebashi and K. Maeda (2010). "Freeze-thawing as a path to concentrate aqueous solution." Separation and Purification Technology 73: 403-408.

[34] Hasan, M. and M. Louhi-Kultanen (2016). "Water purification of aqueous nickel sulfate solutions by air cooled natural freezing." Chemical Engineering Journal 294: 176-184. 
[35] Hasan, M., R. Filimonov, J. Chivavava, J. Sorvari, M. Louhi-Kultanen and A. E. Lewis (2017). "Ice growth on the cooling surface in a jacketed and stirred eutectic freeze crystallizers of aqueous Na2SO4 solutions." Separation and Purification Technology 175: 512-526.

[36] Gao, W., M. Habib and D. W. Smith (2009). "Removal of organic contaminants and toxicity from industrial effluents using freezing processes." Desalination 245: 108-119.

[37] Moreno, F. L., C. M. Robles, Z. Sarmiento, Y. Ruiz and J. M. Pardo (2013). "Effect of separation and thawing mode on block freeze-concentration of coffee brews." Food and Bioproducts Processing 91: 396-402.

[38] (DoITPoMS), Dissemination of IT for the Promotion of Materials Science (2017).

"Constitutional Undercooling." University of Cambridge. Retrieved September 4, 2017, from https://www.doitpoms.ac.uk/tlplib/solidification_alloys/undercooling.php 


\section{Appendix A: Calculations}

The principal objective of the calculations performed in this study is to convert an ICP measurement of magnesium in milligrams per kilogram into the molality of magnesium in the solid, as well as the percentage water recovery associated with the solid.

CMM: Cumulative moles of magnesium in remaining solid

CMW: Cumulative mass of water in remaining solid in grams

DN: Dilution ratio of sample in $5 \% \mathrm{w} / \mathrm{v}$ nitric acid for ICP

ICP: ICP measurement in milligrams per kilogram

Mol Mg: Calculated moles of magnesium in sample

MOLS: Molality of magnesium in remaining solid $\left(\left[\mathrm{Mg}^{2+}\right]_{\text {solid }}\right)$

MS: Mass of Sample in grams (Msample)

MW: Calculated mass of water in sample in grams (M $\left.\mathrm{M}_{\text {Water }}\right)$

VS: Volume of Sample in litres (all samples are diluted to fixed volumes)

WR: Percentage water recovered

The molecular mass of magnesium is $24.305 \mathrm{~g} / \mathrm{mol}$.

The molecular mass of magnesium sulphate is $120.366 \mathrm{~g} / \mathrm{mol}$.

MS is measured on an electronic balance.

VS and DN are determined according to the size and concentration of the sample (higher VS for larger sample, and higher DN for more concentrated sample).

ICP is measured by ICP-OES.

The moles of magnesium in the sample are calculated by converting the milligrams per kilogram measurement of the ICP-OES into milligrams per litre (assuming a density equal to water), and then multiplying by both the dilution factor and the volume of the sample in order to obtain a mass of magnesium in grams. Dividing this mass by the molecular mass of magnesium results in the moles of magnesium of the sample.

$$
M o l M g=\frac{I C P * 1 \frac{k g}{L} * D N * V S}{24.305 \frac{g}{\mathrm{~mol}}}
$$

The mass of water is obtained by subtracting from the mass of the sample the mass of magnesium sulphate in the sample, which is calculated by multiplying the moles of magnesium (which is equivalent to the moles of magnesium sulphate) by the molecular mass of magnesium sulphate. 


$$
M_{\text {Water }}=M_{\text {Sample }}-\text { Mol Mg* } 120.366 \mathrm{~g} / \mathrm{mol}
$$

The cumulative mass of water in the remaining solid (CMW) is calculated by adding together the MW of all remaining samples.

The cumulative moles of magnesium in the remaining solid (CMM) is calculated by adding together the $\mathrm{Mol} \mathrm{Mg}$ of all remaining samples.

The molality of the magnesium in the solid (MOLS) is calculated by dividing the cumulative moles of magnesium in the solid by the cumulative mass of water (after the cumulative mass of water has been converted from grams to kilograms of water).

$$
\left[\mathrm{Mg}^{2+}\right]_{\text {Solid }}=\frac{C M M}{C M W * \frac{1}{1000} \frac{g}{k g}}
$$

The percentage water recovery (WR) is calculated by dividing the cumulative mass of water by the mass of water in the original solution.

$$
W R=\frac{C M W}{M_{\text {Water in Solution }}} * 100
$$




\section{Appendix B: Raw Data for Natural Freezing and Fast Melting Experiments}

The experiments performed here correspond with the results shown in Section 5.2, and in Figure 5 and Figure 8 . Solid frozen at $-2{ }^{\circ} \mathrm{C}$ or $-10{ }^{\circ} \mathrm{C}$ was melted on a tray heated to above $70{ }^{\circ} \mathrm{C}$ placed on top of a hot plate.

\section{Legend:}

S Solid produced via freezing

$\mathrm{L} \quad$ Liquid remaining after solid has been removed

R1 DI water rinse of solid produced

$\mathrm{RC} \quad \mathrm{DI}$ water rinse of freezing container

S0X Melt solution, with S01 being the first solution melted, S02 being the second, and so on

$\begin{array}{ll}\text { MS } & \text { Mass of item in grams } \\ \text { VS } & \text { Volume of item in litres } \\ \text { DN } & \text { Dilution factor } \\ \text { ICP } & \text { ICP measurement of item in milligrams per kilogram } \\ \text { Mol Mg } & \text { Moles of magnesium in item } \\ \text { MW } & \text { Mass of water in item in grams } \\ \text { CMW } & \text { Cumulative mass of water, summing SOX and all subsequent values in grams } \\ \text { CMM } & \text { Cumulative moles of magnesium, summing SOX and all subsequent values in } \\ & \text { moles } \\ \text { CMOL } & \text { Cumulative molality of SOX and all subsequent values in molal } \\ \text { WR } & \text { Water recovered from SOX and all subsequent values as a percentage }\end{array}$

\begin{tabular}{lrrrrrrrrrr} 
NF1 & $-2{ }^{\circ}$ C freezing, hot plate melting & & & & & & & & \\
\multicolumn{1}{c}{ MS } & VS & DN & ICP & Mol Mg & MW & & & & & \\
S & 530.5 & 0.5 & 1000 & 10.78 & 0.2217 & 503.81 & & & & \\
L & 97.7 & 0.25 & 1000 & 9.01 & 0.0926 & 86.55 & & & & \\
R1 & 63.4 & 0.25 & 100 & 25.67 & 0.0264 & 60.22 & & & & \\
RC & 208.6 & 0.25 & 100 & 0.12 & 0.0001 & 208.58 & CMW & CMM & CMOL & WR \\
S01 & 45.8 & 0.1 & 100 & 47.85 & 0.0197 & 43.43 & 363.86 & 0.1000 & 0.2750 & 72.2 \\
S02 & 22.3 & 0.1 & 100 & 26.76 & 0.0110 & 20.97 & 320.43 & 0.0804 & 0.2508 & 63.6 \\
S03 & 21.6 & 0.1 & 100 & 20.70 & 0.0085 & 20.57 & 299.45 & 0.0693 & 0.2316 & 59.4 \\
S04 & 28.7 & 0.1 & 100 & 22.88 & 0.0094 & 27.57 & 278.88 & 0.0608 & 0.2181 & 55.4 \\
S05 & 32.8 & 0.1 & 100 & 25.44 & 0.0105 & 31.54 & 251.31 & 0.0514 & 0.2046 & 49.9 \\
S06 & 28.2 & 0.1 & 100 & 19.57 & 0.0081 & 27.23 & 219.77 & 0.0410 & 0.1863 & 43.6 \\
S07 & 21.4 & 0.1 & 100 & 13.19 & 0.0054 & 20.75 & 192.54 & 0.0329 & 0.1709 & 38.2 \\
S08 & 22.8 & 0.1 & 100 & 12.61 & 0.0052 & 22.18 & 171.79 & 0.0275 & 0.1599 & 34.1
\end{tabular}




$\begin{array}{lrrrrrrrrrr}\text { S09 } & 33.1 & 0.1 & 100 & 16.35 & 0.0067 & 32.29 & 149.62 & 0.0223 & 0.1490 & 29.7 \\ \text { S10 } & 29.1 & 0.1 & 100 & 11.68 & 0.0048 & 28.52 & 117.33 & 0.0156 & 0.1326 & 23.3 \\ \text { S11 } & 25.4 & 0.1 & 100 & 9.75 & 0.0040 & 24.92 & 88.81 & 0.0108 & 0.1211 & 17.6 \\ \text { S12 } & 22.7 & 0.1 & 100 & 7.06 & 0.0029 & 22.35 & 63.89 & 0.0067 & 0.1056 & 12.7 \\ \text { S13 } & 22.8 & 0.1 & 100 & 6.44 & 0.0027 & 22.48 & 41.54 & 0.0038 & 0.0924 & 8.2 \\ \text { S14 } & 19.2 & 0.1 & 100 & 2.89 & 0.0012 & 19.06 & 19.06 & 0.0012 & 0.0624 & 3.8\end{array}$

NF2 $-2{ }^{\circ} \mathrm{C}$ freezing, hot plate melting

$\begin{array}{lrrrrrrrrrr} & \text { MS } & \text { VS } & \text { DN } & \text { ICP } & \text { Mol Mg } & \text { MW } & & & & \\ \text { S } & 530.8 & 0.5 & 1000 & 11.19 & 0.2301 & 503.10 & & & & \\ \text { L } & 232.6 & 0.25 & 1000 & 11.77 & 0.1210 & 218.03 & & & & \\ \text { RC } & 199.7 & 0.25 & 100 & 0.38 & 0.0004 & 199.65 & & & & \\ \text { R1 } & 121.3 & 0.25 & 100 & 29.26 & 0.0301 & 117.68 & \text { CMW } & \text { CMM } & \text { CMOL } & \text { WR } \\ \text { S01 } & 29.8 & 0.1 & 100 & 29.01 & 0.0119 & 28.36 & 318.91 & 0.0846 & 0.2654 & 63.4 \\ \text { S02 } & 31.2 & 0.1 & 100 & 29.07 & 0.0120 & 29.76 & 290.55 & 0.0727 & 0.2502 & 57.8 \\ \text { S03 } & 21 & 0.1 & 100 & 19.60 & 0.0081 & 20.03 & 260.79 & 0.0607 & 0.2329 & 51.8 \\ \text { S04 } & 25.7 & 0.1 & 100 & 21.06 & 0.0087 & 24.66 & 240.76 & 0.0527 & 0.2188 & 47.9 \\ \text { S05 } & 29.3 & 0.1 & 100 & 20.33 & 0.0084 & 28.29 & 216.10 & 0.0440 & 0.2037 & 43.0 \\ \text { S06 } & 23 & 0.1 & 100 & 14.18 & 0.0058 & 22.30 & 187.81 & 0.0356 & 0.1898 & 37.3 \\ \text { S07 } & 21.6 & 0.1 & 100 & 12.40 & 0.0051 & 20.99 & 165.51 & 0.0298 & 0.1801 & 32.9 \\ \text { S08 } & 24.6 & 0.1 & 100 & 17.33 & 0.0071 & 23.74 & 144.53 & 0.0247 & 0.1710 & 28.7 \\ \text { S09 } & 20.1 & 0.1 & 100 & 13.27 & 0.0055 & 19.44 & 120.78 & 0.0176 & 0.1456 & 24.0 \\ \text { S10 } & 24.1 & 0.1 & 100 & 10.91 & 0.0045 & 23.56 & 101.34 & 0.0121 & 0.1196 & 20.1 \\ \text { S11 } & 23 & 0.1 & 100 & 8.48 & 0.0035 & 22.58 & 77.78 & 0.0076 & 0.0981 & 15.5 \\ \text { S12 } & 22.1 & 0.1 & 100 & 5.48 & 0.0023 & 21.83 & 55.20 & 0.0041 & 0.0751 & 11.0 \\ \text { S13 } & 21.3 & 0.1 & 100 & 2.93 & 0.0012 & 21.15 & 33.37 & 0.0019 & 0.0565 & 6.6 \\ \text { S14 } & 12.3 & 0.1 & 100 & 1.65 & 0.0007 & 12.22 & 12.22 & 0.0007 & 0.0556 & 2.4\end{array}$

NF3 $-10^{\circ} \mathrm{C}$ freezing, hot plate melting

$\begin{array}{lrrrrrrrrrr} & \text { MS } & \text { VS } & \text { DN } & \text { ICP } & \text { Mol Mg } & \text { MW } & & & & \\ \text { S } & 531.6 & 0.5 & 1000 & 11.30 & 0.2324 & 503.63 & \text { CMW } & \text { CMM } & \text { CMOL } & \text { WR } \\ \text { S01 } & 32.8 & 0.1 & 100 & 91.05 & 0.0375 & 28.29 & 467.69 & 0.2161 & 0.4621 & 92.9 \\ \text { S02 } & 27.8 & 0.1 & 100 & 52.82 & 0.0217 & 25.18 & 439.40 & 0.1786 & 0.4066 & 87.2 \\ \text { S03 } & 31.3 & 0.1 & 100 & 50.17 & 0.0206 & 28.82 & 414.21 & 0.1569 & 0.3788 & 82.2 \\ \text { S04 } & 23.9 & 0.1 & 100 & 31.13 & 0.0128 & 22.36 & 385.40 & 0.1363 & 0.3536 & 76.5 \\ \text { S05 } & 37.2 & 0.1 & 100 & 42.53 & 0.0175 & 35.09 & 363.04 & 0.1235 & 0.3401 & 72.1 \\ \text { S06 } & 43.2 & 0.1 & 100 & 43.04 & 0.0177 & 41.07 & 327.95 & 0.1060 & 0.3231 & 65.1 \\ \text { S07 } & 29.2 & 0.1 & 100 & 26.65 & 0.0110 & 27.88 & 286.88 & 0.0883 & 0.3076 & 57.0 \\ \text { S08 } & 32.9 & 0.1 & 100 & 26.59 & 0.0109 & 31.58 & 259.00 & 0.0773 & 0.2984 & 51.4 \\ \text { S09 } & 25.6 & 0.1 & 100 & 20.25 & 0.0083 & 24.60 & 227.41 & 0.0664 & 0.2918 & 45.2 \\ \text { S10 } & 27.2 & 0.1 & 100 & 18.86 & 0.0078 & 26.27 & 202.82 & 0.0580 & 0.2861 & 40.3 \\ \text { S11 } & 48.4 & 0.1 & 100 & 32.18 & 0.0132 & 46.81 & 176.55 & 0.0503 & 0.2847 & 35.1 \\ \text { S12 } & 26.1 & 0.1 & 100 & 19.21 & 0.0079 & 25.15 & 129.74 & 0.0370 & 0.2853 & 25.8\end{array}$




$\begin{array}{lrllrlrrrrr}\text { S13 } & 28.8 & 0.1 & 100 & 20.91 & 0.0086 & 27.76 & 104.60 & 0.0291 & 0.2783 & 20.8 \\ \text { S14 } & 40.3 & 0.1 & 100 & 27.74 & 0.0114 & 38.93 & 76.83 & 0.0205 & 0.2669 & 15.3 \\ \text { S15 } & 26.5 & 0.1 & 100 & 16.26 & 0.0067 & 25.69 & 37.91 & 0.0091 & 0.2399 & 7.5 \\ \text { S16 } & 12.5 & 0.1 & 100 & 5.84 & 0.0024 & 12.21 & 12.21 & 0.0024 & 0.1967 & 2.4\end{array}$

NF4 $-10{ }^{\circ} \mathrm{C}$ freezing, hot plate melting

$\begin{array}{lrrrrrrrrrr} & \text { MS } & \text { VS } & \text { DN } & \text { ICP } & \text { Mol Mg } & \text { MW } & & & & \\ \text { S } & 533.5 & 0.5 & 1000 & 11.54 & 0.2374 & 504.93 & \text { CMW } & \text { CMM } & \text { CMOL } & \text { WR } \\ \text { S01 } & 31.5 & 0.1 & 100 & 82.34 & 0.0339 & 27.42 & 455.02 & 0.2017 & 0.4433 & 90.1 \\ \text { S02 } & 31.7 & 0.1 & 100 & 54.32 & 0.0223 & 29.01 & 427.60 & 0.1679 & 0.3926 & 84.7 \\ \text { S03 } & 27.2 & 0.1 & 100 & 37.08 & 0.0153 & 25.36 & 398.59 & 0.1455 & 0.3651 & 78.9 \\ \text { S04 } & 30.7 & 0.1 & 100 & 35.90 & 0.0148 & 28.92 & 373.22 & 0.1303 & 0.3490 & 73.9 \\ \text { S05 } & 30.3 & 0.1 & 100 & 31.82 & 0.0131 & 28.72 & 344.30 & 0.1155 & 0.3354 & 68.2 \\ \text { S06 } & 31 & 0.1 & 100 & 29.70 & 0.0122 & 29.53 & 315.58 & 0.1024 & 0.3245 & 62.5 \\ \text { S07 } & 36.9 & 0.1 & 100 & 32.59 & 0.0134 & 35.29 & 286.05 & 0.0902 & 0.3152 & 56.7 \\ \text { S08 } & 37.7 & 0.1 & 100 & 32.38 & 0.0133 & 36.10 & 250.76 & 0.0768 & 0.3061 & 49.7 \\ \text { S09 } & 48.4 & 0.1 & 100 & 35.90 & 0.0148 & 46.62 & 214.66 & 0.0634 & 0.2955 & 42.5 \\ \text { S10 } & 36.4 & 0.1 & 100 & 28.40 & 0.0117 & 34.99 & 168.04 & 0.0487 & 0.2896 & 33.3 \\ \text { S11 } & 43.4 & 0.1 & 100 & 31.18 & 0.0128 & 41.86 & 133.05 & 0.0370 & 0.2780 & 26.4 \\ \text { S12 } & 37.2 & 0.1 & 100 & 26.70 & 0.0110 & 35.88 & 91.19 & 0.0242 & 0.2649 & 18.1 \\ \text { S13 } & 25.6 & 0.1 & 100 & 16.86 & 0.0069 & 24.77 & 55.31 & 0.0132 & 0.2381 & 11.0 \\ \text { S14 } & 21.9 & 0.1 & 100 & 11.84 & 0.0049 & 21.31 & 30.55 & 0.0062 & 0.2040 & 6.1 \\ \text { S15 } & 9.4 & 0.1 & 101 & 3.27 & 0.0014 & 9.24 & 9.24 & 0.0014 & 0.1473 & 1.8\end{array}$




\section{Appendix C: Raw Data for Natural Freezing and Room Temperature Melting Experiments}

The experiments performed here correspond with the results show in Section 5.3, and in Figure 7 and Figure 8 . Solid frozen at $-2,-3,-10$ or $-26{ }^{\circ} \mathrm{C}$ was melted on a grille at $25^{\circ} \mathrm{C}$.

\section{Legend:}

S Solid produced via freezing

L Liquid remaining after solid has been removed

R1 DI water rinse of solid produced

RC DI water rinse of freezing container

S0X Melt solution, with S01 being the first solution melted, S02 being the second, and so on

$\begin{array}{ll}\text { MS } & \text { Mass of item in grams } \\ \text { VS } & \text { Volume of item in litres } \\ \text { DN } & \text { Dilution factor } \\ \text { ICP } & \text { ICP measurement of item in milligrams per kilogram } \\ \text { Mol Mg } & \text { Moles of magnesium in item } \\ \text { MW } & \text { Mass of water in item in grams } \\ \text { CMW } & \text { Cumulative mass of water, summing SOX and all subsequent values in grams } \\ \text { CMM } & \text { Cumulative moles of magnesium, summing SOX and all subsequent values in } \\ & \text { moles } \\ \text { CMOL } & \text { Cumulative molality of SOX and all subsequent values in molal } \\ \text { WR } & \text { Water recovered from SOX and all subsequent values as a percentage }\end{array}$

$\begin{array}{lrrrrrrrrrr}\text { NFM1 } & -2{ }^{\circ} \mathrm{C} \text { freezing, } 2{ }^{\circ} \mathrm{C} \text { melting } & & & & & & & \\ & \text { MS } & \text { VS } & \text { DN } & \text { ICP } & \text { Mol Mg } & \text { MW } & & & & \\ \text { S } & 530.9 & 0.5 & 1000 & 11.07 & 0.2278 & 503.48 & & & & \\ \text { L } & 96.9 & 0.25 & 1000 & 9.39 & 0.0966 & 85.27 & & & & \\ \text { R1 } & 121.5 & 0.25 & 100 & 32.64 & 0.0336 & 117.46 & & & & \\ \text { RC } & 197.1 & 0.25 & 100 & 0.22 & 0.0002 & 197.07 & \text { CMW } & \text { CMM } & \text { CMOL } & \text { WR } \\ \text { S01 } & 26.0 & 0.1 & 100 & 48.13 & 0.0198 & 23.62 & 321.82 & 0.0912 & 0.2835 & 63.9 \\ \text { S02 } & 26.8 & 0.1 & 100 & 39.42 & 0.0162 & 24.85 & 298.20 & 0.0714 & 0.2395 & 59.2 \\ \text { S03 } & 28.3 & 0.1 & 100 & 34.02 & 0.0140 & 26.62 & 273.36 & 0.0552 & 0.2020 & 54.3 \\ \text { S04 } & 30.0 & 0.1 & 100 & 29.32 & 0.0121 & 28.55 & 246.74 & 0.0412 & 0.1670 & 49.0 \\ \text { S05 } & 25.8 & 0.1 & 100 & 19.70 & 0.0081 & 24.82 & 218.19 & 0.0291 & 0.1336 & 43.3 \\ \text { S06 } & 26.5 & 0.1 & 100 & 16.15 & 0.0066 & 25.70 & 193.37 & 0.0210 & 0.1088 & 38.4 \\ \text { S07 } & 27.5 & 0.1 & 100 & 12.64 & 0.0052 & 26.87 & 167.67 & 0.0144 & 0.0859 & 33.3 \\ \text { S08 } & 27.3 & 0.1 & 100 & 9.54 & 0.0039 & 26.83 & 140.79 & 0.0092 & 0.0653 & 28.0 \\ \text { S09 } & 25.0 & 0.1 & 100 & 5.77 & 0.0024 & 24.71 & 113.97 & 0.0053 & 0.0463 & 22.6\end{array}$




$\begin{array}{llllllllllr}\text { S10 } & 26.6 & 0.1 & 100 & 3.76 & 0.0015 & 26.41 & 89.25 & 0.0029 & 0.0325 & 17.7 \\ \text { S11 } & 25.8 & 0.1 & 100 & 2.06 & 0.0008 & 25.70 & 62.84 & 0.0014 & 0.0215 & 12.5 \\ \text { S12 } & 24.2 & 0.1 & 100 & 0.88 & 0.0004 & 24.16 & 37.14 & 0.0005 & 0.0136 & 7.4 \\ \text { S13 } & 13.0 & 0.1 & 100 & 0.34 & 0.0001 & 12.98 & 12.98 & 0.0001 & 0.0109 & 2.6\end{array}$

NFM2 $-2{ }^{\circ} \mathrm{C}$ freezing, $25 \mathrm{C}$ melting

$\begin{array}{lrrrrrrrrrr} & \text { MS } & \text { VS } & \text { DN } & \text { ICP } & \text { Mol Mg } & \text { MW } & & & & \\ \text { S } & 531.3 & 0.5 & 1000 & 11.17 & 0.2298 & 503.64 & & & & \\ \text { L } & 128.9 & 0.25 & 1000 & 11.61 & 0.1194 & 114.53 & & & & \\ \text { R1 } & 118.0 & 0.25 & 100 & 23.83 & 0.0003 & 117.97 & & & & \\ \text { RC } & 199.7 & 0.25 & 100 & 0.27 & 0.0245 & 196.75 & \text { CMW } & \text { CMM } & \text { CMOL } & \text { WR } \\ \text { S01 } & 26.2 & 0.1 & 100 & 41.14 & 0.0169 & 24.16 & 305.92 & 0.0788 & 0.2576 & 60.7 \\ \text { S02 } & 25.9 & 0.1 & 100 & 33.86 & 0.0139 & 24.22 & 281.75 & 0.0619 & 0.2196 & 55.9 \\ \text { S03 } & 26.8 & 0.1 & 100 & 28.89 & 0.0119 & 25.37 & 257.53 & 0.0479 & 0.1861 & 51.1 \\ \text { S04 } & 28.3 & 0.1 & 100 & 25.55 & 0.0105 & 27.03 & 232.16 & 0.0360 & 0.1553 & 46.1 \\ \text { S05 } & 26.8 & 0.1 & 100 & 19.70 & 0.0081 & 25.82 & 205.13 & 0.0255 & 0.1245 & 40.7 \\ \text { S06 } & 26.3 & 0.1 & 100 & 15.39 & 0.0063 & 25.54 & 179.30 & 0.0174 & 0.0972 & 35.6 \\ \text { S07 } & 25.1 & 0.1 & 100 & 11.06 & 0.0045 & 24.55 & 153.77 & 0.0111 & 0.0721 & 30.5 \\ \text { S08 } & 25.5 & 0.1 & 100 & 7.76 & 0.0032 & 25.12 & 129.21 & 0.0065 & 0.0506 & 25.7 \\ \text { S09 } & 26.4 & 0.1 & 100 & 4.60 & 0.0019 & 26.17 & 104.10 & 0.0034 & 0.0322 & 20.7 \\ \text { S10 } & 32.0 & 0.1 & 100 & 2.67 & 0.0011 & 31.87 & 77.92 & 0.0015 & 0.0187 & 15.5 \\ \text { S11 } & 26.7 & 0.1 & 100 & 0.74 & 0.0003 & 26.66 & 46.06 & 0.0004 & 0.0078 & 9.1 \\ \text { S12 } & 19.4 & 0.1 & 100 & 0.14 & 0.0001 & 19.39 & 19.39 & 0.0001 & 0.0029 & 3.9\end{array}$

NFM3 $\quad-2{ }^{\circ} \mathrm{C}$ freezing, $25^{\circ} \mathrm{C}$ melting

$\begin{array}{lrrrrrrrrrr} & \text { MS } & \text { VS } & \text { DN } & \text { ICP } & \text { Mol Mg } & \text { MW } & & & & \\ \text { S } & 535.6 & 0.5 & 1000 & 11.22 & 0.2308 & 507.82 & & & & \\ \text { L } & 109.6 & 0.25 & 1000 & 10.26 & 0.1055 & 96.90 & & & & \\ \text { R1 } & 112.4 & 0.25 & 100 & 28.25 & 0.0006 & 112.32 & & & & \\ \text { RC } & 201.7 & 0.25 & 100 & 0.62 & 0.0291 & 198.20 & \text { CMW } & \text { CMM } & \text { CMOL } & \text { WR } \\ \text { S01 } & 27.5 & 0.1 & 100 & 49.51 & 0.0204 & 25.05 & 311.61 & 0.0872 & 0.2798 & 61.4 \\ \text { S02 } & 35.6 & 0.1 & 100 & 51.75 & 0.0213 & 33.04 & 286.56 & 0.0668 & 0.2331 & 56.4 \\ \text { S03 } & 28.6 & 0.1 & 100 & 33.11 & 0.0136 & 26.96 & 253.52 & 0.0455 & 0.1795 & 49.9 \\ \text { S04 } & 26.9 & 0.1 & 100 & 25.10 & 0.0103 & 25.66 & 226.56 & 0.0319 & 0.1408 & 44.6 \\ \text { S05 } & 27.5 & 0.1 & 100 & 19.34 & 0.0080 & 26.54 & 200.90 & 0.0216 & 0.1073 & 39.6 \\ \text { S06 } & 31.3 & 0.1 & 100 & 15.23 & 0.0063 & 30.55 & 174.36 & 0.0136 & 0.0780 & 34.3 \\ \text { S07 } & 26.7 & 0.1 & 100 & 8.46 & 0.0035 & 26.28 & 143.82 & 0.0073 & 0.0510 & 28.3 \\ \text { S08 } & 25.5 & 0.1 & 100 & 4.94 & 0.0020 & 25.26 & 117.54 & 0.0039 & 0.0328 & 23.1 \\ \text { S09 } & 5.4 & 0.1 & 100 & 2.65 & 0.0011 & 5.27 & 92.28 & 0.0018 & 0.0198 & 18.2 \\ \text { S10 } & 28.0 & 0.1 & 100 & 1.26 & 0.0005 & 27.94 & 87.01 & 0.0007 & 0.0085 & 17.1 \\ \text { S11 } & 26.3 & 0.1 & 100 & 0.41 & 0.0002 & 26.28 & 59.07 & 0.0002 & 0.0037 & 11.6 \\ \text { S12 } & 20.0 & 0.1 & 100 & 0.11 & 0.0000 & 19.99 & 32.79 & 0.0000 & 0.0015 & 6.5 \\ \text { S13 } & 12.8 & 0.1 & 100 & 0.01 & 0.0000 & 12.80 & 12.80 & 0.0000 & 0.0003 & 2.5\end{array}$




$\begin{array}{lrrrrrrrrrr}\text { NFM4 } & -2{ }^{\circ} \text { C freezing, } 25{ }^{\circ} \mathrm{C} \text { melting } & & & & & & & \\ \text { S } & \text { MS } & \text { VS } & \text { DN } & \text { ICP } & \text { Mol Mg } & \text { MW } & & & & \\ \text { S } & 531.3 & 0.5 & 1000 & 11.15 & 0.2294 & 503.69 & & & & \\ \text { L } & 101.6 & 0.25 & 1000 & 10.09 & 0.1038 & 89.11 & & & & \\ \text { R1 } & 115.1 & 0.25 & 100 & 27.07 & 0.0278 & 111.75 & & & & \\ \text { RC } & 199.8 & 0.25 & 100 & 0.39 & 0.0004 & 199.75 & \text { CMW } & \text { CMM } & \text { CMOL } & \text { WR } \\ \text { S01 } & 41.6 & 0.1 & 100 & 68.96 & 0.0284 & 38.18 & 346.53 & 0.0920 & 0.2655 & 68.8 \\ \text { S02 } & 27.4 & 0.1 & 100 & 35.31 & 0.0145 & 25.65 & 308.34 & 0.0636 & 0.2063 & 61.2 \\ \text { S03 } & 34.1 & 0.1 & 100 & 34.65 & 0.0143 & 32.38 & 282.69 & 0.0491 & 0.1736 & 56.1 \\ \text { S04 } & 25.5 & 0.1 & 100 & 21.12 & 0.0087 & 24.45 & 250.31 & 0.0348 & 0.1392 & 49.7 \\ \text { S05 } & 35.0 & 0.1 & 100 & 23.62 & 0.0097 & 33.83 & 225.85 & 0.0261 & 0.1158 & 44.8 \\ \text { S06 } & 22.4 & 0.1 & 100 & 12.04 & 0.0050 & 21.80 & 192.02 & 0.0164 & 0.0855 & 38.1 \\ \text { S07 } & 19.9 & 0.1 & 100 & 8.84 & 0.0036 & 19.46 & 170.22 & 0.0115 & 0.0674 & 33.8 \\ \text { S08 } & 23.1 & 0.1 & 100 & 7.32 & 0.0030 & 22.74 & 150.76 & 0.0078 & 0.0520 & 29.9 \\ \text { S09 } & 22.8 & 0.1 & 100 & 4.97 & 0.0020 & 22.55 & 128.02 & 0.0048 & 0.0377 & 25.4 \\ \text { S10 } & 21.9 & 0.1 & 100 & 3.31 & 0.0014 & 21.74 & 105.47 & 0.0028 & 0.0263 & 20.9 \\ \text { S11 } & 21.4 & 0.1 & 100 & 1.96 & 0.0008 & 21.30 & 83.73 & 0.0014 & 0.0169 & 16.6 \\ \text { S12 } & 20.9 & 0.1 & 100 & 1.02 & 0.0004 & 20.85 & 62.43 & 0.0006 & 0.0097 & 12.4 \\ \text { S13 } & 18.2 & 0.1 & 100 & 0.35 & 0.0001 & 18.18 & 41.58 & 0.0002 & 0.0045 & 8.3 \\ \text { S14 } & 23.4 & 0.1 & 100 & 0.11 & 0.0000 & 23.39 & 23.39 & 0.0000 & 0.0020 & 4.6\end{array}$

NFM5 $\quad-2{ }^{\circ} \mathrm{C}$ freezing, $25^{\circ} \mathrm{C}$ melting

$\begin{array}{lrrrrrrrrrr} & \text { MS } & \text { VS } & \text { DN } & \text { ICP } & \text { Mol Mg } & \text { MW } & & & & \\ \text { S } & 530.1 & 0.5 & 1000 & 11.31 & 0.2327 & 502.10 & & & & \\ \text { L } & 126.2 & 0.25 & 1000 & 10.81 & 0.1112 & 112.81 & & & & \\ \text { R1 } & 66.1 & 0.25 & 100 & 21.45 & 0.0221 & 63.44 & & & & \\ \text { RC } & 199.3 & 0.25 & 100 & 0.24 & 0.0003 & 199.27 & \text { CMW } & \text { CMM } & \text { CMOL } & \text { WR } \\ \text { S01 } & 22.7 & 0.1 & 100 & 36.99 & 0.0152 & 20.87 & 341.24 & 0.0903 & 0.2645 & 68.0 \\ \text { S02 } & 23.9 & 0.1 & 100 & 35.67 & 0.0147 & 22.13 & 320.37 & 0.0750 & 0.2342 & 63.8 \\ \text { S03 } & 23.3 & 0.1 & 100 & 29.48 & 0.0121 & 21.84 & 298.23 & 0.0604 & 0.2024 & 59.4 \\ \text { S04 } & 23.0 & 0.1 & 100 & 24.63 & 0.0101 & 21.78 & 276.39 & 0.0482 & 0.1745 & 55.0 \\ \text { S05 } & 26.6 & 0.1 & 100 & 23.97 & 0.0099 & 25.41 & 254.61 & 0.0381 & 0.1496 & 50.7 \\ \text { S06 } & 29.2 & 0.1 & 100 & 21.64 & 0.0089 & 28.13 & 229.20 & 0.0282 & 0.1232 & 45.6 \\ \text { S07 } & 27.6 & 0.1 & 100 & 15.75 & 0.0065 & 26.82 & 201.07 & 0.0193 & 0.0962 & 40.0 \\ \text { S08 } & 23.9 & 0.1 & 100 & 10.31 & 0.0042 & 23.39 & 174.25 & 0.0129 & 0.0738 & 34.7 \\ \text { S09 } & 23.7 & 0.1 & 100 & 7.93 & 0.0033 & 23.31 & 150.86 & 0.0086 & 0.0571 & 30.0 \\ \text { S10 } & 24.4 & 0.1 & 100 & 5.93 & 0.0024 & 24.11 & 127.56 & 0.0054 & 0.0420 & 25.4 \\ \text { S11 } & 21.5 & 0.1 & 100 & 3.38 & 0.0014 & 21.33 & 103.45 & 0.0029 & 0.0282 & 20.6 \\ \text { S12 } & 21.9 & 0.1 & 100 & 2.01 & 0.0008 & 21.80 & 82.12 & 0.0015 & 0.0185 & 16.4 \\ \text { S13 } & 20.8 & 0.1 & 100 & 1.00 & 0.0004 & 20.75 & 60.32 & 0.0007 & 0.0115 & 12.0\end{array}$




$\begin{array}{lllllllllll}\text { S14 } & 21.9 & 0.1 & 100 & 0.50 & 0.0002 & 21.88 & 39.57 & 0.0003 & 0.0072 & 7.9 \\ \text { S15 } & 17.7 & 0.1 & 100 & 0.19 & 0.0001 & 17.69 & 17.69 & 0.0001 & 0.0044 & 3.5\end{array}$

\begin{tabular}{lrrrrrrrrrr} 
NFM6 & $-2{ }^{\circ} \mathrm{C}$ freezing, $25{ }^{\circ} \mathrm{C}$ melting & \multicolumn{1}{c}{ ICP } & Mol Mg & MW & & & & & \\
& MS & VS & DN & ICP & & & & \\
S & 535.5 & 0.5 & 1000 & 11.35 & 0.2334 & 507.41 & & & & \\
L & 88.5 & 0.25 & 1000 & 9.36 & 0.0962 & 76.92 & & & & \\
R1 & 60.0 & 0.25 & 100 & 23.06 & 0.0237 & 57.14 & & & & \\
RC & 203.8 & 0.25 & 100 & 0.12 & 0.0001 & 203.78 & CMW & CMM & CMOL & WR \\
S01 & 24.2 & 0.1 & 100 & 45.01 & 0.0185 & 21.97 & 371.22 & 0.1028 & 0.2770 & 73.2 \\
S02 & 31.7 & 0.1 & 100 & 51.83 & 0.0213 & 29.13 & 349.25 & 0.0843 & 0.2414 & 68.8 \\
S03 & 25.6 & 0.1 & 100 & 35.77 & 0.0147 & 23.83 & 320.12 & 0.0630 & 0.1967 & 63.1 \\
S04 & 21.0 & 0.1 & 100 & 26.15 & 0.0108 & 19.70 & 296.29 & 0.0483 & 0.1629 & 58.4 \\
S05 & 29.9 & 0.1 & 100 & 31.59 & 0.0130 & 28.34 & 276.59 & 0.0375 & 0.1356 & 54.5 \\
S06 & 25.7 & 0.1 & 100 & 20.00 & 0.0082 & 24.71 & 248.25 & 0.0245 & 0.0987 & 48.9 \\
S07 & 28.0 & 0.1 & 100 & 15.86 & 0.0065 & 27.21 & 223.54 & 0.0163 & 0.0728 & 44.1 \\
S08 & 26.7 & 0.1 & 100 & 9.89 & 0.0041 & 26.21 & 196.33 & 0.0097 & 0.0496 & 38.7 \\
S09 & 22.7 & 0.1 & 100 & 5.43 & 0.0022 & 22.43 & 170.12 & 0.0057 & 0.0334 & 33.5 \\
S10 & 22.1 & 0.1 & 100 & 3.56 & 0.0015 & 21.92 & 147.69 & 0.0034 & 0.0233 & 29.1 \\
S11 & 22.6 & 0.1 & 100 & 2.32 & 0.0010 & 22.48 & 125.76 & 0.0020 & 0.0157 & 24.8 \\
S12 & 21.8 & 0.1 & 100 & 1.32 & 0.0005 & 21.73 & 103.28 & 0.0010 & 0.0099 & 20.4 \\
S13 & 23.7 & 0.1 & 100 & 0.74 & 0.0003 & 23.66 & 81.54 & 0.0005 & 0.0059 & 16.1 \\
S14 & 21.8 & 0.1 & 100 & 0.31 & 0.0001 & 21.78 & 57.88 & 0.0002 & 0.0030 & 11.4 \\
S15 & 19.9 & 0.1 & 100 & 0.11 & 0.0000 & 19.89 & 36.09 & 0.0000 & 0.0013 & 7.1 \\
S16 & 16.2 & 0.1 & 100 & 0.01 & 0.0000 & 16.20 & 16.20 & 0.0000 & 0.0002 & 3.2
\end{tabular}

NFM7 $\quad-2{ }^{\circ} \mathrm{C}$ freezing, $25^{\circ} \mathrm{C}$ melting

$\begin{array}{lrrrrrrrrrr} & \text { MS } & \text { VS } & \text { DN } & \text { ICP } & \text { Mol Mg } & \text { MW } & & & & \\ \text { S } & 531.6 & 0.5 & 1000 & 11.53 & 0.2371 & 503.06 & & & & \\ \text { L } & 148.2 & 0.25 & 1000 & 13.57 & 0.1396 & 131.40 & & & & \\ \text { R1 } & 57.0 & 0.25 & 100 & 17.58 & 0.0181 & 54.82 & & & & \\ \text { RC } & 167.8 & 0.25 & 100 & 0.12 & 0.0001 & 167.78 & \text { CMW } & \text { CMM } & \text { CMOL } & \text { WR } \\ \text { S01 } & 25.1 & 0.1 & 100 & 39.22 & 0.0161 & 23.16 & 295.31 & 0.0689 & 0.2332 & 58.7 \\ \text { S02 } & 22.6 & 0.1 & 100 & 29.79 & 0.0123 & 21.12 & 272.15 & 0.0527 & 0.1937 & 54.1 \\ \text { S03 } & 23.3 & 0.1 & 100 & 25.02 & 0.0103 & 22.06 & 251.03 & 0.0405 & 0.1612 & 49.9 \\ \text { S04 } & 19.6 & 0.1 & 100 & 18.03 & 0.0074 & 18.71 & 228.97 & 0.0302 & 0.1318 & 45.5 \\ \text { S05 } & 25.5 & 0.1 & 100 & 18.72 & 0.0077 & 24.57 & 210.26 & 0.0228 & 0.1082 & 41.8 \\ \text { S06 } & 21.3 & 0.1 & 100 & 12.22 & 0.0050 & 20.69 & 185.69 & 0.0151 & 0.0811 & 36.9 \\ \text { S07 } & 24.0 & 0.1 & 100 & 9.87 & 0.0041 & 23.51 & 164.99 & 0.0100 & 0.0608 & 32.8 \\ \text { S08 } & 22.7 & 0.1 & 100 & 6.27 & 0.0026 & 22.39 & 141.48 & 0.0060 & 0.0422 & 28.1 \\ \text { S09 } & 19.4 & 0.1 & 100 & 3.67 & 0.0015 & 19.22 & 119.09 & 0.0034 & 0.0285 & 23.7 \\ \text { S10 } & 24.4 & 0.1 & 100 & 3.01 & 0.0012 & 24.25 & 99.87 & 0.0019 & 0.0188 & 19.9 \\ \text { S11 } & 22.2 & 0.1 & 100 & 1.12 & 0.0005 & 22.14 & 75.62 & 0.0006 & 0.0085 & 15.0\end{array}$




$\begin{array}{lrllllllllr}\text { S12 } & 22.3 & 0.1 & 100 & 0.37 & 0.0002 & 22.28 & 53.48 & 0.0002 & 0.0034 & 10.6 \\ \text { S13 } & 19.8 & 0.1 & 100 & 0.07 & 0.0000 & 19.80 & 31.20 & 0.0000 & 0.0009 & 6.2 \\ \text { S14 } & 11.4 & 0.1 & 100 & 0.00 & 0.0000 & 11.40 & 11.40 & 0.0000 & 0.0000 & 2.3\end{array}$

NFM8 $\quad-2{ }^{\circ} \mathrm{C}$ freezing, $25^{\circ} \mathrm{C}$ melting

$\begin{array}{lrrrrrrrrrr} & \text { MS } & \text { VS } & \text { DN } & \text { ICP } & \text { Mol Mg } & \text { MW } & & & & \\ \text { S } & 531.4 & 0.5 & 1000 & 11.48 & 0.2363 & 502.96 & & & & \\ \text { L } & 103.6 & 0.25 & 1000 & 9.78 & 0.1006 & 91.49 & & & & \\ \text { R1 } & 70.0 & 0.25 & 100 & 27.82 & 0.0286 & 66.56 & & & & \\ \text { RC } & 202.1 & 0.25 & 100 & 0.10 & 0.0001 & 202.09 & \text { CMW } & \text { CMM } & \text { CMOL } & \text { WR } \\ \text { S01 } & 44.2 & 0.1 & 100 & 71.89 & 0.0296 & 40.64 & 358.38 & 0.1032 & 0.2879 & 71.3 \\ \text { S02 } & 22.8 & 0.1 & 100 & 32.28 & 0.0133 & 21.20 & 317.74 & 0.0736 & 0.2317 & 63.2 \\ \text { S03 } & 21.3 & 0.1 & 100 & 26.59 & 0.0109 & 19.98 & 296.54 & 0.0603 & 0.2035 & 59.0 \\ \text { S04 } & 34.7 & 0.1 & 100 & 37.06 & 0.0152 & 32.86 & 276.55 & 0.0494 & 0.1786 & 55.0 \\ \text { S05 } & 22.4 & 0.1 & 100 & 19.62 & 0.0081 & 21.43 & 243.69 & 0.0341 & 0.1401 & 48.5 \\ \text { S06 } & 27.1 & 0.1 & 100 & 19.87 & 0.0082 & 26.12 & 222.26 & 0.0261 & 0.1173 & 44.2 \\ \text { S07 } & 24.7 & 0.1 & 100 & 14.47 & 0.0060 & 23.98 & 196.15 & 0.0179 & 0.0913 & 39.0 \\ \text { S08 } & 24.0 & 0.1 & 100 & 10.57 & 0.0043 & 23.48 & 172.16 & 0.0119 & 0.0694 & 34.2 \\ \text { S09 } & 21.9 & 0.1 & 100 & 7.14 & 0.0029 & 21.55 & 148.69 & 0.0076 & 0.0511 & 29.6 \\ \text { S10 } & 20.8 & 0.1 & 100 & 4.94 & 0.0020 & 20.56 & 127.14 & 0.0047 & 0.0366 & 25.3 \\ \text { S11 } & 20.5 & 0.1 & 100 & 2.94 & 0.0012 & 20.35 & 106.58 & 0.0026 & 0.0246 & 21.2 \\ \text { S12 } & 21.9 & 0.1 & 100 & 1.92 & 0.0008 & 21.81 & 86.23 & 0.0014 & 0.0164 & 17.1 \\ \text { S13 } & 23.0 & 0.1 & 100 & 1.00 & 0.0004 & 22.95 & 64.42 & 0.0006 & 0.0097 & 12.8 \\ \text { S14 } & 20.0 & 0.1 & 100 & 0.37 & 0.0002 & 19.98 & 41.47 & 0.0002 & 0.0052 & 8.2 \\ \text { S15 } & 21.5 & 0.1 & 100 & 0.15 & 0.0001 & 21.49 & 21.49 & 0.0001 & 0.0028 & 4.3\end{array}$

NFM9 $\quad-2{ }^{\circ} \mathrm{C}$ freezing, $25{ }^{\circ} \mathrm{C}$ melting

$\begin{array}{lrrrrrrrrrr} & \text { MS } & \text { VS } & \text { DN } & \text { ICP } & \text { Mol Mg } & \text { MW } & & & & \\ \text { S } & 532.6 & 0.5 & 1000 & 11.79 & 29.1948 & 503.41 & & & & \\ \text { L } & 124.2 & 0.25 & 1000 & 11.15 & 13.8040 & 110.40 & & & & \\ \text { R1 } & 58.7 & 0.25 & 100 & 16.48 & 2.0404 & 56.66 & & & & \\ \text { RC } & 196.7 & 0.25 & 100 & 0.20 & 0.0246 & 196.68 & \text { CMW } & \text { CMM } & \text { CMOL } & \text { WR } \\ \text { S01 } & 41.1 & 0.1 & 100 & 71.03 & 3.5176 & 37.58 & 346.75 & 0.0976 & 0.2816 & 68.9 \\ \text { S02 } & 22.7 & 0.1 & 100 & 33.29 & 1.6487 & 21.05 & 309.16 & 0.0684 & 0.2213 & 61.4 \\ \text { S03 } & 20.3 & 0.1 & 100 & 25.78 & 1.2766 & 19.02 & 288.11 & 0.0547 & 0.1899 & 57.2 \\ \text { S04 } & 33.5 & 0.1 & 100 & 35.35 & 1.7507 & 31.75 & 269.09 & 0.0441 & 0.1640 & 53.5 \\ \text { S05 } & 21.9 & 0.1 & 100 & 18.56 & 0.9192 & 20.98 & 237.34 & 0.0296 & 0.1246 & 47.1 \\ \text { S06 } & 25.9 & 0.1 & 100 & 17.50 & 0.8665 & 25.03 & 216.36 & 0.0219 & 0.1014 & 43.0 \\ \text { S07 } & 24.7 & 0.1 & 100 & 12.80 & 0.6341 & 24.07 & 191.33 & 0.0147 & 0.0770 & 38.0 \\ \text { S08 } & 24.6 & 0.1 & 100 & 8.94 & 0.4428 & 24.16 & 167.26 & 0.0095 & 0.0566 & 33.2 \\ \text { S09 } & 23.8 & 0.1 & 100 & 6.24 & 0.3091 & 23.49 & 143.10 & 0.0058 & 0.0405 & 28.4 \\ \text { S10 } & 21.7 & 0.1 & 100 & 3.68 & 0.1821 & 21.52 & 119.61 & 0.0032 & 0.0270 & 23.8 \\ \text { S11 } & 18.5 & 0.1 & 100 & 1.93 & 0.0958 & 18.40 & 98.09 & 0.0017 & 0.0174 & 19.5\end{array}$




$\begin{array}{lrllllllllr}\text { S12 } & 23.6 & 0.1 & 100 & 1.35 & 0.0668 & 23.53 & 79.69 & 0.0009 & 0.0115 & 15.8 \\ \text { S13 } & 22.4 & 0.1 & 100 & 0.58 & 0.0288 & 22.37 & 56.16 & 0.0004 & 0.0064 & 11.2 \\ \text { S14 } & 33.8 & 0.1 & 100 & 0.29 & 0.0146 & 33.79 & 33.79 & 0.0001 & 0.0036 & 6.7\end{array}$

NFM10 $-2{ }^{\circ} \mathrm{C}$ freezing, $25^{\circ} \mathrm{C}$ melting

$\begin{array}{lrrrrrrrrrr} & \text { MS } & \text { VS } & \text { DN } & \text { ICP } & \text { Mol Mg } & \text { MW } & & & & \\ \text { S } & 531.9 & 0.5 & 1000 & 10.39 & 0.2137 & 506.18 & & & & \\ \text { L } & 140.3 & 0.25 & 1000 & 11.42 & 0.1175 & 126.16 & & & & \\ \text { R1 } & 58.3 & 0.25 & 100 & 17.97 & 0.0185 & 56.07 & & & & \\ \text { RC } & 208.2 & 0.25 & 100 & 0.18 & 0.0002 & 208.18 & \text { CMW } & \text { CMM } & \text { CMOL } & \text { WR } \\ \text { S01 } & 22.6 & 0.1 & 100 & 35.16 & 0.0145 & 20.86 & 320.75 & 0.0727 & 0.2265 & 63.4 \\ \text { S02 } & 22.2 & 0.1 & 100 & 29.42 & 0.0121 & 20.74 & 299.89 & 0.0582 & 0.1941 & 59.2 \\ \text { S03 } & 32.7 & 0.1 & 100 & 35.09 & 0.0144 & 30.96 & 279.15 & 0.0461 & 0.1651 & 55.1 \\ \text { S04 } & 30.5 & 0.1 & 100 & 24.81 & 0.0102 & 29.27 & 248.19 & 0.0317 & 0.1276 & 49.0 \\ \text { S05 } & 29.5 & 0.1 & 100 & 17.11 & 0.0070 & 28.65 & 218.92 & 0.0214 & 0.0980 & 43.2 \\ \text { S06 } & 36.6 & 0.1 & 100 & 16.06 & 0.0066 & 35.80 & 190.27 & 0.0144 & 0.0757 & 37.6 \\ \text { S07 } & 25.9 & 0.1 & 100 & 7.81 & 0.0032 & 25.51 & 154.46 & 0.0078 & 0.0505 & 30.5 \\ \text { S08 } & 36.2 & 0.1 & 100 & 6.42 & 0.0026 & 35.88 & 128.95 & 0.0046 & 0.0356 & 25.5 \\ \text { S09 } & 26.0 & 0.1 & 100 & 2.56 & 0.0011 & 25.87 & 93.07 & 0.0019 & 0.0209 & 18.4 \\ \text { S10 } & 24.6 & 0.1 & 100 & 1.39 & 0.0006 & 24.53 & 67.19 & 0.0009 & 0.0133 & 13.3 \\ \text { S11 } & 42.7 & 0.1 & 100 & 0.78 & 0.0003 & 42.66 & 42.66 & 0.0003 & 0.0075 & 8.4\end{array}$

NFM11 $-3{ }^{\circ} \mathrm{C}$ freezing, $25^{\circ} \mathrm{C}$ melting

$\begin{array}{lrrrrrrrrrr} & \text { MS } & \text { VS } & \text { DN } & \text { ICP } & \text { Mol Mg } & \text { MW } & & & & \\ \text { S } & 535.7 & 0.5 & 1000 & 11.25 & 0.2314 & 507.85 & & & & \\ \text { L } & 61.4 & 0.25 & 1000 & 6.69 & 0.0688 & 53.12 & & & & \\ \text { R1 } & 114.7 & 0.25 & 100 & 28.93 & 0.0298 & 111.12 & & & & \\ \text { RC } & 198.9 & 0.25 & 100 & 0.29 & 0.0003 & 198.86 & \text { CMW } & \text { CMM } & \text { CMOL } & \text { WR } \\ \text { S01 } & 28.3 & 0.1 & 100 & 61.58 & 0.0253 & 25.25 & 380.94 & 0.1251 & 0.3285 & 75.0 \\ \text { S02 } & 28.0 & 0.1 & 100 & 51.84 & 0.0213 & 25.43 & 355.69 & 0.0998 & 0.2805 & 70.0 \\ \text { S03 } & 28.5 & 0.1 & 100 & 45.69 & 0.0188 & 26.24 & 330.26 & 0.0785 & 0.2376 & 65.0 \\ \text { S04 } & 28.2 & 0.1 & 100 & 38.56 & 0.0159 & 26.29 & 304.02 & 0.0597 & 0.1962 & 59.9 \\ \text { S05 } & 29.0 & 0.1 & 100 & 33.13 & 0.0136 & 27.36 & 277.73 & 0.0438 & 0.1577 & 54.7 \\ \text { S06 } & 22.4 & 0.1 & 100 & 20.79 & 0.0086 & 21.37 & 250.37 & 0.0302 & 0.1205 & 49.3 \\ \text { S07 } & 26.5 & 0.1 & 100 & 18.46 & 0.0076 & 25.59 & 229.00 & 0.0216 & 0.0944 & 45.1 \\ \text { S08 } & 24.6 & 0.1 & 100 & 12.30 & 0.0051 & 23.99 & 203.41 & 0.0140 & 0.0689 & 40.1 \\ \text { S09 } & 26.5 & 0.1 & 100 & 8.81 & 0.0036 & 26.06 & 179.42 & 0.0090 & 0.0499 & 35.3 \\ \text { S10 } & 25.4 & 0.1 & 100 & 7.20 & 0.0030 & 25.04 & 153.36 & 0.0053 & 0.0348 & 30.2 \\ \text { S11 } & 27.0 & 0.1 & 100 & 3.30 & 0.0014 & 26.84 & 128.32 & 0.0024 & 0.0184 & 25.3 \\ \text { S12 } & 25.7 & 0.1 & 100 & 1.47 & 0.0006 & 25.63 & 101.48 & 0.0010 & 0.0099 & 20.0 \\ \text { S13 } & 25.7 & 0.1 & 100 & 0.66 & 0.0003 & 25.67 & 75.85 & 0.0004 & 0.0053 & 14.9\end{array}$




$\begin{array}{lllllllllll}\mathrm{S} 14 & 24.9 & 0.1 & 100 & 0.22 & 0.0001 & 24.89 & 50.18 & 0.0001 & 0.0026 & 9.9 \\ \mathrm{~S} 15 & 25.3 & 0.1 & 100 & 0.10 & 0.0000 & 25.30 & 25.30 & 0.0000 & 0.0016 & 5.0\end{array}$

NFM12 $-3{ }^{\circ} \mathrm{C}$ freezing, $25^{\circ} \mathrm{C}$ melting

$\begin{array}{lrrrrrrrrrr} & \text { MS } & \text { VS } & \text { DN } & \text { ICP } & \text { Mol Mg } & \text { MW } & & & & \\ \text { S } & 530.9 & 0.5 & 1000 & 11.16 & 0.2295 & 503.27 & & & & \\ \text { L } & 66.6 & 0.25 & 1000 & 7.99 & 0.0822 & 56.71 & & & & \\ \text { R1 } & 48.3 & 0.25 & 100 & 19.19 & 0.0197 & 45.92 & & & & \\ \text { RC } & 202.4 & 0.25 & 100 & 0.08 & 0.0001 & 202.39 & \text { CMW } & \text { CMM } & \text { CMOL } & \text { WR } \\ \text { S01 } & 30.2 & 0.1 & 100 & 66.32 & 0.0273 & 26.92 & 393.18 & 0.1273 & 0.3238 & 78.1 \\ \text { S02 } & 35.3 & 0.1 & 100 & 63.66 & 0.0262 & 32.15 & 366.26 & 0.1000 & 0.2731 & 72.8 \\ \text { S03 } & 27.4 & 0.1 & 100 & 40.90 & 0.0168 & 25.37 & 334.11 & 0.0738 & 0.2210 & 66.4 \\ \text { S04 } & 27.2 & 0.1 & 100 & 33.82 & 0.0139 & 25.53 & 308.74 & 0.0570 & 0.1846 & 61.3 \\ \text { S05 } & 29.7 & 0.1 & 100 & 30.20 & 0.0124 & 28.20 & 283.21 & 0.0431 & 0.1521 & 56.3 \\ \text { S06 } & 27.7 & 0.1 & 100 & 21.41 & 0.0088 & 26.64 & 255.01 & 0.0307 & 0.1203 & 50.7 \\ \text { S07 } & 21.1 & 0.1 & 100 & 13.51 & 0.0056 & 20.43 & 228.37 & 0.0219 & 0.0957 & 45.4 \\ \text { S08 } & 27.2 & 0.1 & 100 & 13.24 & 0.0054 & 26.54 & 207.94 & 0.0163 & 0.0784 & 41.3 \\ \text { S09 } & 22.5 & 0.1 & 100 & 7.94 & 0.0033 & 22.11 & 181.39 & 0.0108 & 0.0598 & 36.0 \\ \text { S10 } & 23.5 & 0.1 & 100 & 5.74 & 0.0024 & 23.22 & 159.29 & 0.0076 & 0.0476 & 31.7 \\ \text { S11 } & 22.1 & 0.1 & 100 & 3.50 & 0.0014 & 21.93 & 136.07 & 0.0052 & 0.0384 & 27.0 \\ \text { S12 } & 25.3 & 0.1 & 100 & 2.24 & 0.0009 & 25.19 & 114.15 & 0.0038 & 0.0331 & 22.7 \\ \text { S13 } & 20.1 & 0.1 & 100 & 0.98 & 0.0004 & 20.05 & 88.96 & 0.0029 & 0.0321 & 17.7 \\ \text { S14 } & 18.7 & 0.1 & 100 & 0.50 & 0.0002 & 18.68 & 68.90 & 0.0025 & 0.0356 & 13.7 \\ \text { S15 } & 17.1 & 1.1 & 101 & 0.23 & 0.0011 & 16.97 & 50.23 & 0.0022 & 0.0447 & 10.0 \\ \text { S16 } & 33.4 & 2.1 & 102 & 0.13 & 0.0012 & 33.26 & 33.26 & 0.0012 & 0.0353 & 6.6\end{array}$

NFM13 $-3{ }^{\circ} \mathrm{C}$ freezing, $25^{\circ} \mathrm{C}$ melting

$\begin{array}{lrrrrrrrrrr} & \text { MS } & \text { VS } & \text { DN } & \text { ICP } & \text { Mol Mg } & \text { MW } & & & & \\ \text { S } & 532.2 & 0.5 & 1000 & 11.52 & 0.2370 & 503.67 & & & & \\ \text { L } & 71.9 & 0.25 & 1000 & 7.75 & 0.0797 & 62.31 & & & & \\ \text { R1 } & 50.2 & 0.25 & 100 & 18.03 & 0.0185 & 47.97 & & & & \\ \text { RC } & 206.8 & 0.25 & 100 & 0.17 & 0.0002 & 206.78 & \text { CMW } & \text { CMM } & \text { CMOL } & \text { WR } \\ \text { S01 } & 31.4 & 0.1 & 100 & 60.59 & 0.0249 & 28.40 & 408.41 & 0.1295 & 0.3170 & 81.1 \\ \text { S02 } & 30.6 & 0.1 & 100 & 53.32 & 0.0219 & 27.96 & 380.02 & 0.1046 & 0.2751 & 75.4 \\ \text { S03 } & 28.6 & 0.1 & 100 & 43.58 & 0.0179 & 26.44 & 352.06 & 0.0826 & 0.2347 & 69.9 \\ \text { S04 } & 24.5 & 0.1 & 100 & 32.35 & 0.0133 & 22.90 & 325.61 & 0.0647 & 0.1987 & 64.6 \\ \text { S05 } & 31.8 & 0.1 & 100 & 33.97 & 0.0140 & 30.12 & 302.72 & 0.0514 & 0.1697 & 60.1 \\ \text { S06 } & 28.0 & 0.1 & 100 & 24.19 & 0.0100 & 26.80 & 272.60 & 0.0374 & 0.1372 & 54.1 \\ \text { S07 } & 23.5 & 0.1 & 100 & 17.19 & 0.0071 & 22.65 & 245.80 & 0.0274 & 0.1117 & 48.8 \\ \text { S08 } & 34.5 & 0.1 & 100 & 19.78 & 0.0081 & 33.52 & 223.15 & 0.0204 & 0.0913 & 44.3 \\ \text { S09 } & 30.4 & 0.1 & 100 & 12.17 & 0.0050 & 29.80 & 189.63 & 0.0122 & 0.0646 & 37.6 \\ \text { S10 } & 25.6 & 0.1 & 100 & 6.29 & 0.0026 & 25.29 & 159.83 & 0.0072 & 0.0453 & 31.7 \\ \text { S11 } & 24.8 & 0.1 & 100 & 3.48 & 0.0014 & 24.63 & 134.54 & 0.0046 & 0.0345 & 26.7\end{array}$




$\begin{array}{lrlllllllll}\text { S12 } & 21.2 & 0.1 & 100 & 1.83 & 0.0008 & 21.11 & 109.91 & 0.0032 & 0.0292 & 21.8 \\ \text { S13 } & 22.4 & 0.1 & 100 & 1.17 & 0.0005 & 22.34 & 88.80 & 0.0025 & 0.0277 & 17.6 \\ \text { S14 } & 25.4 & 0.1 & 100 & 0.65 & 0.0003 & 25.37 & 66.46 & 0.0020 & 0.0297 & 13.2 \\ \text { S15 } & 22.8 & 1.1 & 101 & 0.26 & 0.0012 & 22.66 & 41.09 & 0.0017 & 0.0415 & 8.2 \\ \text { S16 } & 18.5 & 2.1 & 102 & 0.06 & 0.0005 & 18.44 & 18.44 & 0.0005 & 0.0287 & 3.7\end{array}$

NFM14 $-10{ }^{\circ} \mathrm{C}$ freezing, $25{ }^{\circ} \mathrm{C}$ melting

$\begin{array}{lrrrrrrrrrr} & \text { MS } & \text { VS } & \text { DN } & \text { ICP } & \text { Mol Mg } & \text { MW } & & & & \\ \text { S } & 531.7 & 0.5 & 1000 & 11.39 & 0.2342 & 503.51 & & & & \\ \text { L } & 0.0 & 0.25 & 1000 & 0.00 & 0.0000 & 0.00 & & & & \\ \text { R1 } & 0.0 & 0.25 & 100 & 0.00 & 0.0000 & 0.00 & & & & \\ \text { RC } & 198.0 & 0.25 & 100 & 0.04 & 0.0000 & 198.00 & \text { CMW } & \text { CMM } & \text { CMOL } & \text { WR } \\ \text { S01 } & 30.3 & 0.1 & 100 & 105.28 & 0.0433 & 25.09 & 424.34 & 0.2223 & 0.5239 & 84.3 \\ \text { S02 } & 34.2 & 0.1 & 100 & 107.54 & 0.0442 & 28.87 & 399.25 & 0.1790 & 0.4483 & 79.3 \\ \text { S03 } & 32.5 & 0.1 & 100 & 79.25 & 0.0326 & 28.58 & 370.38 & 0.1348 & 0.3638 & 73.6 \\ \text { S04 } & 32.7 & 0.1 & 100 & 63.59 & 0.0262 & 29.55 & 341.80 & 0.1021 & 0.2988 & 67.9 \\ \text { S05 } & 30.8 & 0.1 & 100 & 49.79 & 0.0205 & 28.33 & 312.25 & 0.0760 & 0.2433 & 62.0 \\ \text { S06 } & 34.0 & 0.1 & 100 & 43.06 & 0.0177 & 31.87 & 283.92 & 0.0555 & 0.1955 & 56.4 \\ \text { S07 } & 25.6 & 0.1 & 100 & 24.99 & 0.0103 & 24.36 & 252.05 & 0.0378 & 0.1499 & 50.1 \\ \text { S08 } & 32.1 & 0.1 & 100 & 24.67 & 0.0101 & 30.88 & 227.69 & 0.0275 & 0.1208 & 45.2 \\ \text { S09 } & 24.1 & 0.1 & 100 & 14.35 & 0.0059 & 23.39 & 196.81 & 0.0174 & 0.0882 & 39.1 \\ \text { S10 } & 24.5 & 0.1 & 100 & 9.69 & 0.0040 & 24.02 & 173.42 & 0.0115 & 0.0660 & 34.4 \\ \text { S11 } & 23.8 & 0.1 & 100 & 6.44 & 0.0026 & 23.48 & 149.40 & 0.0075 & 0.0500 & 29.7 \\ \text { S12 } & 35.2 & 0.1 & 100 & 5.42 & 0.0022 & 34.93 & 125.92 & 0.0048 & 0.0383 & 25.0 \\ \text { S13 } & 25.2 & 0.1 & 100 & 2.69 & 0.0011 & 25.07 & 90.99 & 0.0026 & 0.0284 & 18.1 \\ \text { S14 } & 25.9 & 0.1 & 100 & 2.22 & 0.0009 & 25.79 & 65.92 & 0.0015 & 0.0225 & 13.1 \\ \text { S15 } & 21.8 & 0.1 & 100 & 0.92 & 0.0004 & 21.75 & 40.13 & 0.0006 & 0.0141 & 8.0 \\ \text { S16 } & 18.4 & 0.1 & 100 & 0.46 & 0.0002 & 18.38 & 18.38 & 0.0002 & 0.0104 & 3.6\end{array}$

NFM15 $-10{ }^{\circ} \mathrm{C}$ freezing, $25^{\circ} \mathrm{C}$ melting

$\begin{array}{lrrrrrrrrrr} & \text { MS } & \text { VS } & \text { DN } & \text { ICP } & \text { Mol Mg } & \text { MW } & & & & \\ \text { S } & 533.4 & 0.5 & 1000 & 11.24 & 0.2313 & 505.56 & & & & \\ \text { L } & 2.1 & 0.25 & 1000 & 1.00 & 0.0103 & 0.86 & & & & \\ \text { R1 } & 0.0 & 0.25 & 100 & 0.00 & 0.0000 & 0.00 & & & & \\ \text { RC } & 200.2 & 0.25 & 100 & 1.03 & 0.0011 & 200.07 & \text { CMW } & \text { CMM } & \text { CMOL } & \text { WR } \\ \text { S01 } & 31.1 & 0.1 & 100 & 107.68 & 0.0443 & 25.77 & 462.73 & 0.2191 & 0.4735 & 91.5 \\ \text { S02 } & 28.7 & 0.1 & 100 & 74.44 & 0.0306 & 25.01 & 436.96 & 0.1748 & 0.4000 & 86.4 \\ \text { S03 } & 41.0 & 0.1 & 100 & 87.15 & 0.0359 & 36.68 & 411.95 & 0.1442 & 0.3500 & 81.5 \\ \text { S04 } & 27.2 & 0.1 & 100 & 47.30 & 0.0195 & 24.86 & 375.26 & 0.1083 & 0.2886 & 74.2 \\ \text { S05 } & 26.0 & 0.1 & 100 & 39.20 & 0.0161 & 24.06 & 350.41 & 0.0888 & 0.2535 & 69.3 \\ \text { S06 } & 29.4 & 0.1 & 100 & 38.37 & 0.0158 & 27.50 & 326.35 & 0.0727 & 0.2228 & 64.6 \\ \text { S07 } & 27.6 & 0.1 & 100 & 30.47 & 0.0125 & 26.09 & 298.85 & 0.0569 & 0.1905 & 59.1 \\ \text { S08 } & 25.5 & 0.1 & 100 & 23.90 & 0.0098 & 24.32 & 272.76 & 0.0444 & 0.1627 & 54.0\end{array}$




$\begin{array}{lrrrrrrrrrr}\text { S09 } & 26.0 & 0.1 & 100 & 20.63 & 0.0085 & 24.98 & 248.44 & 0.0346 & 0.1391 & 49.1 \\ \text { S10 } & 23.1 & 0.1 & 100 & 15.63 & 0.0064 & 22.33 & 223.46 & 0.0261 & 0.1166 & 44.2 \\ \text { S11 } & 26.5 & 0.1 & 100 & 14.99 & 0.0062 & 25.76 & 201.14 & 0.0196 & 0.0976 & 39.8 \\ \text { S12 } & 25.9 & 0.1 & 100 & 11.24 & 0.0046 & 25.34 & 175.38 & 0.0135 & 0.0768 & 34.7 \\ \text { S13 } & 28.3 & 0.1 & 100 & 8.75 & 0.0036 & 27.87 & 150.04 & 0.0088 & 0.0589 & 29.7 \\ \text { S14 } & 23.9 & 0.1 & 100 & 5.52 & 0.0023 & 23.63 & 122.17 & 0.0052 & 0.0429 & 24.2 \\ \text { S15 } & 24.1 & 0.1 & 100 & 3.67 & 0.0015 & 23.92 & 98.54 & 0.0030 & 0.0301 & 19.5 \\ \text { S16 } & 22.4 & 0.1 & 100 & 1.96 & 0.0008 & 22.30 & 74.62 & 0.0015 & 0.0195 & 14.8 \\ \text { S17 } & 21.2 & 0.1 & 100 & 0.86 & 0.0004 & 21.16 & 52.32 & 0.0007 & 0.0124 & 10.3 \\ \text { S18 } & 23.2 & 0.1 & 100 & 0.60 & 0.0002 & 23.17 & 31.16 & 0.0003 & 0.0095 & 6.2 \\ \text { S19 } & 8.0 & 0.1 & 100 & 0.12 & 0.0000 & 7.99 & 7.99 & 0.0000 & 0.0061 & 1.6\end{array}$

NFM16 $-10{ }^{\circ} \mathrm{C}$ freezing, $25^{\circ} \mathrm{C}$ melting

$\begin{array}{lrrrrrrrrrr} & \text { MS } & \text { VS } & \text { DN } & \text { ICP } & \text { Mol Mg } & \text { MW } & & & & \\ \text { S } & 533.4 & 0.5 & 1000 & 11.33 & 0.2330 & 505.35 & & & & \\ \text { L } & 0.0 & 0.25 & 1000 & 0.00 & 0.0000 & 0.00 & & & & \\ \text { R1 } & 0.0 & 0.25 & 100 & 0.00 & 0.0000 & 0.00 & & & & \\ \text { RC } & 198.6 & 0.25 & 100 & 0.01 & 0.0000 & 198.60 & \text { CMW } & \text { CMM } & \text { CMOL } & \text { WR } \\ \text { S01 } & 35.0 & 0.1 & 100 & 113.97 & 0.0469 & 29.36 & 474.28 & 0.2203 & 0.4645 & 93.9 \\ \text { S02 } & 27.9 & 0.1 & 100 & 79.14 & 0.0326 & 23.98 & 444.93 & 0.1734 & 0.3898 & 88.0 \\ \text { S03 } & 27.3 & 0.1 & 100 & 66.79 & 0.0275 & 23.99 & 420.94 & 0.1409 & 0.3346 & 83.3 \\ \text { S04 } & 42.1 & 0.1 & 100 & 88.00 & 0.0362 & 37.74 & 396.95 & 0.1134 & 0.2856 & 78.5 \\ \text { S05 } & 27.5 & 0.1 & 100 & 45.40 & 0.0187 & 25.25 & 359.21 & 0.0772 & 0.2149 & 71.1 \\ \text { S06 } & 27.1 & 0.1 & 100 & 35.11 & 0.0144 & 25.36 & 333.96 & 0.0585 & 0.1752 & 66.1 \\ \text { S07 } & 23.3 & 0.1 & 100 & 23.89 & 0.0098 & 22.12 & 308.60 & 0.0441 & 0.1428 & 61.1 \\ \text { S08 } & 20.2 & 0.1 & 100 & 15.59 & 0.0064 & 19.43 & 286.48 & 0.0342 & 0.1195 & 56.7 \\ \text { S09 } & 21.3 & 0.1 & 100 & 13.99 & 0.0058 & 20.61 & 267.05 & 0.0278 & 0.1041 & 52.8 \\ \text { S10 } & 24.6 & 0.1 & 100 & 14.07 & 0.0058 & 23.90 & 246.45 & 0.0221 & 0.0895 & 48.8 \\ \text { S11 } & 24.0 & 0.1 & 100 & 10.79 & 0.0044 & 23.47 & 222.54 & 0.0163 & 0.0731 & 44.0 \\ \text { S12 } & 20.6 & 0.1 & 100 & 7.65 & 0.0031 & 20.22 & 199.08 & 0.0118 & 0.0594 & 39.4 \\ \text { S13 } & 22.2 & 0.1 & 100 & 6.69 & 0.0028 & 21.87 & 178.86 & 0.0087 & 0.0485 & 35.4 \\ \text { S14 } & 23.8 & 0.1 & 100 & 5.35 & 0.0022 & 23.54 & 156.99 & 0.0059 & 0.0378 & 31.1 \\ \text { S15 } & 26.2 & 0.1 & 100 & 4.14 & 0.0017 & 25.99 & 133.45 & 0.0037 & 0.0279 & 26.4 \\ \text { S16 } & 25.7 & 0.1 & 100 & 2.43 & 0.0010 & 25.58 & 107.46 & 0.0020 & 0.0188 & 21.3 \\ \text { S17 } & 23.4 & 0.1 & 100 & 1.17 & 0.0005 & 23.34 & 81.88 & 0.0010 & 0.0125 & 16.2 \\ \text { S18 } & 21.0 & 0.1 & 100 & 0.56 & 0.0002 & 20.97 & 58.53 & 0.0005 & 0.0092 & 11.6 \\ \text { S19 } & 21.5 & 0.1 & 100 & 0.27 & 0.0001 & 21.49 & 37.56 & 0.0003 & 0.0082 & 7.4 \\ \text { S20 } & 16.1 & 0.1 & 100 & 0.48 & 0.0002 & 16.08 & 16.08 & 0.0002 & 0.0124 & 3.2\end{array}$

NFM17 $-10{ }^{\circ} \mathrm{C}$ freezing, $25^{\circ} \mathrm{C}$ melting

$\begin{array}{rrrrrrr} & \text { MS } & \text { VS } & \text { DN } & \text { ICP } & \text { Mol Mg } & \text { MW } \\ \text { S } & 536.9 & 0.5 & 1000 & 11.42 & 0.2348 & 508.63 \\ \mathrm{~L} & 4.3 & 0.1 & 1000 & 1.51 & 0.0062 & 3.55\end{array}$




$\begin{array}{lrrrrrrrrrr}\text { R1 } & 0.0 & 0.25 & 100 & 0.00 & 0.0000 & 0.00 & & & & \\ \text { RC } & 200.5 & 0.25 & 100 & 0.62 & 0.0006 & 200.42 & \text { CMW } & \text { CMM } & \text { CMOL } & \text { WR } \\ \text { S01 } & 32.6 & 0.1 & 100 & 101.36 & 0.0417 & 27.58 & 482.69 & 0.2153 & 0.4460 & 94.9 \\ \text { S02 } & 25.5 & 0.1 & 100 & 70.49 & 0.0290 & 22.01 & 455.11 & 0.1736 & 0.3814 & 89.5 \\ \text { S03 } & 26.0 & 0.1 & 100 & 61.89 & 0.0255 & 22.93 & 433.10 & 0.1446 & 0.3339 & 85.1 \\ \text { S04 } & 31.3 & 0.1 & 100 & 63.46 & 0.0261 & 28.16 & 410.16 & 0.1191 & 0.2904 & 80.6 \\ \text { S05 } & 25.9 & 0.1 & 100 & 45.80 & 0.0188 & 23.63 & 382.00 & 0.0930 & 0.2435 & 75.1 \\ \text { S06 } & 29.6 & 0.1 & 100 & 48.27 & 0.0199 & 27.21 & 358.37 & 0.0742 & 0.2070 & 70.5 \\ \text { S07 } & 27.8 & 0.1 & 100 & 36.45 & 0.0150 & 25.99 & 331.16 & 0.0543 & 0.1640 & 65.1 \\ \text { S08 } & 28.9 & 0.1 & 100 & 29.15 & 0.0120 & 27.46 & 305.17 & 0.0393 & 0.1288 & 60.0 \\ \text { S09 } & 26.2 & 0.1 & 100 & 19.49 & 0.0080 & 25.23 & 277.71 & 0.0273 & 0.0984 & 54.6 \\ \text { S10 } & 21.9 & 0.1 & 100 & 12.43 & 0.0051 & 21.28 & 252.48 & 0.0193 & 0.0765 & 49.6 \\ \text { S11 } & 26.7 & 0.1 & 100 & 11.86 & 0.0049 & 26.11 & 231.19 & 0.0142 & 0.0614 & 45.5 \\ \text { S12 } & 26.6 & 0.1 & 100 & 8.40 & 0.0035 & 26.18 & 205.08 & 0.0093 & 0.0454 & 40.3 \\ \text { S13 } & 22.2 & 0.1 & 100 & 5.02 & 0.0021 & 21.95 & 178.90 & 0.0059 & 0.0327 & 35.2 \\ \text { S14 } & 25.8 & 0.1 & 100 & 4.17 & 0.0017 & 25.59 & 156.94 & 0.0038 & 0.0241 & 30.9 \\ \text { S15 } & 22.8 & 0.1 & 100 & 2.20 & 0.0009 & 22.69 & 131.35 & 0.0021 & 0.0158 & 25.8 \\ \text { S16 } & 25.9 & 0.1 & 100 & 1.43 & 0.0006 & 25.83 & 108.66 & 0.0012 & 0.0108 & 21.4 \\ \text { S17 } & 21.7 & 0.1 & 100 & 0.73 & 0.0003 & 21.66 & 82.83 & 0.0006 & 0.0070 & 16.3 \\ \text { S18 } & 19.8 & 0.1 & 100 & 0.36 & 0.0001 & 19.78 & 61.17 & 0.0003 & 0.0046 & 12.0 \\ \text { S19 } & 22.8 & 0.1 & 100 & 0.20 & 0.0001 & 22.79 & 41.38 & 0.0001 & 0.0033 & 8.1 \\ \text { S20 } & 18.6 & 0.1 & 100 & 0.13 & 0.0001 & 18.59 & 18.59 & 0.0001 & 0.0028 & 3.7\end{array}$

NFM18 $-10{ }^{\circ} \mathrm{C}$ freezing, $25^{\circ} \mathrm{C}$ melting

$\begin{array}{lrrrrrrrrrr} & \text { MS } & \text { VS } & \text { DN } & \text { ICP } & \text { Mol Mg } & \text { MW } & & & & \\ \text { S } & 531.7 & 0.5 & 1000 & 11.68 & 0.2403 & 502.78 & & & & \\ \text { L } & 0.0 & 0.25 & 1000 & 0.00 & 0.0000 & 0.00 & & & & \\ \text { R1 } & 0.0 & 0.25 & 100 & 0.00 & 0.0000 & 0.00 & & & & \\ \text { RC } & 203.7 & 0.25 & 100 & 2.72 & 0.0028 & 203.36 & \text { CMW } & \text { CMM } & \text { CMOL } & \text { WR } \\ \text { S01 } & 32.6 & 0.1 & 100 & 112.81 & 0.0464 & 27.01 & 480.21 & 0.2284 & 0.4756 & 95.5 \\ \text { S02 } & 51.0 & 0.1 & 100 & 129.49 & 0.0533 & 44.59 & 453.20 & 0.1820 & 0.4016 & 90.1 \\ \text { S03 } & 33.6 & 0.1 & 100 & 70.66 & 0.0291 & 30.10 & 408.61 & 0.1287 & 0.3150 & 81.3 \\ \text { S04 } & 23.6 & 0.1 & 100 & 42.86 & 0.0176 & 21.48 & 378.51 & 0.0996 & 0.2632 & 75.3 \\ \text { S05 } & 36.3 & 0.1 & 100 & 58.48 & 0.0241 & 33.40 & 357.03 & 0.0820 & 0.2297 & 71.0 \\ \text { S06 } & 32.6 & 0.1 & 100 & 41.41 & 0.0170 & 30.55 & 323.63 & 0.0579 & 0.1790 & 64.4 \\ \text { S07 } & 35.5 & 0.1 & 100 & 33.04 & 0.0136 & 33.86 & 293.08 & 0.0409 & 0.1396 & 58.3 \\ \text { S08 } & 31.5 & 0.1 & 100 & 21.12 & 0.0087 & 30.45 & 259.21 & 0.0273 & 0.1054 & 51.6 \\ \text { S09 } & 32.5 & 0.1 & 100 & 14.29 & 0.0059 & 31.79 & 228.76 & 0.0186 & 0.0814 & 45.5 \\ \text { S10 } & 29.9 & 0.1 & 100 & 8.62 & 0.0035 & 29.47 & 196.97 & 0.0127 & 0.0647 & 39.2 \\ \text { S11 } & 30.5 & 0.1 & 100 & 5.46 & 0.0022 & 30.23 & 167.49 & 0.0092 & 0.0549 & 33.3 \\ \text { S12 } & 27.5 & 0.1 & 100 & 3.17 & 0.0013 & 27.34 & 137.26 & 0.0069 & 0.0506 & 27.3 \\ \text { S13 } & 27.2 & 0.1 & 100 & 1.93 & 0.0008 & 27.10 & 109.92 & 0.0056 & 0.0513 & 21.9\end{array}$




$\begin{array}{llllllllllr}\text { S14 } & 29.9 & 0.1 & 100 & 1.22 & 0.0005 & 29.84 & 82.82 & 0.0048 & 0.0585 & 16.5 \\ \text { S15 } & 24.4 & 1.1 & 101 & 0.50 & 0.0023 & 24.12 & 52.98 & 0.0043 & 0.0820 & 10.5 \\ \text { S16 } & 29.1 & 2.1 & 102 & 0.23 & 0.0020 & 28.85 & 28.85 & 0.0020 & 0.0706 & 5.7\end{array}$

NFM19 $-26{ }^{\circ} \mathrm{C}$ freezing, $25^{\circ} \mathrm{C}$ melting

$\begin{array}{lrrrrrrrrrr} & \text { MS } & \text { VS } & \text { DN } & \text { ICP } & \text { Mol Mg } & \text { MW } & & & & \\ \text { S } & 533.4 & 0.5 & 1000 & 11.54 & 0.2375 & 504.82 & & & & \\ \text { L } & 0.0 & 0.25 & 1000 & 0.00 & 0.0000 & 0.00 & & & & \\ \text { R1 } & 0.0 & 0.25 & 100 & 0.00 & 0.0000 & 0.00 & & & & \\ \text { RC } & 185.1 & 0.25 & 100 & 0.47 & 0.0005 & 185.04 & \text { CMW } & \text { CMM } & \text { CMOL } & \text { WR } \\ \text { S01 } & 46.4 & 0.1 & 100 & 132.73 & 0.0546 & 39.83 & 467.79 & 0.2227 & 0.4761 & 92.7 \\ \text { S02 } & 29.4 & 0.1 & 100 & 73.53 & 0.0303 & 25.76 & 427.97 & 0.1681 & 0.3928 & 84.8 \\ \text { S03 } & 29.1 & 0.1 & 100 & 60.81 & 0.0250 & 26.09 & 402.21 & 0.1378 & 0.3427 & 79.7 \\ \text { S04 } & 27.7 & 0.1 & 100 & 59.91 & 0.0246 & 24.73 & 376.12 & 0.1128 & 0.3000 & 74.5 \\ \text { S05 } & 27.6 & 0.1 & 100 & 45.50 & 0.0187 & 25.35 & 351.39 & 0.0882 & 0.2509 & 69.6 \\ \text { S06 } & 28.2 & 0.1 & 100 & 33.42 & 0.0138 & 26.54 & 326.04 & 0.0695 & 0.2130 & 64.6 \\ \text { S07 } & 37.7 & 0.1 & 100 & 37.34 & 0.0154 & 35.85 & 299.49 & 0.0557 & 0.1860 & 59.3 \\ \text { S08 } & 29.1 & 0.1 & 100 & 25.66 & 0.0106 & 27.83 & 263.64 & 0.0403 & 0.1530 & 52.2 \\ \text { S09 } & 29.9 & 0.1 & 100 & 21.93 & 0.0090 & 28.81 & 235.82 & 0.0298 & 0.1263 & 46.7 \\ \text { S10 } & 26.5 & 0.1 & 100 & 15.39 & 0.0063 & 25.74 & 207.00 & 0.0208 & 0.1003 & 41.0 \\ \text { S11 } & 25.6 & 0.1 & 100 & 11.81 & 0.0049 & 25.02 & 181.26 & 0.0144 & 0.0796 & 35.9 \\ \text { S12 } & 31.5 & 0.1 & 100 & 11.09 & 0.0046 & 30.95 & 156.25 & 0.0096 & 0.0612 & 31.0 \\ \text { S13 } & 29.7 & 0.1 & 100 & 6.74 & 0.0028 & 29.37 & 125.30 & 0.0050 & 0.0399 & 24.8 \\ \text { S14 } & 32.5 & 0.1 & 100 & 3.92 & 0.0016 & 32.31 & 95.93 & 0.0022 & 0.0233 & 19.0 \\ \text { S15 } & 24.0 & 0.1 & 100 & 1.23 & 0.0005 & 23.94 & 63.63 & 0.0006 & 0.0097 & 12.6 \\ \text { S16 } & 26.7 & 0.1 & 100 & 0.17 & 0.0001 & 26.69 & 39.69 & 0.0001 & 0.0029 & 7.9 \\ \text { S17 } & 13.0 & 0.1 & 100 & 0.11 & 0.0000 & 12.99 & 12.99 & 0.0000 & 0.0034 & 2.6\end{array}$

NFM20 $-26{ }^{\circ} \mathrm{C}$ freezing, $25^{\circ} \mathrm{C}$ melting

$\begin{array}{lrrrrrrrrrr} & \text { MS } & \text { VS } & \text { DN } & \text { ICP } & \text { Mol Mg } & \text { MW } & & & & \\ \text { S } & 531.4 & 0.5 & 1000 & 10.54 & 0.2167 & 505.31 & & & & \\ \text { L } & 0.0 & 0.25 & 1000 & 0.00 & 0.0000 & 0.00 & & & & \\ \text { R1 } & 28.5 & 0.1 & 100 & 0.33 & 0.0001 & 28.48 & & & & \\ \text { RC } & 204.3 & 0.25 & 100 & 0.05 & 0.0001 & 204.29 & \text { CMW } & \text { CMM } & \text { CMOL } & \text { WR } \\ \text { S01 } & 26.4 & 0.1 & 100 & 76.55 & 0.0315 & 22.61 & 488.08 & 0.2161 & 0.4428 & 95.8 \\ \text { S02 } & 31.5 & 0.1 & 100 & 85.85 & 0.0353 & 27.25 & 465.48 & 0.1846 & 0.3967 & 91.3 \\ \text { S03 } & 29.4 & 0.1 & 100 & 71.69 & 0.0295 & 25.85 & 438.23 & 0.1493 & 0.3407 & 86.0 \\ \text { S04 } & 35.6 & 0.1 & 100 & 68.51 & 0.0282 & 32.21 & 412.38 & 0.1198 & 0.2906 & 80.9 \\ \text { S05 } & 27.8 & 0.1 & 100 & 42.95 & 0.0177 & 25.67 & 380.17 & 0.0916 & 0.2410 & 74.6 \\ \text { S06 } & 31.5 & 0.1 & 100 & 42.12 & 0.0173 & 29.41 & 354.50 & 0.0740 & 0.2086 & 69.6 \\ \text { S07 } & 31.2 & 0.1 & 100 & 34.55 & 0.0142 & 29.49 & 325.08 & 0.0566 & 0.1742 & 63.8 \\ \text { S08 } & 29.3 & 0.1 & 100 & 26.47 & 0.0109 & 27.99 & 295.59 & 0.0424 & 0.1435 & 58.0 \\ \text { S09 } & 32.6 & 0.1 & 100 & 22.80 & 0.0094 & 31.47 & 267.61 & 0.0315 & 0.1178 & 52.5\end{array}$




$\begin{array}{lrrrrrrrrrr}\text { S10 } & 26.6 & 0.1 & 100 & 15.11 & 0.0062 & 25.85 & 236.13 & 0.0221 & 0.0938 & 46.3 \\ \text { S11 } & 32.1 & 0.1 & 100 & 14.14 & 0.0058 & 31.40 & 210.28 & 0.0159 & 0.0758 & 41.3 \\ \text { S12 } & 32.0 & 0.1 & 100 & 10.17 & 0.0042 & 31.50 & 178.88 & 0.0101 & 0.0565 & 35.1 \\ \text { S13 } & 26.9 & 0.1 & 100 & 6.30 & 0.0026 & 26.59 & 147.39 & 0.0059 & 0.0402 & 28.9 \\ \text { S14 } & 32.0 & 0.1 & 100 & 4.52 & 0.0019 & 31.78 & 120.80 & 0.0033 & 0.0276 & 23.7 \\ \text { S15 } & 26.9 & 0.1 & 100 & 2.06 & 0.0008 & 26.80 & 89.02 & 0.0015 & 0.0166 & 17.5 \\ \text { S16 } & 31.7 & 0.1 & 100 & 1.24 & 0.0005 & 31.64 & 62.22 & 0.0006 & 0.0101 & 12.2 \\ \text { S17 } & 30.6 & 0.1 & 100 & 0.29 & 0.0001 & 30.59 & 30.59 & 0.0001 & 0.0039 & 6.1\end{array}$

NFM21 $-26^{\circ} \mathrm{C}$ freezing, $25^{\circ} \mathrm{C}$ melting

$\begin{array}{lrrrrrrrrrr} & \text { MS } & \text { VS } & \text { DN } & \text { ICP } & \text { Mol Mg } & \text { MW } & & & & \\ \text { S } & 533.3 & 0.5 & 1000 & 10.70 & 0.2201 & 506.81 & & & & \\ \text { L } & 0.0 & 0.25 & 1000 & 0.00 & 0.0000 & 0.00 & & & & \\ \text { R1 } & 29.7 & 0.1 & 100 & 2.89 & 0.0012 & 29.56 & & & & \\ \text { RC } & 202.3 & 0.25 & 100 & 0.01 & 0.0000 & 202.30 & \text { CMW } & \text { CMM } & \text { CMOL } & \text { WR } \\ \text { S01 } & 27.4 & 0.1 & 100 & 85.10 & 0.0350 & 23.19 & 491.88 & 0.2162 & 0.4395 & 97.1 \\ \text { S02 } & 29.1 & 0.1 & 100 & 84.29 & 0.0347 & 24.93 & 468.70 & 0.1812 & 0.3865 & 92.5 \\ \text { S03 } & 26.3 & 0.1 & 100 & 64.11 & 0.0264 & 23.13 & 443.77 & 0.1465 & 0.3301 & 87.6 \\ \text { S04 } & 31.1 & 0.1 & 100 & 60.51 & 0.0249 & 28.10 & 420.64 & 0.1201 & 0.2855 & 83.0 \\ \text { S05 } & 23.8 & 0.1 & 100 & 42.05 & 0.0173 & 21.72 & 392.54 & 0.0952 & 0.2425 & 77.5 \\ \text { S06 } & 23.7 & 0.1 & 100 & 37.58 & 0.0155 & 21.84 & 370.82 & 0.0779 & 0.2101 & 73.2 \\ \text { S07 } & 28.5 & 0.1 & 100 & 35.30 & 0.0145 & 26.75 & 348.98 & 0.0624 & 0.1789 & 68.9 \\ \text { S08 } & 26.5 & 0.1 & 100 & 28.24 & 0.0116 & 25.10 & 322.23 & 0.0479 & 0.1487 & 63.6 \\ \text { S09 } & 37.8 & 0.1 & 100 & 31.39 & 0.0129 & 36.25 & 297.13 & 0.0363 & 0.1222 & 58.6 \\ \text { S10 } & 29.0 & 0.1 & 100 & 16.15 & 0.0066 & 28.20 & 260.89 & 0.0234 & 0.0896 & 51.5 \\ \text { S11 } & 26.3 & 0.1 & 100 & 12.14 & 0.0050 & 25.70 & 232.69 & 0.0167 & 0.0719 & 45.9 \\ \text { S12 } & 31.5 & 0.1 & 100 & 10.90 & 0.0045 & 30.96 & 206.99 & 0.0117 & 0.0567 & 40.8 \\ \text { S13 } & 25.3 & 0.1 & 100 & 6.37 & 0.0026 & 24.98 & 176.03 & 0.0073 & 0.0412 & 34.7 \\ \text { S14 } & 25.2 & 0.1 & 100 & 4.68 & 0.0019 & 24.97 & 151.04 & 0.0046 & 0.0307 & 29.8 \\ \text { S15 } & 29.4 & 0.1 & 100 & 3.25 & 0.0013 & 29.24 & 126.07 & 0.0027 & 0.0215 & 24.9 \\ \text { S16 } & 31.2 & 0.1 & 100 & 2.18 & 0.0009 & 31.09 & 96.83 & 0.0014 & 0.0142 & 19.1 \\ \text { S17 } & 34.3 & 0.1 & 100 & 0.94 & 0.0004 & 34.25 & 65.74 & 0.0005 & 0.0073 & 13.0 \\ \text { S18 } & 31.5 & 0.1 & 100 & 0.23 & 0.0001 & 31.49 & 31.49 & 0.0001 & 0.0030 & 6.2\end{array}$




\section{Appendix D: Raw Data for Natural Freezing and $3{ }^{\circ} \mathrm{C}$ Melting Experiments}

The experiments performed here correspond with the results show in Section 5.4, and in Figure 10 and Figure 11 . Solid frozen at -2 and $-10{ }^{\circ} \mathrm{C}$ was melted on a grille at $3{ }^{\circ} \mathrm{C}$.

\section{Legend:}

S Solid produced via freezing

L Liquid remaining after solid has been removed

R1 DI water rinse of solid produced

RC DI water rinse of freezing container

S0X Melt solution, with S01 being the first solution melted, S02 being the second, and so on

MS Mass of item in grams

VS Volume of item in litres

DN Dilution factor

ICP ICP measurement of item in milligrams per kilogram

Mol Mg Moles of magnesium in item

MW Mass of water in item in grams

CMW Cumulative mass of water, summing SOX and all subsequent values in grams

CMM Cumulative moles of magnesium, summing SOX and all subsequent values in

\section{moles}

CMOL Cumulative molality of SOX and all subsequent values in molal

WR Water recovered from SOX and all subsequent values as a percentage

$\begin{array}{lrrrrrrrrrr}\text { NFFM1 } & -2{ }^{\circ} \mathrm{C} \text { freezing, } 3{ }^{\circ} \mathrm{C} \text { melting } & & & & & & & \\ \text { S } & \text { MS } & \text { VS } & \text { DN } & \text { ICP } & \text { Mol Mg } & \text { MW } & & & & \\ \text { S } & 530.9 & 0.5 & 1000 & 11.25 & 0.2315 & 503.03 & & & & \\ \text { L } & 129.5 & 0.25 & 1000 & 12.35 & 0.1271 & 114.20 & & & & \\ \text { R1 } & 107.6 & 0.25 & 100 & 21.79 & 0.0224 & 104.90 & & & & \\ \text { RC } & 199.2 & 0.25 & 100 & 0.29 & 0.0003 & 199.16 & \text { CMW } & \text { CMM } & \text { CMOL } & \text { WR } \\ \text { S01 } & 26.4 & 0.1 & 100 & 41.70 & 0.0172 & 24.33 & 305.47 & 0.0759 & 0.2483 & 60.7 \\ \text { S02 } & 28.6 & 0.1 & 100 & 33.10 & 0.0136 & 26.96 & 281.14 & 0.0587 & 0.2088 & 55.9 \\ \text { S03 } & 27.3 & 0.1 & 100 & 24.83 & 0.0102 & 26.07 & 254.17 & 0.0451 & 0.1773 & 50.5 \\ \text { S04 } & 24.5 & 0.1 & 100 & 18.89 & 0.0078 & 23.56 & 228.10 & 0.0349 & 0.1528 & 45.3 \\ \text { S05 } & 26.3 & 0.1 & 100 & 17.59 & 0.0072 & 25.43 & 204.54 & 0.0271 & 0.1324 & 40.7 \\ \text { S06 } & 28.7 & 0.1 & 100 & 16.11 & 0.0066 & 27.90 & 179.11 & 0.0199 & 0.1108 & 35.6 \\ \text { S07 } & 25.7 & 0.1 & 100 & 9.93 & 0.0041 & 25.21 & 151.21 & 0.0132 & 0.0875 & 30.1 \\ \text { S08 } & 24.2 & 0.1 & 100 & 7.06 & 0.0029 & 23.85 & 126.00 & 0.0091 & 0.0725 & 25.0 \\ \text { S09 } & 34.2 & 0.1 & 100 & 8.74 & 0.0036 & 33.77 & 102.15 & 0.0062 & 0.0610 & 20.3\end{array}$




$\begin{array}{lrllllllllr}\text { S10 } & 24.8 & 0.1 & 100 & 4.06 & 0.0017 & 24.60 & 68.38 & 0.0026 & 0.0385 & 13.6 \\ \text { S11 } & 22.0 & 0.1 & 100 & 1.86 & 0.0008 & 21.91 & 43.78 & 0.0010 & 0.0220 & 8.7 \\ \text { S12 } & 21.9 & 0.1 & 100 & 0.48 & 0.0002 & 21.88 & 21.88 & 0.0002 & 0.0091 & 4.3\end{array}$

NFFM2 $-2{ }^{\circ} \mathrm{C}$ freezing, $3{ }^{\circ} \mathrm{C}$ melting

$\begin{array}{lrrrrrrrrrr} & \text { MS } & \text { VS } & \text { DN } & \text { ICP } & \text { Mol Mg } & \text { MW } & & & & \\ \text { S } & 531.0 & 0.5 & 1000 & 10.45 & 0.2151 & 505.11 & & & & \\ \text { L } & 143.9 & 0.25 & 1000 & 12.99 & 0.1336 & 127.81 & & & & \\ \text { R1 } & 56.3 & 0.25 & 100 & 16.09 & 0.0166 & 54.31 & & & & \\ \text { RC } & 197.7 & 0.25 & 100 & 0.15 & 0.0002 & 197.68 & \text { CMW } & \text { CMM } & \text { CMOL } & \text { WR } \\ \text { S01 } & 23.3 & 0.1 & 100 & 38.34 & 0.0158 & 21.40 & 308.56 & 0.0776 & 0.2514 & 61.1 \\ \text { S02 } & 24.7 & 0.1 & 100 & 30.13 & 0.0124 & 23.21 & 287.16 & 0.0618 & 0.2152 & 56.9 \\ \text { S03 } & 27.6 & 0.1 & 100 & 26.68 & 0.0110 & 26.28 & 263.95 & 0.0494 & 0.1872 & 52.3 \\ \text { S04 } & 32.0 & 0.1 & 100 & 25.69 & 0.0106 & 30.73 & 237.67 & 0.0384 & 0.1617 & 47.1 \\ \text { S05 } & 32.8 & 0.1 & 100 & 21.31 & 0.0088 & 31.74 & 206.95 & 0.0279 & 0.1346 & 41.0 \\ \text { S06 } & 24.6 & 0.1 & 100 & 13.26 & 0.0055 & 23.94 & 175.20 & 0.0191 & 0.1090 & 34.7 \\ \text { S07 } & 24.1 & 0.1 & 100 & 10.11 & 0.0042 & 23.60 & 151.26 & 0.0136 & 0.0902 & 29.9 \\ \text { S08 } & 23.2 & 0.1 & 100 & 7.94 & 0.0033 & 22.81 & 127.66 & 0.0095 & 0.0743 & 25.3 \\ \text { S09 } & 23.2 & 0.1 & 100 & 7.11 & 0.0029 & 22.85 & 104.85 & 0.0062 & 0.0593 & 20.8 \\ \text { S10 } & 25.1 & 0.1 & 100 & 5.29 & 0.0022 & 24.84 & 82.00 & 0.0033 & 0.0401 & 16.2 \\ \text { S11 } & 18.9 & 0.1 & 100 & 1.79 & 0.0007 & 18.81 & 57.17 & 0.0011 & 0.0194 & 11.3 \\ \text { S12 } & 20.1 & 0.1 & 100 & 0.58 & 0.0002 & 20.07 & 38.36 & 0.0004 & 0.0097 & 7.6 \\ \text { S13 } & 18.3 & 0.1 & 100 & 0.33 & 0.0001 & 18.28 & 18.28 & 0.0001 & 0.0075 & 3.6\end{array}$

NFFM3 $-2{ }^{\circ} \mathrm{C}$ freezing, $3^{\circ} \mathrm{C}$ melting

$\begin{array}{lrrrrrrrrrr} & \text { MS } & \text { VS } & \text { DN } & \text { ICP } & \text { Mol Mg } & \text { MW } & & & & \\ \text { S } & 533.1 & 0.5 & 1000 & 10.82 & 0.2226 & 506.31 & & & & \\ \text { L } & 133.5 & 0.25 & 1000 & 12.91 & 0.1328 & 117.52 & & & & \\ \text { R1 } & 60.9 & 0.25 & 100 & 17.16 & 0.0177 & 58.78 & & & & \\ \text { RC } & 200.6 & 0.25 & 100 & 0.25 & 0.0003 & 200.57 & \text { CMW } & \text { CMM } & \text { CMOL } & \text { WR } \\ \text { S01 } & 28.6 & 0.1 & 100 & 47.98 & 0.0197 & 26.22 & 322.61 & 0.0796 & 0.2468 & 63.7 \\ \text { S02 } & 33.3 & 0.1 & 100 & 38.60 & 0.0159 & 31.39 & 296.39 & 0.0599 & 0.2021 & 58.5 \\ \text { S03 } & 30.9 & 0.1 & 100 & 26.81 & 0.0110 & 29.57 & 265.00 & 0.0440 & 0.1661 & 52.3 \\ \text { S04 } & 26.3 & 0.1 & 100 & 19.22 & 0.0079 & 25.35 & 235.43 & 0.0330 & 0.1401 & 46.5 \\ \text { S05 } & 30.4 & 0.1 & 100 & 18.47 & 0.0076 & 29.49 & 210.08 & 0.0251 & 0.1193 & 41.5 \\ \text { S06 } & 25.4 & 0.1 & 100 & 12.74 & 0.0052 & 24.77 & 180.60 & 0.0175 & 0.0967 & 35.7 \\ \text { S07 } & 27.8 & 0.1 & 100 & 11.53 & 0.0047 & 27.23 & 155.83 & 0.0122 & 0.0785 & 30.8 \\ \text { S08 } & 22.8 & 0.1 & 100 & 6.79 & 0.0028 & 22.46 & 128.60 & 0.0075 & 0.0582 & 25.4 \\ \text { S09 } & 23.5 & 0.1 & 100 & 5.43 & 0.0022 & 23.23 & 106.14 & 0.0047 & 0.0442 & 21.0 \\ \text { S10 } & 20.2 & 0.1 & 100 & 3.36 & 0.0014 & 20.03 & 82.90 & 0.0025 & 0.0297 & 16.4 \\ \text { S11 } & 22.2 & 0.1 & 100 & 1.85 & 0.0008 & 22.11 & 62.87 & 0.0011 & 0.0171 & 12.4 \\ \text { S12 } & 17.8 & 0.1 & 100 & 0.54 & 0.0002 & 17.77 & 40.76 & 0.0003 & 0.0078 & 8.1 \\ \text { S13 } & 23.0 & 0.1 & 100 & 0.22 & 0.0001 & 22.99 & 22.99 & 0.0001 & 0.0040 & 4.5\end{array}$




\begin{tabular}{lrrrrrrrrrr} 
NFFM4 & $-2{ }^{\circ} \mathrm{C}$ freezing, $3{ }^{\circ} \mathrm{C}$ melting & \multicolumn{1}{c}{ ICP } & Mol Mg & MW & & & & \\
& MS & VS & DN & ICP & & & & \\
S & 530.9 & 0.5 & 1000 & 11.60 & 0.2386 & 502.18 & & & & \\
L & 147.3 & 0.25 & 1000 & 13.47 & 0.1386 & 130.62 & & & & \\
R1 & 55.9 & 0.25 & 100 & 14.83 & 0.0153 & 54.06 & & & & \\
RC & 199.6 & 0.25 & 100 & 0.15 & 0.0002 & 199.58 & CMW & CMM & CMOL & WR \\
S01 & 25.3 & 0.1 & 100 & 39.96 & 0.0164 & 23.32 & 309.44 & 0.0728 & 0.2351 & 61.6 \\
S02 & 27.9 & 0.1 & 100 & 34.51 & 0.0142 & 26.19 & 286.12 & 0.0563 & 0.1968 & 57.0 \\
S03 & 25.5 & 0.1 & 100 & 25.53 & 0.0105 & 24.24 & 259.93 & 0.0421 & 0.1621 & 51.8 \\
S04 & 48.3 & 0.1 & 100 & 35.87 & 0.0148 & 46.52 & 235.69 & 0.0316 & 0.1342 & 46.9 \\
S05 & 26.1 & 0.1 & 100 & 13.71 & 0.0056 & 25.42 & 189.17 & 0.0169 & 0.0891 & 37.7 \\
S06 & 29.2 & 0.1 & 100 & 11.38 & 0.0047 & 28.64 & 163.75 & 0.0112 & 0.0685 & 32.6 \\
S07 & 24.0 & 0.1 & 100 & 6.58 & 0.0027 & 23.67 & 135.11 & 0.0065 & 0.0484 & 26.9 \\
S08 & 27.1 & 0.1 & 100 & 5.04 & 0.0021 & 26.85 & 111.44 & 0.0038 & 0.0344 & 22.2 \\
S09 & 22.6 & 0.1 & 100 & 2.45 & 0.0010 & 22.48 & 84.59 & 0.0018 & 0.0207 & 16.8 \\
S10 & 22.4 & 0.1 & 100 & 1.20 & 0.0005 & 22.34 & 62.11 & 0.0007 & 0.0120 & 12.4 \\
S11 & 17.4 & 0.1 & 100 & 0.33 & 0.0001 & 17.38 & 39.77 & 0.0003 & 0.0063 & 7.9 \\
S12 & 22.4 & 0.1 & 100 & 0.28 & 0.0001 & 22.39 & 22.39 & 0.0001 & 0.0052 & 4.5
\end{tabular}

NFFM5 $-2{ }^{\circ} \mathrm{C}$ freezing, $3{ }^{\circ} \mathrm{C}$ melting

$\begin{array}{lrrrrrrrrrr} & \text { MS } & \text { VS } & \text { DN } & \text { ICP } & \text { Mol Mg } & \text { MW } & & & & \\ \text { S } & 535.3 & 0.5 & 1000 & 10.39 & 0.2137 & 509.58 & & & & \\ \text { L } & 177.0 & 0.25 & 1000 & 12.17 & 0.1251 & 161.94 & & & & \\ \text { R1 } & 62.9 & 0.25 & 100 & 17.49 & 0.0180 & 60.73 & & & & \\ \text { RC } & 194.7 & 0.25 & 100 & 0.12 & 0.0001 & 194.69 & \text { CMW } & \text { CMM } & \text { CMOL } & \text { WR } \\ \text { S01 } & 27.7 & 0.1 & 100 & 36.96 & 0.0152 & 25.87 & 287.29 & 0.0533 & 0.1854 & 56.4 \\ \text { S02 } & 26.2 & 0.1 & 100 & 27.32 & 0.0112 & 24.85 & 249.06 & 0.0344 & 0.1380 & 48.9 \\ \text { S03 } & 21.9 & 0.1 & 100 & 22.39 & 0.0092 & 20.79 & 218.62 & 0.0231 & 0.1057 & 42.9 \\ \text { S04 } & 36.5 & 0.1 & 100 & 29.29 & 0.0121 & 35.05 & 191.06 & 0.0153 & 0.0802 & 37.5 \\ \text { S05 } & 25.2 & 0.1 & 100 & 15.55 & 0.0064 & 24.43 & 159.12 & 0.0090 & 0.0563 & 31.2 \\ \text { S06 } & 40.9 & 0.1 & 100 & 18.06 & 0.0074 & 40.01 & 130.30 & 0.0050 & 0.0386 & 25.6 \\ \text { S07 } & 44.5 & 0.1 & 100 & 10.82 & 0.0045 & 43.96 & 104.07 & 0.0028 & 0.0266 & 20.4 \\ \text { S08 } & 32.5 & 0.1 & 100 & 3.15 & 0.0013 & 32.34 & 77.44 & 0.0013 & 0.0169 & 15.2 \\ \text { S09 } & 27.1 & 0.1 & 100 & 0.77 & 0.0003 & 27.06 & 51.34 & 0.0005 & 0.0101 & 10.1 \\ \text { S10 } & 28.0 & 0.1 & 100 & 0.11 & 0.0000 & 27.99 & 26.68 & 0.0001 & 0.0055 & 5.2\end{array}$

NFFM6 $-10^{\circ} \mathrm{C}$ freezing, $3^{\circ} \mathrm{C}$ melting

$\begin{array}{lrrrrrrrrr} & \text { MS } & \text { VS } & \text { DN } & \text { ICP } & \text { Mol Mg } & \text { MW } & & & \\ \text { S } & 532.0 & 0.5 & 1000 & 11.89 & 0.2446 & 502.55 & & & \\ \text { L } & 0.0 & 0.25 & 1000 & 0.00 & 0.0000 & 0.00 & & & \\ \text { R1 } & 0.0 & 0.25 & 100 & 0.00 & 0.0000 & 0.00 & & & \\ \text { RC } & 198.6 & 0.25 & 100 & 0.10 & 0.0001 & 198.59 & \text { CMW } & \text { CMM } & \text { CMOL WR }\end{array}$




$\begin{array}{lrlllllllll}\text { S01 } & 29.0 & 0.1 & 100 & 102.15 & 0.0420 & 23.94 & 474.71 & 0.2242 & 0.4724 & 94.5 \\ \text { S02 } & 31.4 & 0.1 & 100 & 100.49 & 0.0413 & 26.42 & 450.77 & 0.1822 & 0.4042 & 89.7 \\ \text { S03 } & 30.6 & 0.1 & 100 & 72.02 & 0.0296 & 27.03 & 424.34 & 0.1409 & 0.3320 & 84.4 \\ \text { S04 } & 27.6 & 0.1 & 100 & 52.13 & 0.0214 & 25.02 & 397.31 & 0.1112 & 0.2800 & 79.1 \\ \text { S05 } & 34.3 & 0.1 & 100 & 54.07 & 0.0222 & 31.62 & 372.29 & 0.0898 & 0.2412 & 74.1 \\ \text { S06 } & 29.5 & 0.1 & 100 & 38.18 & 0.0157 & 27.61 & 340.67 & 0.0675 & 0.1982 & 67.8 \\ \text { S07 } & 33.3 & 0.1 & 100 & 35.55 & 0.0146 & 31.54 & 313.06 & 0.0518 & 0.1656 & 62.3 \\ \text { S08 } & 33.8 & 0.1 & 100 & 28.57 & 0.0118 & 32.39 & 281.52 & 0.0372 & 0.1321 & 56.0 \\ \text { S09 } & 33.6 & 0.1 & 100 & 21.83 & 0.0090 & 32.52 & 249.14 & 0.0254 & 0.1021 & 49.6 \\ \text { S10 } & 31.4 & 0.1 & 100 & 15.12 & 0.0062 & 30.65 & 216.62 & 0.0165 & 0.0760 & 43.1 \\ \text { S11 } & 33.2 & 0.1 & 100 & 10.79 & 0.0044 & 32.67 & 185.97 & 0.0102 & 0.0551 & 37.0 \\ \text { S12 } & 31.9 & 0.1 & 100 & 6.44 & 0.0027 & 31.58 & 153.30 & 0.0058 & 0.0379 & 30.5 \\ \text { S13 } & 26.6 & 0.1 & 100 & 3.57 & 0.0015 & 26.42 & 121.72 & 0.0032 & 0.0259 & 24.2 \\ \text { S14 } & 27.8 & 0.1 & 100 & 2.14 & 0.0009 & 27.69 & 95.30 & 0.0017 & 0.0177 & 19.0 \\ \text { S15 } & 28.5 & 0.1 & 100 & 1.26 & 0.0005 & 28.44 & 67.60 & 0.0008 & 0.0119 & 13.5 \\ \text { S16 } & 21.0 & 0.1 & 100 & 0.52 & 0.0002 & 20.97 & 39.17 & 0.0003 & 0.0073 & 7.8 \\ \text { S17 } & 18.2 & 0.1 & 100 & 0.18 & 0.0001 & 18.19 & 18.19 & 0.0001 & 0.0040 & 3.6\end{array}$

NFFM7 $-10{ }^{\circ} \mathrm{C}$ freezing, $3{ }^{\circ} \mathrm{C}$ melting

$\begin{array}{lrrrrrrrrrr} & \text { MS } & \text { VS } & \text { DN } & \text { ICP } & \text { Mol Mg } & \text { MW } & & & & \\ \text { S } & 533.0 & 0.5 & 1000 & 11.11 & 0.2286 & 505.48 & & & & \\ \text { L } & 7.7 & 0.1 & 1000 & 2.72 & 0.0112 & 6.35 & & & & \\ \text { R1 } & 0.0 & 0.25 & 100 & 0.00 & 0.0000 & 0.00 & & & & \\ \text { RC } & 201.5 & 0.25 & 100 & 1.22 & 0.0013 & 201.35 & \text { CMW } & \text { CMM } & \text { CMOL } & \text { WR } \\ \text { S01 } & 34.7 & 0.1 & 100 & 102.61 & 0.0422 & 29.62 & 481.00 & 0.2085 & 0.4335 & 95.2 \\ \text { S02 } & 33.5 & 0.1 & 100 & 84.42 & 0.0347 & 29.32 & 451.39 & 0.1663 & 0.3684 & 89.3 \\ \text { S03 } & 30.7 & 0.1 & 100 & 64.58 & 0.0266 & 27.50 & 422.07 & 0.1315 & 0.3117 & 83.5 \\ \text { S04 } & 26.4 & 0.1 & 100 & 46.54 & 0.0191 & 24.10 & 394.56 & 0.1050 & 0.2660 & 78.1 \\ \text { S05 } & 27.7 & 0.1 & 100 & 42.06 & 0.0173 & 25.62 & 370.47 & 0.0858 & 0.2317 & 73.3 \\ \text { S06 } & 28.3 & 0.1 & 100 & 35.97 & 0.0148 & 26.52 & 344.85 & 0.0685 & 0.1987 & 68.2 \\ \text { S07 } & 29.0 & 0.1 & 100 & 30.96 & 0.0127 & 27.47 & 318.33 & 0.0537 & 0.1687 & 63.0 \\ \text { S08 } & 27.7 & 0.1 & 100 & 24.20 & 0.0100 & 26.50 & 290.87 & 0.0410 & 0.1409 & 57.5 \\ \text { S09 } & 29.2 & 0.1 & 100 & 20.62 & 0.0085 & 28.18 & 264.37 & 0.0310 & 0.1173 & 52.3 \\ \text { S10 } & 29.3 & 0.1 & 100 & 16.21 & 0.0067 & 28.50 & 236.19 & 0.0225 & 0.0954 & 46.7 \\ \text { S11 } & 29.7 & 0.1 & 100 & 13.89 & 0.0057 & 29.01 & 207.69 & 0.0159 & 0.0764 & 41.1 \\ \text { S12 } & 27.5 & 0.1 & 100 & 9.35 & 0.0038 & 27.04 & 178.68 & 0.0102 & 0.0568 & 35.3 \\ \text { S13 } & 19.7 & 0.1 & 100 & 4.80 & 0.0020 & 19.46 & 151.64 & 0.0063 & 0.0416 & 30.0 \\ \text { S14 } & 26.9 & 0.1 & 100 & 4.74 & 0.0020 & 26.67 & 132.18 & 0.0043 & 0.0328 & 26.1 \\ \text { S15 } & 21.0 & 0.1 & 100 & 2.43 & 0.0010 & 20.88 & 105.51 & 0.0024 & 0.0226 & 20.9 \\ \text { S16 } & 20.3 & 0.1 & 100 & 1.61 & 0.0007 & 20.22 & 84.63 & 0.0014 & 0.0163 & 16.7 \\ \text { S17 } & 25.6 & 0.1 & 100 & 1.23 & 0.0005 & 25.54 & 64.41 & 0.0007 & 0.0112 & 12.7 \\ \text { S18 } & 19.9 & 0.1 & 100 & 0.36 & 0.0001 & 19.88 & 38.87 & 0.0002 & 0.0055 & 7.7 \\ \text { S19 } & 19.0 & 0.1 & 100 & 0.16 & 0.0001 & 18.99 & 18.99 & 0.0001 & 0.0035 & 3.8\end{array}$




\section{Appendix E: Raw Data for Natural Freezing and Other Melting Experiments}

The experiments performed here correspond with the results show in Section 5.5.

\section{Legend:}

S Solid produced via freezing

L Liquid remaining after solid has been removed

R1 DI water rinse of solid produced

RC DI water rinse of freezing container

S0X Melt solution, with S01 being the first solution melted, S02 being the second, and so on

$\begin{array}{ll}\text { MS } & \text { Mass of item in grams } \\ \text { VS } & \text { Volume of item in litres } \\ \text { DN } & \text { Dilution factor } \\ \text { ICP } & \text { ICP measurement of item in milligrams per kilogram } \\ \text { Mol Mg } & \text { Moles of magnesium in item } \\ \text { MW } & \text { Mass of water in item in grams } \\ \text { CMW } & \text { Cumulative mass of water, summing SOX and all subsequent values in grams } \\ \text { CMM } & \text { Cumulative moles of magnesium, summing SOX and all subsequent values in } \\ & \text { moles } \\ \text { CMOL } & \text { Cumulative molality of SOX and all subsequent values in molal } \\ \text { WR } & \text { Water recovered from SOX and all subsequent values as a percentage }\end{array}$

Case A: $\quad$ Freeze at air temperature of $-2{ }^{\circ} \mathrm{C}$, remove solid and freeze at $-26{ }^{\circ} \mathrm{C}$ for 24 hours before melting at room temperature. See Section 5.5.1 and Figure 12.

\begin{tabular}{|c|c|c|c|c|c|c|c|c|c|c|}
\hline CA1 & $-2{ }^{\circ} \mathrm{C}$ free & $26^{\circ} \mathrm{C}$ & ze, 25 & elting & & & & & & \\
\hline & MS & VS & DN & ICP & Mol Mg & MW & & & & \\
\hline$S$ & 532.9 & 0.5 & 1000 & 11.19 & 0.2302 & 505.19 & & & & \\
\hline L & 173.4 & 0.25 & 1000 & 13.07 & 0.1344 & 157.22 & & & & \\
\hline $\mathrm{R} 1$ & 0.0 & 0.25 & 100 & 0.30 & 0.0003 & -0.04 & & & & \\
\hline $\mathrm{RC}$ & 203.8 & 0.25 & 100 & 0.30 & 0.0003 & 203.76 & CMW & CMM & CMOL & WR \\
\hline S01 & 26.9 & 0.1 & 100 & 78.38 & 0.0322 & 23.02 & 333.38 & 0.0840 & 0.2521 & 66.0 \\
\hline SO2 & 27.4 & 0.1 & 100 & 36.77 & 0.0151 & 25.58 & 310.37 & 0.0518 & 0.1669 & 61.4 \\
\hline SO3 & 53.0 & 0.1 & 100 & 43.25 & 0.0178 & 50.86 & 284.79 & 0.0367 & 0.1287 & 56.4 \\
\hline SO4 & 28.1 & 0.1 & 100 & 13.28 & 0.0055 & 27.44 & 233.93 & 0.0189 & 0.0807 & 46.3 \\
\hline S05 & 23.8 & 0.1 & 100 & 16.16 & 0.0066 & 23.00 & 206.49 & 0.0134 & 0.0649 & 40.9 \\
\hline
\end{tabular}




$\begin{array}{lrlllllllll}\text { S06 } & 40.8 & 0.1 & 100 & 8.95 & 0.0037 & 40.36 & 183.49 & 0.0068 & 0.0368 & 36.3 \\ \text { S07 } & 50.0 & 0.1 & 100 & 2.94 & 0.0012 & 49.85 & 143.13 & 0.0031 & 0.0215 & 28.3 \\ \text { S08 } & 24.0 & 0.1 & 100 & 2.31 & 0.0009 & 23.89 & 93.28 & 0.0019 & 0.0200 & 18.5 \\ \text { S09 } & 25.8 & 0.1 & 100 & 0.90 & 0.0004 & 25.76 & 69.39 & 0.0009 & 0.0132 & 13.7 \\ \text { S10 } & 22.0 & 0.1 & 100 & 0.40 & 0.0002 & 21.98 & 43.63 & 0.0005 & 0.0125 & 8.6 \\ \text { S11 } & 21.7 & 0.1 & 100 & 0.93 & 0.0004 & 21.65 & 21.65 & 0.0004 & 0.0176 & 4.3 \\ \text { S12 } & 27.0 & 0.1 & 100 & 0.44 & 0.0002 & 26.98 & 48.63 & 0.0006 & 0.0116 & 9.6 \\ \text { S13 } & 28.1 & 0.1 & 100 & 0.18 & 0.0001 & 28.09 & 76.72 & 0.0006 & 0.0083 & 15.2\end{array}$

CA2 $-2{ }^{\circ} \mathrm{C}$ freeze, $-26{ }^{\circ} \mathrm{C}$ freeze, $25{ }^{\circ} \mathrm{C}$ melting

$\begin{array}{lrrrrrrrrrr} & \text { MS } & \text { VS } & \text { DN } & \text { ICP } & \text { Mol Mg } & \text { MW } & & & & \\ \text { S } & 533.5 & 0.5 & 1000 & 10.85 & 0.2233 & 506.63 & & & & \\ \text { L } & 114.7 & 0.25 & 1000 & 10.22 & 0.1051 & 102.05 & & & & \\ \text { R1 } & 0.0 & 0.25 & 100 & 0.00 & 0.0000 & 0.00 & & & & \\ \text { RC } & 211.8 & 0.25 & 100 & 0.27 & 0.0003 & 211.77 & \text { CMW } & \text { CMM } & \text { CMOL } & \text { WR } \\ \text { S01 } & 26.9 & 0.1 & 100 & 72.32 & 0.0298 & 23.32 & 373.04 & 0.1218 & 0.3266 & 73.6 \\ \text { S02 } & 30.3 & 0.1 & 100 & 58.91 & 0.0242 & 27.38 & 349.72 & 0.0921 & 0.2633 & 69.0 \\ \text { S03 } & 28.1 & 0.1 & 100 & 42.55 & 0.0175 & 25.99 & 322.34 & 0.0678 & 0.2104 & 63.6 \\ \text { S04 } & 27.1 & 0.1 & 100 & 33.97 & 0.0140 & 25.42 & 296.34 & 0.0503 & 0.1698 & 58.5 \\ \text { S05 } & 24.8 & 0.1 & 100 & 24.57 & 0.0101 & 23.58 & 270.92 & 0.0364 & 0.1342 & 53.5 \\ \text { S06 } & 25.6 & 0.1 & 100 & 18.60 & 0.0077 & 24.68 & 247.34 & 0.0262 & 0.1061 & 48.8 \\ \text { S07 } & 36.0 & 0.1 & 100 & 18.43 & 0.0076 & 35.09 & 222.66 & 0.0186 & 0.0835 & 44.0 \\ \text { S08 } & 31.8 & 0.1 & 100 & 11.19 & 0.0046 & 31.25 & 187.58 & 0.0110 & 0.0587 & 37.0 \\ \text { S09 } & 31.6 & 0.1 & 100 & 7.18 & 0.0030 & 31.24 & 156.33 & 0.0064 & 0.0409 & 30.9 \\ \text { S10 } & 40.8 & 0.1 & 100 & 5.04 & 0.0021 & 40.55 & 125.09 & 0.0034 & 0.0276 & 24.7 \\ \text { S11 } & 24.0 & 0.1 & 100 & 1.82 & 0.0007 & 23.91 & 84.53 & 0.0014 & 0.0162 & 16.7 \\ \text { S12 } & 21.9 & 0.1 & 100 & 0.97 & 0.0004 & 21.85 & 60.62 & 0.0006 & 0.0103 & 12.0 \\ \text { S13 } & 20.8 & 0.1 & 100 & 0.48 & 0.0002 & 20.78 & 38.77 & 0.0002 & 0.0059 & 7.7 \\ \text { S14 } & 18.0 & 0.1 & 100 & 0.07 & 0.0000 & 18.00 & 18.00 & 0.0000 & 0.0017 & 3.6\end{array}$

\begin{tabular}{|c|c|c|c|c|c|c|c|c|c|c|}
\hline \multirow[t]{2}{*}{ CA3 } & \multicolumn{6}{|c|}{$-2{ }^{\circ} \mathrm{C}$ freeze, $-26{ }^{\circ} \mathrm{C}$ freeze, $25{ }^{\circ} \mathrm{C}$ melting } & & & & \\
\hline & MS & VS & DN & ICP & Mol Mg & MW & & & & \\
\hline$S$ & 532.6 & 0.5 & 1000 & 11.34 & 0.2333 & 504.52 & & & & \\
\hline $\mathrm{L}$ & 194.4 & 0.25 & 1000 & 14.31 & 0.1472 & 176.69 & & & & \\
\hline $\mathrm{R} 1$ & 0.0 & 0.25 & 100 & 0.00 & 0.0000 & 0.00 & & & & \\
\hline $\mathrm{RC}$ & 210.7 & 0.25 & 100 & 100.00 & 0.0002 & 210.68 & CMW & CMM & CMOL & WR \\
\hline S01 & 28.3 & 0.1 & 100 & 100.00 & 0.0264 & 25.12 & 293.32 & 0.0805 & 0.2743 & 58.1 \\
\hline SO2 & 33.5 & 0.1 & 100 & 100.00 & 0.0217 & 30.88 & 268.19 & 0.0540 & 0.2015 & 53.2 \\
\hline S03 & 29.5 & 0.1 & 100 & 100.00 & 0.0127 & 27.97 & 237.31 & 0.0323 & 0.1362 & 47.0 \\
\hline SO4 & 26.3 & 0.1 & 100 & 100.00 & 0.0071 & 25.45 & 209.34 & 0.0196 & 0.0937 & 41.5 \\
\hline S05 & 31.3 & 0.1 & 100 & 100.00 & 0.0052 & 30.67 & 183.89 & 0.0125 & 0.0680 & 36.4 \\
\hline S06 & 25.5 & 0.1 & 100 & 100.00 & 0.0027 & 25.17 & 153.22 & 0.0073 & 0.0477 & 30.4 \\
\hline
\end{tabular}




$\begin{array}{lrlllllllll}\text { S07 } & 21.8 & 0.1 & 100 & 100.00 & 0.0018 & 21.58 & 128.05 & 0.0046 & 0.0360 & 25.4 \\ \text { S08 } & 25.3 & 0.1 & 100 & 100.00 & 0.0014 & 25.14 & 106.46 & 0.0028 & 0.0263 & 21.1 \\ \text { S09 } & 25.0 & 0.1 & 100 & 100.00 & 0.0009 & 24.89 & 81.33 & 0.0014 & 0.0176 & 16.1 \\ \text { S10 } & 21.3 & 0.1 & 100 & 100.00 & 0.0004 & 21.26 & 56.43 & 0.0006 & 0.0099 & 11.2 \\ \text { S11 } & 35.2 & 0.1 & 100 & 100.00 & 0.0002 & 35.18 & 35.18 & 0.0002 & 0.0056 & 7.0\end{array}$

Case B: $\quad$ Freeze at air temperature of $-2{ }^{\circ} \mathrm{C}$, remove solid and leave on grille at $-2{ }^{\circ} \mathrm{C}$ for 48 hours before melting at room temperature. See Section 5.5.2 and Figure 13.

CB1 $\quad-2{ }^{\circ} \mathrm{C}$ freezing, $-2{ }^{\circ} \mathrm{C}$ hold, $25{ }^{\circ} \mathrm{C}$ melting

$\begin{array}{lrrrrrrrrrr} & \text { MS } & \text { VS } & \text { DN } & \text { ICP } & \text { Mol Mg } & \text { MW } & & & & \\ \text { S } & 530.5 & 0.5 & 1000 & 11.26 & 0.2317 & 502.61 & & & & \\ \text { L } & 89.0 & 0.25 & 1000 & 8.62 & 0.0887 & 78.33 & & & & \\ \text {-2C L } & 22.7 & 0.1 & 1000 & 7.09 & 0.0292 & 19.19 & & & & \\ \text { RC } & 207.9 & 0.25 & 100 & 0.12 & 0.0001 & 207.88 & \text { CMW } & \text { CMM } & \text { CMOL } & \text { WR } \\ \text { S01 } & 32.3 & 0.1 & 100 & 65.33 & 0.0269 & 29.06 & 337.45 & 0.1060 & 0.3140 & 67.1 \\ \text { S02 } & 24.4 & 0.1 & 100 & 44.21 & 0.0182 & 22.21 & 308.38 & 0.0791 & 0.2564 & 61.4 \\ \text { S03 } & 39.3 & 0.1 & 100 & 59.56 & 0.0245 & 36.35 & 286.17 & 0.0609 & 0.2128 & 56.9 \\ \text { S04 } & 29.8 & 0.1 & 100 & 33.06 & 0.0136 & 28.16 & 249.82 & 0.0364 & 0.1456 & 49.7 \\ \text { S05 } & 27.4 & 0.1 & 100 & 21.04 & 0.0087 & 26.36 & 221.66 & 0.0228 & 0.1028 & 44.1 \\ \text { S06 } & 33.2 & 0.1 & 100 & 16.60 & 0.0068 & 32.38 & 195.30 & 0.0141 & 0.0723 & 38.9 \\ \text { S07 } & 27.8 & 0.1 & 100 & 8.32 & 0.0034 & 27.39 & 162.92 & 0.0073 & 0.0448 & 32.4 \\ \text { S08 } & 27.4 & 0.1 & 100 & 4.77 & 0.0020 & 27.16 & 135.53 & 0.0039 & 0.0285 & 27.0 \\ \text { S09 } & 35.4 & 0.1 & 100 & 2.99 & 0.0012 & 35.25 & 108.37 & 0.0019 & 0.0176 & 21.6 \\ \text { S10 } & 29.3 & 0.1 & 100 & 1.21 & 0.0005 & 29.24 & 73.12 & 0.0007 & 0.0092 & 14.5 \\ \text { S11 } & 21.1 & 0.1 & 100 & 0.31 & 0.0001 & 21.08 & 43.88 & 0.0002 & 0.0040 & 8.7 \\ \text { S12 } & 22.8 & 0.1 & 100 & 0.12 & 0.0000 & 22.79 & 22.79 & 0.0000 & 0.0022 & 4.5\end{array}$

\begin{tabular}{|c|c|c|c|c|c|c|c|c|c|c|}
\hline \multirow[t]{2}{*}{ CB1 } & \multicolumn{4}{|c|}{$-2{ }^{\circ} \mathrm{C}$ freezing, $-2{ }^{\circ} \mathrm{C}$ hold, $25^{\circ} \mathrm{C}$ melting } & & \multirow[b]{2}{*}{ MW } & & & & \\
\hline & MS & VS & DN & ICP & Mol Mg & & & & & \\
\hline$S$ & 531.3 & 0.5 & 1000 & 11.15 & 0.2293 & 503.70 & & & & \\
\hline $\mathrm{L}$ & 126.2 & 0.25 & 1000 & 11.26 & 0.1158 & 112.26 & & & & \\
\hline$-2 C L$ & 17.5 & 0.1 & 1000 & 5.35 & 0.0220 & 14.85 & & & & \\
\hline $\mathrm{RC}$ & 204.1 & 0.25 & 100 & 0.17 & 0.0002 & 204.08 & CMW & CMM & CMOL & WR \\
\hline S01 & 32.0 & 0.1 & 100 & 61.04 & 0.0251 & 28.98 & 299.66 & 0.0859 & 0.2868 & 59.5 \\
\hline SO2 & 27.8 & 0.1 & 100 & 43.71 & 0.0180 & 25.64 & 270.68 & 0.0608 & 0.2247 & 53.7 \\
\hline SO3 & 26.7 & 0.1 & 100 & 34.98 & 0.0144 & 24.97 & 245.04 & 0.0428 & 0.1748 & 48.6 \\
\hline SO4 & 29.2 & 0.1 & 100 & 28.39 & 0.0117 & 27.79 & 220.08 & 0.0284 & 0.1292 & 43.7 \\
\hline S05 & 28.0 & 0.1 & 100 & 19.61 & 0.0081 & 27.03 & 192.28 & 0.0168 & 0.0872 & 38.2 \\
\hline
\end{tabular}




$\begin{array}{lrrrrrrrrrr}\text { S06 } & 35.0 & 0.1 & 100 & 12.13 & 0.0050 & 34.40 & 165.25 & 0.0087 & 0.0526 & 32.8 \\ \text { S07 } & 21.7 & 0.1 & 100 & 4.00 & 0.0016 & 21.50 & 130.85 & 0.0037 & 0.0283 & 26.0 \\ \text { S08 } & 30.9 & 0.1 & 100 & 3.14 & 0.0013 & 30.74 & 109.35 & 0.0021 & 0.0188 & 21.7 \\ \text { S09 } & 21.3 & 0.1 & 100 & 1.00 & 0.0004 & 21.25 & 78.61 & 0.0008 & 0.0097 & 15.6 \\ \text { S10 } & 25.5 & 0.1 & 100 & 0.58 & 0.0002 & 25.47 & 57.36 & 0.0003 & 0.0061 & 11.4 \\ \text { S11 } & 18.9 & 0.1 & 100 & 0.21 & 0.0001 & 18.89 & 31.89 & 0.0001 & 0.0034 & 6.3 \\ \text { S12 } & 13.0 & 0.1 & 100 & 0.06 & 0.0000 & 13.00 & 13.00 & 0.0000 & 0.0018 & 2.6\end{array}$

Case C: $\quad$ Freeze at air temperature of $-26^{\circ} \mathrm{C}$, remove solid and leave on grille at $-0.2{ }^{\circ} \mathrm{C}$ for 48 hours before melting at room temperature. See Section 5.5.3 and Figure 14.

\begin{tabular}{lrrrrrrrrrr} 
CC1 & $-26{ }^{\circ} \mathrm{C}$ freeze, $-0.2{ }^{\circ} \mathrm{C}$ hold, $25^{\circ} \mathrm{C}$ melt \\
\multicolumn{1}{c}{ MS } & VS & DN & ICP & Mol Mg & MW & & & & & \\
S & 534.6 & 0.5 & 1000 & 10.97 & 0.2256 & 507.45 & & & & \\
L & 188.3 & 0.25 & 1000 & 15.91 & 0.1636 & 168.61 & & & & \\
RC & 209.0 & 0.25 & 100 & 0.20 & 0.0002 & 208.97 & CMW & CMM & CMOL & WR \\
S01 & 45.9 & 0.1 & 100 & 41.83 & 0.0172 & 43.83 & 292.65 & 0.0561 & 0.1918 & 57.7 \\
S02 & 28.5 & 0.1 & 100 & 23.96 & 0.0099 & 27.31 & 248.82 & 0.0389 & 0.1564 & 49.0 \\
S03 & 27.0 & 0.1 & 100 & 20.47 & 0.0084 & 25.99 & 221.50 & 0.0290 & 0.1311 & 43.7 \\
S04 & 30.5 & 0.1 & 100 & 19.64 & 0.0081 & 29.53 & 195.52 & 0.0206 & 0.1055 & 38.5 \\
S05 & 27.3 & 0.1 & 100 & 13.45 & 0.0055 & 26.63 & 165.99 & 0.0125 & 0.0756 & 32.7 \\
S06 & 36.3 & 0.1 & 100 & 10.71 & 0.0044 & 35.77 & 139.36 & 0.0070 & 0.0503 & 27.5 \\
S07 & 27.4 & 0.1 & 100 & 3.77 & 0.0015 & 27.21 & 103.59 & 0.0026 & 0.0252 & 20.4 \\
S08 & 24.9 & 0.1 & 100 & 1.56 & 0.0006 & 24.82 & 76.37 & 0.0011 & 0.0139 & 15.1 \\
S09 & 26.4 & 0.1 & 100 & 0.71 & 0.0003 & 26.36 & 51.55 & 0.0004 & 0.0081 & 10.2 \\
S10 & 25.2 & 0.1 & 100 & 0.29 & 0.0001 & 25.19 & 25.19 & 0.0001 & 0.0048 & 5.0
\end{tabular}

CC2 $\quad-26{ }^{\circ} \mathrm{C}$ freeze, $-0.2{ }^{\circ} \mathrm{C}$ hold, $25^{\circ} \mathrm{C}$ melt

$\begin{array}{lrrrrrrrrrr} & \text { MS } & \text { VS } & \text { DN } & \text { ICP } & \text { Mol Mg } & \text { MW } & & & & \\ \text { S } & 533.1 & 0.5 & 1000 & 11.20 & 0.2304 & 505.36 & & & & \\ \text { L } & 229.0 & 0.25 & 1000 & 17.57 & 0.1807 & 207.25 & & & & \\ \text { RC } & 204.6 & 0.25 & 100 & 0.19 & 0.0002 & 204.58 & \text { CMW } & \text { CMM } & \text { CMOL } & \text { WR } \\ \text { S01 } & 31.4 & 0.1 & 100 & 25.60 & 0.0105 & 30.13 & 240.01 & 0.0423 & 0.1763 & 47.5 \\ \text { S02 } & 26.6 & 0.1 & 100 & 19.45 & 0.0080 & 25.64 & 209.87 & 0.0318 & 0.1515 & 41.5 \\ \text { S03 } & 34.8 & 0.1 & 100 & 22.00 & 0.0091 & 33.71 & 184.24 & 0.0238 & 0.1291 & 36.5 \\ \text { S04 } & 34.6 & 0.1 & 100 & 17.00 & 0.0070 & 33.76 & 150.53 & 0.0147 & 0.0979 & 29.8 \\ \text { S05 } & 29.5 & 0.1 & 100 & 9.99 & 0.0041 & 29.01 & 116.77 & 0.0077 & 0.0663 & 23.1 \\ \text { S06 } & 29.3 & 0.1 & 100 & 5.33 & 0.0022 & 29.04 & 87.76 & 0.0036 & 0.0414 & 17.4 \\ \text { S07 } & 29.1 & 0.1 & 100 & 2.59 & 0.0011 & 28.97 & 58.73 & 0.0014 & 0.0245 & 11.6\end{array}$


Case D: $\quad$ Freeze at air temperature of $-2{ }^{\circ} \mathrm{C}$, remove solid and leave on grille at $-2{ }^{\circ} \mathrm{C}$ for 24 hours, then $-1{ }^{\circ} \mathrm{C}$ for 24 hours, and then $-0.1{ }^{\circ} \mathrm{C}$ for 24 hours before melting at room temperature. See Section 5.5.4 and Figure 15.

\begin{tabular}{|c|c|c|c|c|c|c|c|c|c|c|}
\hline CD1 & $-2{ }^{\circ} \mathrm{C}$ free & $e,-2^{\circ}$ & old, -1 & hold, - & C hold, 25 & nelting & & & & \\
\hline & MS & VS & DN & ICP & Mol Mg & MW & & & & \\
\hline$S$ & 532.2 & 0.5 & 1000 & 10.60 & 0.2181 & 505.95 & & & & \\
\hline $\mathrm{L}$ & 105.5 & 0.25 & 1000 & 10.27 & 0.1056 & 92.79 & & & & \\
\hline$-2 C L$ & 11.8 & 0.1 & 100 & 33.00 & 0.0136 & 10.17 & & & & \\
\hline$-1 C L$ & 24.2 & 0.1 & 100 & 51.82 & 0.0213 & 21.63 & & & & \\
\hline$-0.1 C L$ & 81.0 & 0.25 & 100 & 45.74 & 0.0470 & 75.34 & & & & \\
\hline $\mathrm{RC}$ & 208.1 & 0.25 & 100 & 0.17 & 0.0002 & 208.08 & CMW & CMM & CMOL & WR \\
\hline S01 & 45.6 & 0.1 & 100 & 37.06 & 0.0152 & 43.76 & 194.62 & 0.0356 & 0.1829 & 38.5 \\
\hline SO2 & 28.1 & 0.1 & 100 & 20.70 & 0.0085 & 27.07 & 150.85 & 0.0203 & 0.1349 & 29.8 \\
\hline S03 & 38.9 & 0.1 & 100 & 18.77 & 0.0077 & 37.97 & 123.78 & 0.0118 & 0.0956 & 24.5 \\
\hline SO4 & 21.7 & 0.1 & 100 & 5.68 & 0.0023 & 21.42 & 85.81 & 0.0041 & 0.0479 & 17.0 \\
\hline S05 & 27.5 & 0.1 & 100 & 3.32 & 0.0014 & 27.34 & 64.39 & 0.0018 & 0.0275 & 12.7 \\
\hline S06 & 37.1 & 0.1 & 100 & 0.98 & 0.0004 & 37.05 & 37.05 & 0.0004 & 0.0109 & 7.3 \\
\hline
\end{tabular}

\begin{tabular}{|c|c|c|c|c|c|c|c|c|c|c|}
\hline \multirow[t]{2}{*}{ CD2 } & \multicolumn{6}{|c|}{$-2{ }^{\circ} \mathrm{C}$ freeze, $-2{ }^{\circ} \mathrm{C}$ hold, $-1{ }^{\circ} \mathrm{C}$ hold, $-0.1{ }^{\circ} \mathrm{C}$ hold, $25{ }^{\circ} \mathrm{C}$ melting } & & & & \\
\hline & MS & VS & DN & ICP & Mol Mg & MW & & & & \\
\hline S & 531.8 & 0.5 & 1000 & 11.09 & 0.2282 & 504.34 & & & & \\
\hline $\mathrm{L}$ & 150.9 & 0.25 & 1000 & 12.77 & 0.1314 & 135.09 & & & & \\
\hline$-2 C L$ & 13.6 & 0.1 & 100 & 37.86 & 0.0156 & 11.73 & & & & \\
\hline$-1 C L$ & 11.8 & 0.1 & 100 & 25.91 & 0.0107 & 10.52 & & & & \\
\hline$-0.1 C L$ & 68.8 & 0.25 & 100 & 36.27 & 0.0373 & 64.31 & & & & \\
\hline $\mathrm{RC}$ & 205.7 & 0.25 & 100 & 0.27 & 0.0003 & 205.67 & CMW & CMM & CMOL & WR \\
\hline S01 & 40.2 & 0.1 & 100 & 30.75 & 0.0127 & 38.68 & 179.03 & 0.0313 & 0.1748 & 35.5 \\
\hline SO2 & 35.4 & 0.1 & 100 & 22.32 & 0.0092 & 34.29 & 140.35 & 0.0187 & 0.1329 & 27.8 \\
\hline SO3 & 30.2 & 0.1 & 100 & 13.78 & 0.0057 & 29.52 & 106.06 & 0.0095 & 0.0893 & 21.0 \\
\hline SO4 & 20.9 & 0.1 & 100 & 5.69 & 0.0023 & 20.62 & 76.54 & 0.0038 & 0.0496 & 15.2 \\
\hline SO5 & 22.9 & 0.1 & 100 & 2.61 & 0.0011 & 22.77 & 55.92 & 0.0015 & 0.0261 & 11.1 \\
\hline S06 & 33.2 & 0.1 & 100 & 0.93 & 0.0004 & 33.15 & 33.15 & 0.0004 & 0.0116 & 6.6 \\
\hline
\end{tabular}


Case E: Freeze at air temperature of $-2{ }^{\circ} \mathrm{C}$, remove solid and leave on grille at $-2{ }^{\circ} \mathrm{C}$ for 24 hours, then $-0.2{ }^{\circ} \mathrm{C}$ for 24 hours, and then $-2{ }^{\circ} \mathrm{C}$ again for 24 hours before melting at room temperature. See Section 5.5.5 and Figure 16.

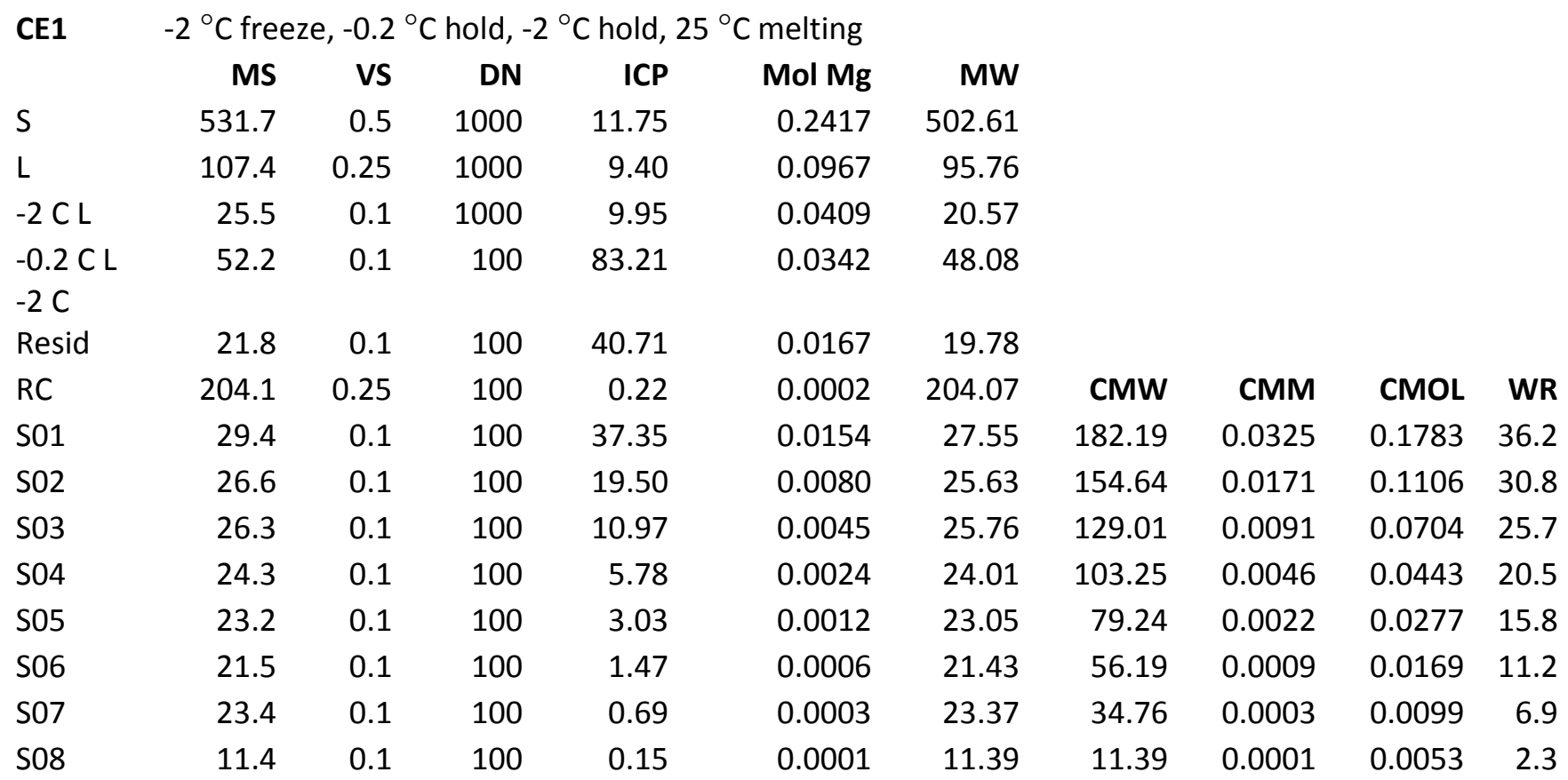

\begin{tabular}{|c|c|c|c|c|c|c|c|c|c|c|}
\hline \multirow[t]{2}{*}{ CE1 } & \multicolumn{2}{|c|}{$-2{ }^{\circ} \mathrm{C}$ freeze, -0.2} & hold, - & Chold, & melting & \multirow[b]{2}{*}{ MW } & & & & \\
\hline & MS & VS & DN & ICP & Mol Mg & & & & & \\
\hline S & 533.0 & 0.5 & 1000 & 11.53 & 0.2373 & 504.44 & & & & \\
\hline L & 173.1 & 0.25 & 1000 & 13.52 & 0.1391 & 156.36 & & & & \\
\hline$-2 C L$ & 20.4 & 0.1 & 1000 & 6.91 & 0.0284 & 16.98 & & & & \\
\hline$-0.2 C L$ & 43.5 & 0.1 & 100 & 60.19 & 0.0248 & 40.52 & & & & \\
\hline \multicolumn{11}{|l|}{$-2 C$} \\
\hline Resid & 15.8 & 0.1 & 100 & 26.71 & 0.0110 & 14.48 & & & & \\
\hline $\mathrm{RC}$ & 206.2 & 0.25 & 100 & 0.21 & 0.0002 & 206.17 & CMW & CMM & CMOL & WR \\
\hline S01 & 25.0 & 0.1 & 100 & 28.48 & 0.0117 & 23.59 & 149.43 & 0.0230 & 0.1541 & 29.6 \\
\hline SO2 & 25.7 & 0.1 & 100 & 14.89 & 0.0061 & 24.96 & 125.84 & 0.0113 & 0.0898 & 24.9 \\
\hline SO3 & 26.7 & 0.1 & 100 & 7.97 & 0.0033 & 26.31 & 100.88 & 0.0052 & 0.0513 & 20.0 \\
\hline SO4 & 25.4 & 0.1 & 100 & 3.24 & 0.0013 & 25.24 & 74.57 & 0.0019 & 0.0255 & 14.8 \\
\hline S05 & 21.0 & 0.1 & 100 & 0.94 & 0.0004 & 20.95 & 49.33 & 0.0006 & 0.0115 & 9.8 \\
\hline S06 & 28.4 & 0.1 & 100 & 0.43 & 0.0002 & 28.38 & 28.38 & 0.0002 & 0.0063 & 5.6 \\
\hline
\end{tabular}




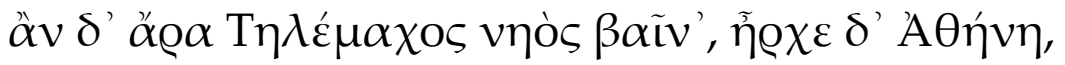

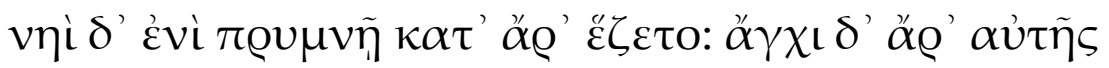

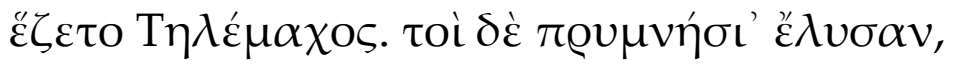

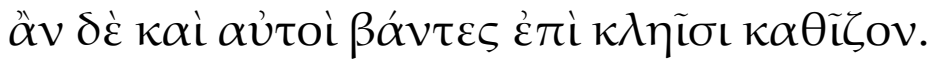

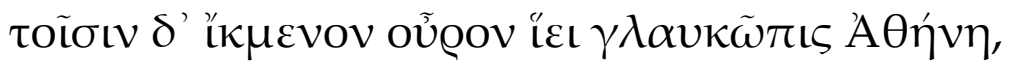

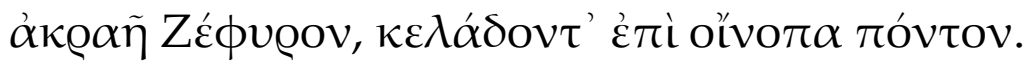

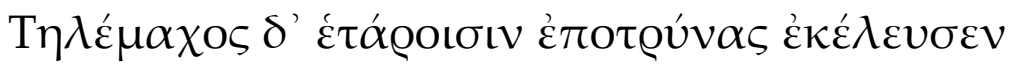

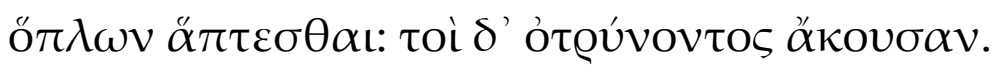

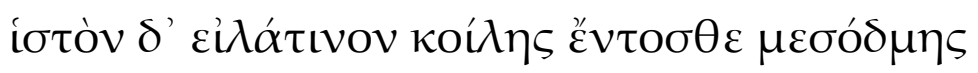

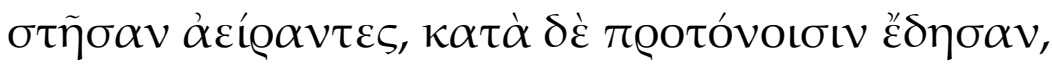

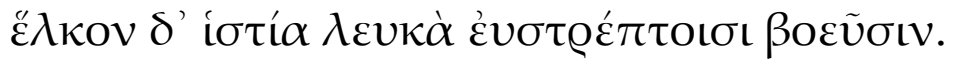

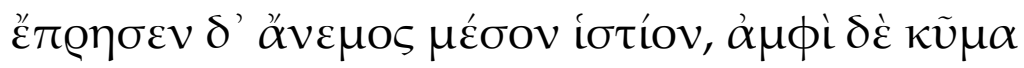

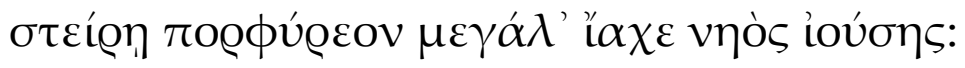
$\eta \dot{\eta} \delta$ '

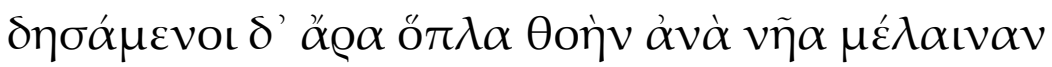

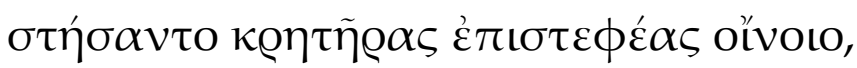

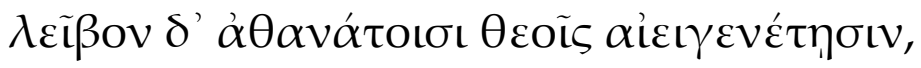

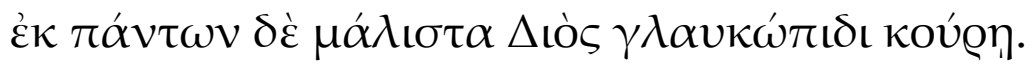

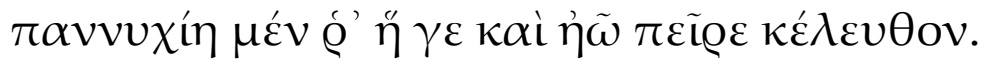

Hom. Od. II.416-434 